$\Delta \Delta^{\Delta} \Delta \Delta$

$\Delta \Delta \triangle \triangle$

$\triangle \Delta \Delta \Delta \Delta$

$\triangle \triangle \triangle \triangle \Delta_{\triangle}$

$\triangle \backsim \Delta \triangle$

$\Delta \Delta \Delta \Delta$

$\triangle \triangle \triangle$

$\mathrm{MA}_{\triangle} \Delta_{\Delta \Delta} \Delta_{\Delta}$

4

$\Delta$

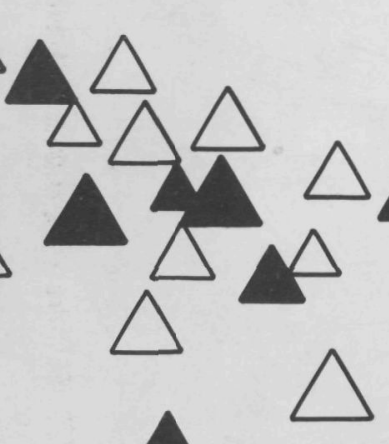

elastic moduli and internal friction of cold worked copper single crystals
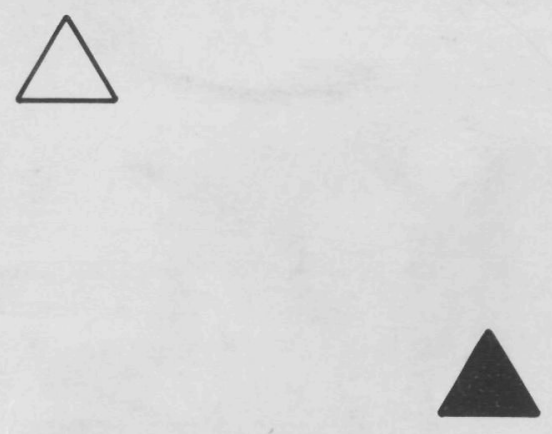

$\triangle$

$\triangle$

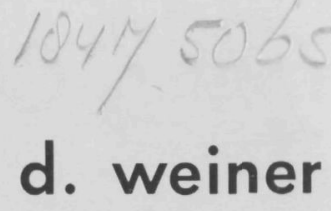


elastic moduli and internal friction of cold worked copper single crystals

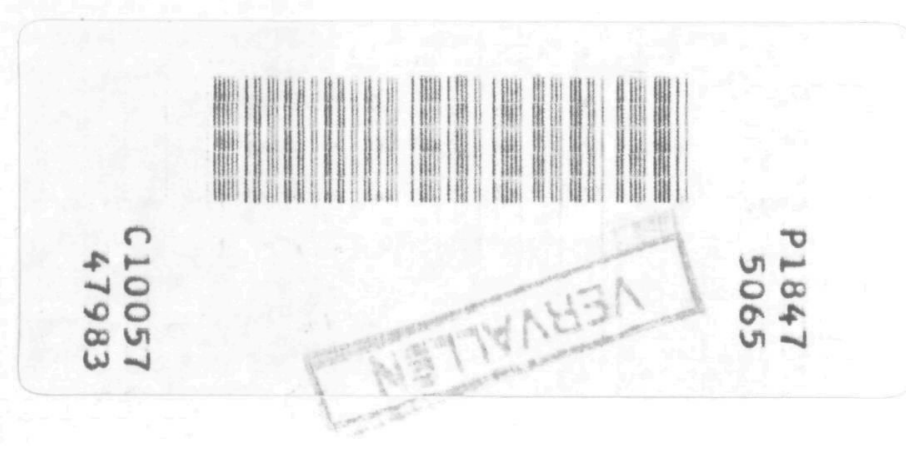

BIBLIOTHEEK TU Delft

P 18475065

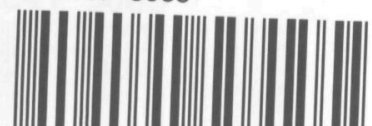

C 


\title{
elastic moduli and internal friction of \\ cold worked copper single crystals
}

\begin{abstract}
ter verkrijging van de graad van doctor in de technische wetenschappen aan de Technische Hogeschool Delft, op gezag van de rector magnificus ir. H.B. Boerema, hoogleraar in de afdeling der Elektrotechniek, voor een commissie aangewezen door het college van dekanen te verdedigen op woensdag 15 mei 1974 te 14.00 uur
\end{abstract}

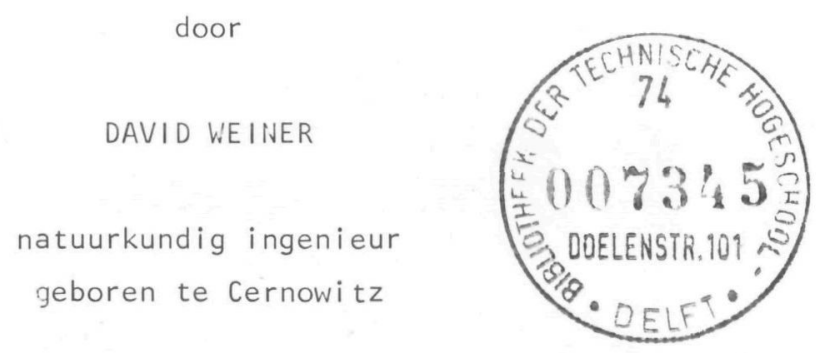

Academic Service - Vinkeveen 
Dit proefschrift is goedgekeurd door de promotor Lector Dr.Ir. A. van den Beukel 
In memory of my parents Anczel and Klara Weiner and

Saul Dorf

To Zipora and Amir 
.... but for us, who, by divine kindness were given an accurate observer such as Tycho Brahe, for us it is fitting that we should acknowledge this divine gift and put it to use.....

Johannes Kepler in Astronomia Hova. 


\section{contents}

I Introduction . . . . . . . . . . . . . . 9

11 Experimental Procedure . . . . . . . . . 13

11.1 Growth of copper single crystals . . . . . . . 13

11.2 Load-elongation test . . . . . . . . . . . . . 19

11.3 Measurement of E, G and internal friction . . . 20

III Calculation of modulus effects from experimental data 26

III.1 $\Delta G$ effect . . . . . . . . . . . . . 26

$111.2 \Delta \mathrm{E}$ effect . . . . . . . . . . . . . . . . 33

I।I.2.1 Variation of the elastic modulus during

plastic deformation of one specimen . . . 36

III.2.2 Comparison of the elastic constants of different undeformed specimens (<111> orientation) 38

111.2.3 Specimens of different orientations . . . 40

IV Extension of copper single crystals . . . . . . 42

$\checkmark$ Experimental results . . . . . . . . . . . . 52

V.1 The stress-strain curve . . . . . . . . 52

V.1.1 Introduction . . . . . . . . . . 52

V.1.2 Experimental results . . . . . . . 54

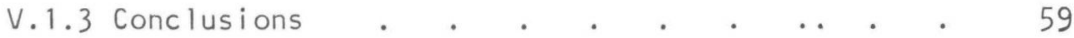

V.2 The change in orientation of copper single crystals as a result of plastic extension . . . . . . . 61

V.2.1 Introduction . . . . . . . . . . 61

V.2.2 X-ray methods . . . . . . . . . . 63

V.2.3 Experimental results . . . . . . . . . 66

V.2.4 Summary and conclusions . . . . . . . $\quad$. 71

V.3 Mechanical twinning . . . . . . . . . . . 72

V.3.1 Introduction . . . . . . . . . 72

V.3.2 Results and discussion. . . . . . . 72 
V.3.2.1 Deformation by elongation . . . . . 72

V.3.2.2 Deformation by torsion . . . . . . 82

V.3.2.3 Relation between twinning and strain to fracture. . . . . . . . . . . 83

V.3.3 Summary and conclusions . . . . . . . 84

V.4 Change of the elastic moduli and internal friction as

a function of deformation . . . . . . . . 85

V.4.1 Introduction. . . . . . . . . 85

V.4.2 Experimental results on $\langle 001\rangle,\langle 011\rangle,\langle 111\rangle$ oriented crystals . . . . . . . . . 85

V.4.2.1 Modulus effect after plastic elongation . . 86

V.4.2.2 Modulus effect after plastic torsion . . . 89

V.4.3 Modulus effect of various orientations after plastic extension . . . . . . . . . 96

V.4.4 Recovery measurements . . . . . . . 98

V.4.5 Change of internal friction by plastic extension. . . . . . . . . . 101

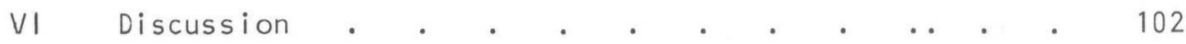

VI.1 Introduction . . . . . . . . . . . . . . 102

VI.2 The influence of mechanical twinning on the elastic $\operatorname{moduli}$. $\quad . \quad$. $\quad . \quad$. . . . . . . 103

VI.3 The influence of orientation on the modulus effect . 107

VI.4 The influence of dislocation multiplication on the elastic moduli E, G and internal friction . . . 109

VI.5 A qualitative discussion of some aspects of "easy glide" . . . . . . . . . . . . . . . . . . 119

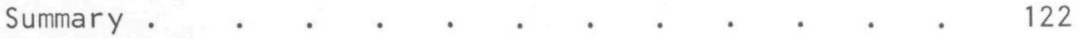

Samenvatting . $. \quad . \quad . \quad . \quad . \quad . \quad . \quad . \quad 125$

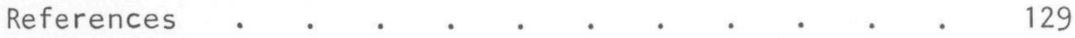




\section{introduction}

Plastic deformation of metal crystals takes place by the mechanism of slip. The slip process is carried by the formation and motion of dislocations. In the undeformed state the crystal contains about $10^{3}-10^{6} \mathrm{~cm} / \mathrm{cm}^{3}$ dislocation line, which during the deformation process rapidly multiplies to values of $10^{9}-10^{11} \mathrm{~cm} / \mathrm{cm}^{3}$. Due to dislocation intersection processes also point defects, e.g. vacancies and interstitials are produced. The presence of these various kinds of lattice defects in the crystal causes a change of the physical properties as compared to the undeformed state.

If the deformation is carried out at a low enough temperature the produced lattice defects will not anneal out. The change of a certain physical property, for instance the electrical resistivity, will then be due to the sum of the contributions of the various kinds of lattice defects. These contributions can be separated in principle by warming up the specimen. Each type of lattice defect will anneal out in its own specific temperature range, which gives rise to a stepwise decrease of the electrical resistivity and corresponding changes of the other physical properties. The analysis of this recovery spectrum should yield information on the kind and concentration of the various types of lattice defects present in the deformed state.

The problem of identifying the very complicated recovery spectrum of deformed metals still has not been completely solved (see the review article by Van den Beukel (1970)). Especially the interpretation of the point defect stages (labeled stages 11,111 and IV) is still subject of controversy. It is, however, generally agreed that significant annealing out of dislocations only occurs in the annealing stage $V$, which is accompanied by recrystallization. For this reason the mechanical properties like hardness and flow stress, which are mainly governed by dislocations and not by point defects show only one dominant annealing stage (stage $V$ ). 
In this context the behaviour of the elastic moduli Youngs ' modulus (E) and the shear modulus (G) is interesting. It was predicted by Mott (1952) and Friedel (1953) that dislocations should give rise to a decrease of the elastic moduli because upon a small applied shear stress dislocations will bow out like stretched strings. This causes an extra elastic shear strain and therefore a decrease of the elastic moduli. According to Mott and Friedel a dislocation network of density $\Lambda$ and average dislocation line length $L$ gives rise to a relative modulus change $\frac{\Delta M}{M} \simeq 1 / 10 \Lambda L^{2}$ which is if the order of $10 \%$, as $\Lambda L^{2}$ is of the order of 1 . It can be shown on theoretical grounds and it has been also confirmed experimentally that the contribution of the point defects formed in plastic deformation to the modulus change is much smaller than the effect of the dislocations. Therefore it was expected that low temperature deformation should cause a decrease of the elastic moduli of about $10 \%$, which is entirely due to dislocations.

It must be noted here that at first sight the modulus change upon plastic deformation should be expected to be very small, if not zero. The reason is that also in the annealed crystal a dislocation network of low density is present. As for a dislocation network $\Lambda L^{2}$ is about 1 , independent of the network size, the change of the dislocation network size during plastic deformation should not change the contribution of dislocations to the elastic moduli. In fact, however, changes of the moduli between $10 \%$ and $20 \%$ are observed in copper during the first few percents of plastic deformation at low temperatures (Druyvesteyn et al 1959, Lems 1962). The explanation is that in the annealed crystal the dislocations are prevented to bow out by the presence of impurities, which collected at the dislocations during the annealing treatment, due to the attractive interaction between dislocations and impurities. It is said that the dislocations are pinned by the impurity atoms. This picture is confirmed by the fact that irradiation of annealed crystals by electrons or neutrons cause an increase of the modulus of a few per cent at most. This effect is due to the point defects (vacancies, interstitials) 
produced by the irradiation, which anneal out to the dislocations and pin them. In cold work experiments pinning of dislocations by point defects also plays an important role. When after deformation at low temperatures, where the large modulus effects of $10-20 \%$ are observed, the specimen is warmed up, it is seen that the modulus effect is reduced in the various recovery stages where point defects are believed to anneal out (see e.g. Lems 1962).

The present investigation was undertaken in consequence of the results of De Kock et.al. (1965) and Brouwer and Groenenboom-Eijgelaar (1967). It was found by these authors that in polycrystalline copper the change of a certain elastic modulus was dependent on the mode of plastic deformation, i.e. deformation in elongation gives rise to a large decrease of $E$ and a small decrease of $G$, whereas deformation in torsion gave the reverse effect. The results where explained by the assumption that the burgers vectors of the dislocations generated by small plastic deformation in a polycrystalline material lie near the direction of maximum shear stress. In that case a large modulus effect is expected when the state of stress during the deformation and the modulus measurement is the same. In the case of deformation of single crystals, the active slip systems and therefore the burgers vectors of the dislocations produced are known. For that reason it was decided to measure the modulus effect of copper single crystals of various orientations, deformed at $78 \mathrm{~K}$.

In the present investigation the change of both the elastic moduli and the internal friction of copper crystals was measured during deformation at 78K. According to the theory of Koehler, Granato and Lücke (K.G.L.) the contribution of dislocations to the amplitude independent internal friction is proportional to $f \Lambda L^{4}$ where $f$ is the measuring frequency. It follows that simultaneous measurement of modulus and internal friction changes yields information on the change of the dislocation density $\Lambda$ and dislocation line length $L$ during plastic deformation. The K.G.L. theory has been proved mainly in the high frequency ( $M H Z$ ) region. Recently some doubt has risen about the validity in the low frequency region (Den Buurman and Weiner (1971)) 
especially as far as the frequency dependence is concerned. It seems, however, that the dependence on $\Lambda$ and $L$ of the internal friction and modulus effect is valid also at low frequencies so that the measurements are at least useful to provide a qualitative indication of the change of $L$ and $\Lambda$ during deformation (see e.g. Den Buurman and Snoep (1972)).

The work on single crystals, although aimed to simplify the results, raised a series of new problems. Deformation in torsion was only possible for a very limited number of orientations. During deformation in extension the initial circular cross section of the crystal changes into an elliptic one. As a consequence the specimen shows two eigenfrequencies in flexural vibration, corresponding to the directions perpendicular to the long and short axis of the elliptical cross section. More difficulties presents the fact that also in torsional vibrations two or three eigenfrequencies were found. Further, as is well known, during plastic deformation the orientation of the crystal changes.

As the elastic moduli are dependent on orientation this fact induces a purely crystallographic modulus'effect which has to be corrected for. A similar effect is induced by the occurrence of mechanical twinning, because during twinning part of the crystal changes its orientation, which again results in a change of the elastic moduli, independent of dislocations.

For all these reasons a substantial part of this thesis is devoted to the problems mentioned and the ways to circumvent them in order to isolate the modulus effect due to dislocations alone as was the original purpose. In removing the obstacles, however, a number of results were obtained which were not originally aimed but which were interesting enough to be described here.

In this context we especially mention the results on deformation twinning and the relation between twinning and fracture as described in chapter V.3. 


\section{experimental procedure}

\section{II.1 GROWTH OF COPPER SINGLE CRYSTALS}

Copper single crystals were grown in graphite moulds from $99.999 \%$ pure copper wire, supplied by Johnson Matthey Co., London, by a modified Bridgeman (1925) - Stockbarger (1936) methode.

The graphite mould was made from a 99.99 pure graphite rod, $10 \mathrm{~mm}$ in diameter and $250 \mathrm{~mm}$ long, in which a bore of $2 \mathrm{~mm}$ was drilled over the whole length. The graphite could be drilled to give a very smooth finish which did not deteriorate with continued use. The asgrown crystal therefore also had a smooth surface and there was no tendency for mechanical "bonding" to the mould. When a mould with a closed bottom is used, the single crystal grown in it has a random orientation. If a single crystal of a particular orientation is needed, a small single crystal having that orientation is used as a seed. At the beginning of the growth of the single crystal the copper wire above the seed and a small part of the seed are melted. By moving the mould downwards, the molten copper solidifies in a single crystal, taking over the orientation of the seed and as the mould passes further downwards, the whole copper wire melts and grows as a single crystal in the same orientation as the seed.

The mould was adapted to the holder ( $\mathrm{fig}$. 1) by making it over a length of $10 \mathrm{~mm}$ thinner $(8 \mathrm{~mm})$, and as the holder was $14 \mathrm{~mm}$ deep, a space of $4 \mathrm{~mm}$ was left between the bottom of the holder and the mould. This was done in order to enable the seed to lose heat by radiation and at the same time it gave us an opportunity to see if the seed is not completely melted at the beginning.

The copper wire was $1.5 \mathrm{~mm}$ in diameter and straigthened so that it could glide freely in the mould. It was also a few centimeters longer than the mould. 


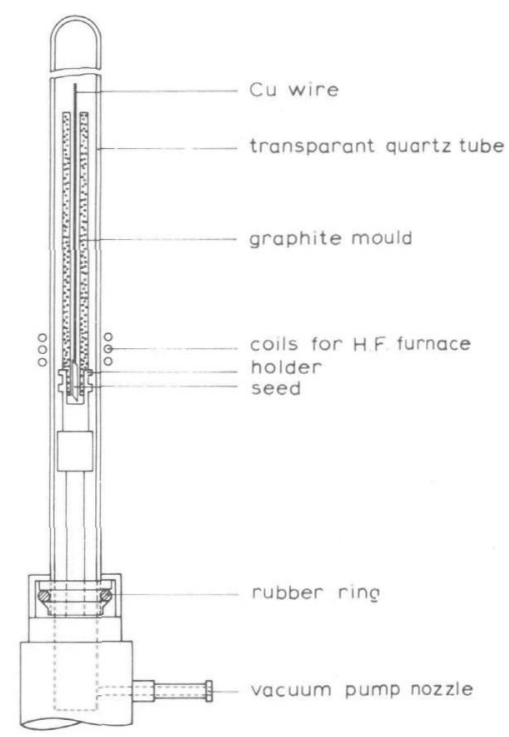

Fig. 1 - Apparatus for the preparation of oriented copper single crystals.

The temperature was measured on the outside of the mould using an optical micropyrometer.

A Philips High-Frequency furnace was used as a heat source. Three coils were connected to the furnace in such a way that the outer two produced a field opposite in sign to the one produced by the central coil. In this way the molten zone was kept narrow and it was possible to ascertain the location of the solid-liquid interface to within $4 \mathrm{~mm}$. An extra stabilizing unit was added to the H.F. furnace in order to suppress the electrical power supply fluctuations.

In order to start the melting of the copper wire, the temperature has to be increased to about $1450^{\circ} \mathrm{C}$ since in a vacuum the wire is heated only by radiation. The onset of melting can be seen as the copper wire above the mould starts to sink, and the temperature must then immediately be reduced to $1180 \pm 5^{\circ} \mathrm{C}$, as there is now a direct heat transfer from the mould to the metal. 
The mould is moved downward at a velocity of 0.5-2 mm per minute until the whole mould has passed between the H.F. furnace coils.

When cooled down to room temperature, a single crystal grown by this method contracts sufficiently in order to be easily extracted from the mould. The single crystal is then glued on to a metal holder and cut, by means of a spark errosion wire cutter, to the required length. The glue is then dissolved in acetone. Two M5 screws are then soldered, with a copper-silver alloy, in a vacuum on to both ends of the single crystal.

The first part of every crystal was kept as a seed for future crystals of the same orientation. From every crystal, at least four specimens were made in addition to the seed.

The perfection of the as-grown single crystals was verified in two ways: $x$-ray photographs were taken using the grazing incidence method and in some specimens the dislocation density was determined by etch pit counting.

As will become clear later on, the behaviour of the copper single crystals seems to be related to the value of the internal friction in the as-grown crystals. For this reason the internal friction was always measured, even though it is a rather indirect measure of the perfection of the crystal.

$X$-ray" photographs are usually taken in order to find the orientation of a single crystal, but they can also be used for a qualitative estimate of the dislocation density. X-ray photographs of single crystals with very low dislocation densities $\left(10^{2}-10^{3} \mathrm{~cm}^{-2}\right)$ have very little background radiation and the reflections from crystallographic planes give sharp and weak spots on the film. For higher dislocation densities $\left(10^{6} \mathrm{~cm}^{-2}\right)$ background blackening of the $\mathrm{film}$ occurs and the spots are much "heavier", although they are still sharp. For very high dislocation densities $\left(10^{7}-10^{8} \mathrm{~cm}^{-2}\right)$ as, for example after a small deformation, the spots become distorted by asterism. All these $x$-ray photographs are made at the same exposure time.

The $x$-ray photographs taken of the copper single crystals grown 


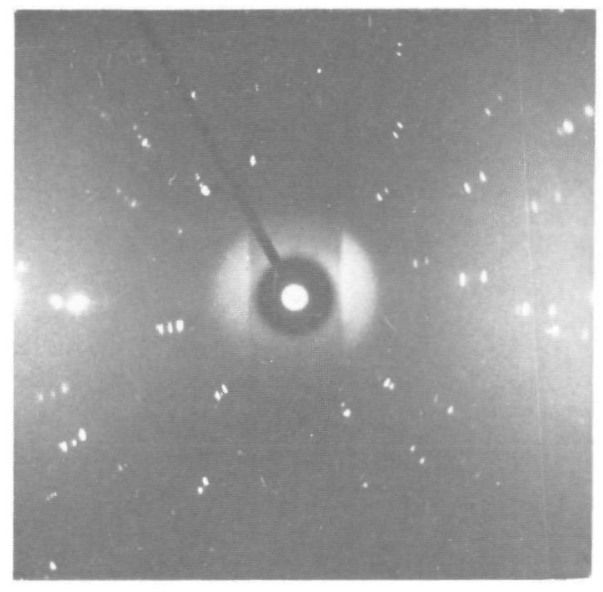

Fig. 2 - Laue $x$-roy photogroph of $a<145>$ oriented copper single crystal showing double and multiple spots, as a result of the presence of subboundaries.

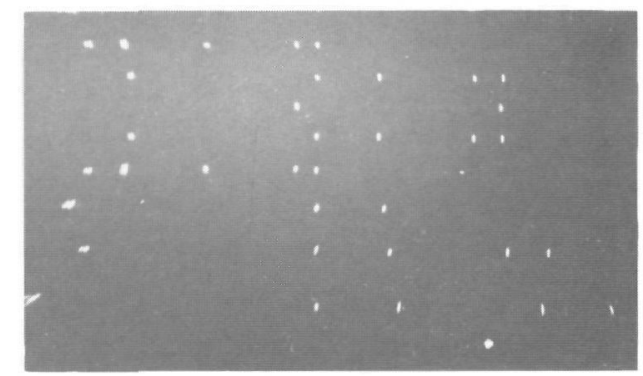

Fig. 3 - X-roy photogroph of $a<145>$ oriented copper single crystal with subboundaries made with the rotating specimen method.

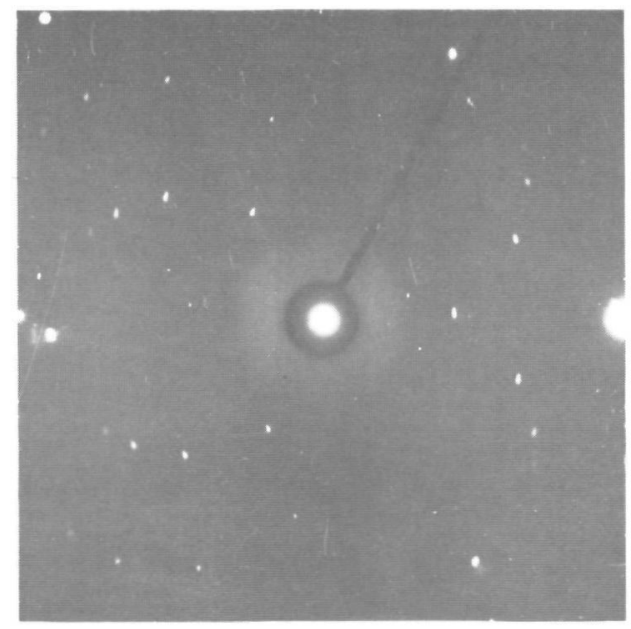

Eig. 4 - Laue $x$-roy photogroph of $a<110\rangle$ oriented copper single crystal without subboundaries. 
by the method described here, always had sharp spots with background blackening varying between slight and very heavy. X-ray photographs from single crystals of orientations having a $\{111\}$ plane parallel to the axis sometimes show double or multiple reflections from one crystallographic plane (fig. 2) as a result of low angle $\left(2^{\circ}\right.$ to $\left.3^{\circ}\right)$ subboundaries. When an $x$-ray photograph is taken by the rotating specimen method, of the same crystal as in fig. 2, which has a <145> orientation, there is nothing unusual, as there are no extra spots (fig. 3). It is concluded from this last fact that all the crystallites are rotated $2^{\circ}$ to $3^{\circ}$ in respect of one another round an axis which is parallel to the specimen axis.

When the conditions for the growth of the single crystals are optimal (such conditions will be defined later) also these orientations have only single reflections from each crystallographic plane (see fig. 4, an $x$-ray photograph of a $<011>$ oriented specimen).

A number of specimens were prepared for etch pit counting, by polishing them, in order to obtain a smooth $\{111\}$ plane.

The specimens were first polished mechanically, with as finest powder, diamond paste of $3 \mu$. The final chemical polish was done with ammonia. To reveal etch pits, the Livingstone etch (1962) and $\left(\mathrm{NH}_{4}\right)_{2} \mathrm{~S}_{2} \mathrm{O}_{8}$ were used. The results were the same for both, but the latter produced clearer pits. The dislocation densities found were $10^{3}-10^{4} \mathrm{~cm}^{-2}$ and a comparison of the $x$-ray photographs (background blackening) showed that these specimens were not the ones with the lowest densities. No attempt was made to find the dislocation density of a specimen with subboundaries, but it was assumed that the mean dislocation density was the same as found by Akita and Fiore (1970) i.e. $10^{6} \mathrm{~cm}^{-2}$, as the single crystals had the same properties as found by them.

The perfection of the single crystals is influenced by a number of factors:

a) Orientation: All orientations which have a $\{111\}$ plane parallel to the growth direction are very sensitive to growth conditions and when these are not optimal they have subboundaries, as 
al ready mentioned.

2) Temperature: The temperature as measured on the outside of the mould by means of an optical micropyrometer must be $1180 \pm 5^{\circ} \mathrm{C}$, otherwise the single crystal is less perfect and cannot be extracted easily from the mould. It was also found by Young and Savage (1964), who used a similar growth method, that single crystals grown at $1180^{\circ} \mathrm{C}$ have the lowest dislocation density.

3) Position of the mould: The mould must be precisely in the centre of the coils during the growth of the single crystal.

4) Stabizity: It was observed that the most important factor is the stability of the electrical power supply and the prevention of the vibration of the apparatus during the growth of the single crystal. The best crystals were grown at a time when this was the only apparatus in use in the laboratory. An attempt was made during such a "quiet time" to grow a single crystal with subboundaries for a certain experiment, but the crystal had none. To achieve good stability it is advisable to grow single crystals in a separate room with a vibration-free floor and a stabilized power supply.

Finally a method will be outlined for improving the orientation of <111> single crystals. When the orientation of a single crystal differs from the true $\langle 111\rangle$ up to $4^{\circ}$ this misorientation can be reduced considerably by extending it less than $1 \%$ and using it as a seed. In section $V .2$ it will be shown that an extension of such a single crystals causes a rotation of the axis towards <111>. As a consequence the single crystal grown from this seed is better oriented and by repeating this process several times is it possible to get a much better <111> oriented single crystal. This is to be seen in fig. 5 and 6 , which show x-ray photographs taken by the rotating specimen method of a misoriented and of a $\langle 111\rangle$ oriented single crystal, grown, starting with the former one and using the abovementioned method. It must be stressed, however, that the extension must be less than $1 \%$, otherwise by heating the seed, recrystalization 
twinning will occur and the orientation of the single crystal which will be grown will be different.

This method is suitable only for the <111> orientation, as will be shown in section V.2.

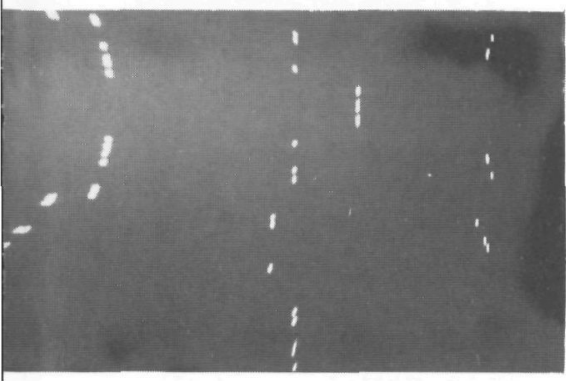

Fig. 5 .

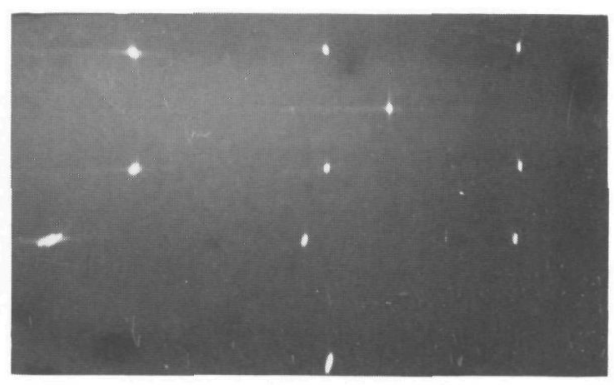

Fig. 6 .

$X-r a y$ photographs of a copper single crystal $4^{0}$

from <111> (fig. 5) and <111> (fig, 6).

\section{II.2 LOAD-ELONGATION TEST}

The deformation was carried out on an Instron T.T.C.L. machine at room temperature $\left(24^{\circ} \mathrm{C}\right)$ and liquid nitrogen temperature $(78 \mathrm{~K})$. Fig. 7 shows the mounting of the specimen in the Instron, for extension.

Fig. 7 - Mounting of the specimen for extension in the Instron.

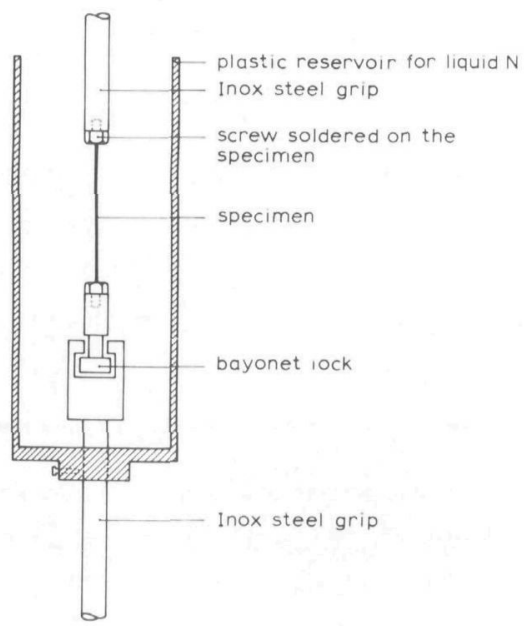


For an extension at low temperature when the specimen is cooled down, it contracts, as do the grips, and when the specimen is rigidly mounted, it extends during this process. To prevent this, the specimen is mounted rigidly only on the upper grip and on the lower grip there is a bayonet lock (see fig. 7) which permits a contraction up to $5 \mathrm{~mm}$.

The connection between cryostat and lower grip was sealed with water. This froze when the liquid nitrogen was added and so prevented the liquid from leaking out.

The load was measured with an element of $50-5000 \mathrm{~kg}$ and traced on paper by the Instron Recorder.

The extension was performed with constant grip velocity i.e. the distance between the grips increased linearly with time. The extension velocity was between 0.1-0.5 mm per minute and the length of the specimen was $20-38 \mathrm{~mm}$.

From the load elongation curves, resolved shear stress vs strain curves where computed, assuming that the single crystals deformed on one slip system until the orientation is on the [001]-[11] line and that then the deformation continues evenly on two slip systems. This assumption will be discussed later and the formulae to be used will be derived in chapter IV.

\section{II.3 HEASLREMENT OF E, G AND INTERNAL FRICTION}

The elastic constants were measured by a dynamic method in an apparatus designed by $C$. Groenenboom-Eijgelaar (Brouwer and Groenenboom-Eijgelaar (1967)). This apparatus (fig. 8) consists of a brass neck and base connected by a Pyrex tube. In the neck a threaded manipulation bar can be moved vertically or rotated by means of two control rings. A cylindrical philitex coil holder, containing four coils, is attached to the lower end of the manipulation bar. The specimen is screwed on to the base. A magnet holder with two bolts on the side (see fig. 8) is screwed to the upper end of the 
specimen. The specimen can be given a plastic deformation both in extension and torsion by gripping the bolts of the magnet holder in a bayonet catch in the bottom of the coil holder. During the deformation, base and tube are immersed in a bath of liquid nitrogen. The apparatus can be evacuated to prevent ice formation and air friction and to diminish heat exchange between the specimen and its environment.

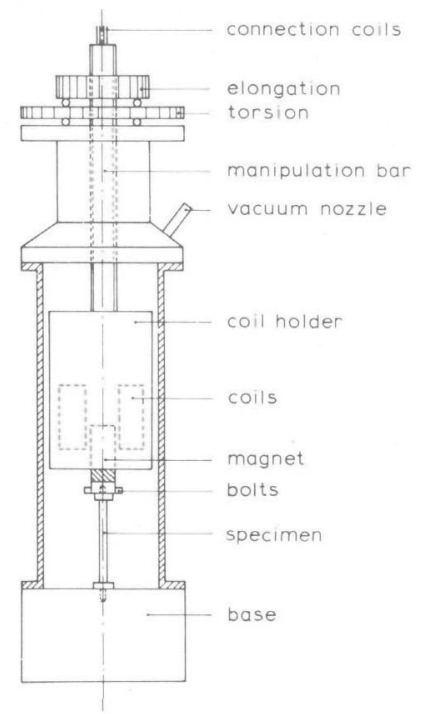

Fig. 8 - Apparatus for low

temperature measurements.

A cylindrical permanent magnet, magnetized in a direction perpendicular to the axis is fixed on top of the specimen. This magnet can oscillate inside the coil holder. The coils (2000 turns each) are arranged in a square, their planes being parallel to the specimen (and magnet) axis. A correct electrical arrangement of the coils will cause either torsional or flexural oscillations of the specimen. Fig. 9 shows a top view of the coils and magnet as well as a block diagram of the electronic system. The arrows show the direction of winding of the coils and numbers 1-6 give the connections of the 
wires fed into the "switching box". The two connections marked 0 are short circuited.

Excitation and indication of the oscillations are obtained as follows: when an alternating current (excitation signal) is sent through coils a and b (see fig. 9) the magnet and specimen will oscillate in torsional oscillations with the same frequency as the alternating current and induce a voltage (indication signal) in coils $c$ and $d$, proportional to the angular velocity. In this arrangement, the direct signal transmission (crosstalk) is negligible. When the excitation signal is sent only through coil b and the magnet is rotated so that $S$ (or $N$ ) is opposite to the middle of this coil, the specimen will oscillate in flexural oscillations and induce a voltage (indication signal) in coils a, $c$ and $d$.

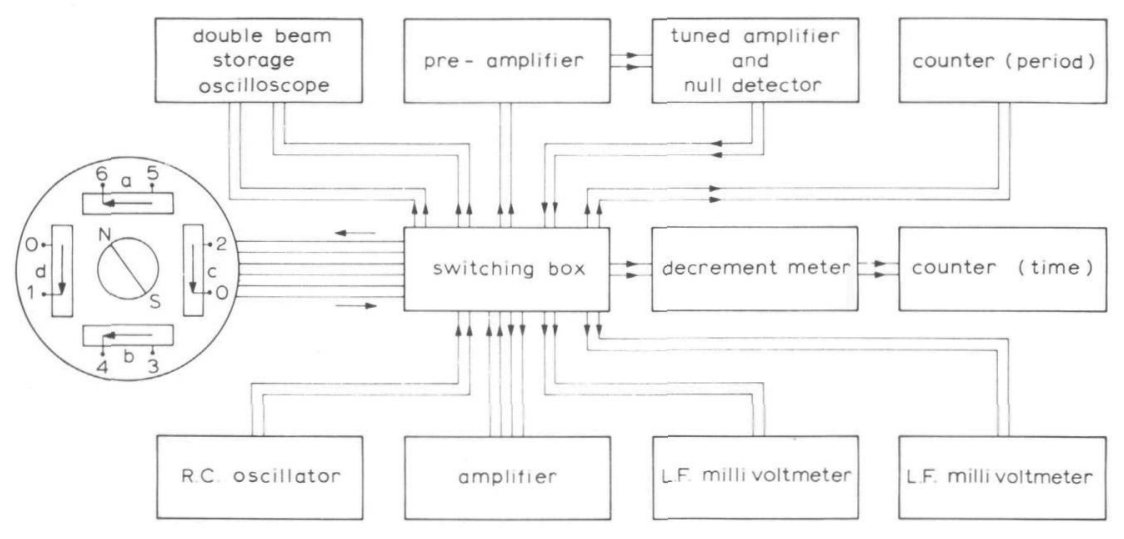

Fig. 9 - Block diagram of the electronic system and the position of the magnet and coils.

A suitable connection of the coits is: for torsion

1. and 2. ind. vortage

for fleme

3. and 6. exc. voltage

1. and 6. ind. voltage

4. and 5. short circuited

3. and 4. exc. voltage

2. and 5. short circuited 
Excitation and indication coils are connected through an amplifier with negligible phase shift in the frequency region 10-10.000 $\mathrm{Hz}$. An automatic gain control circuit adjusts the loop gain to be one at a certain output level. The amplitude of the oscillations can be adjusted by regulating the output level. The frequency is measured by connecting the indication signal to an electronic counter.

Provision is made so that the system can be used in self-excitation or driven by external forces.

Self-excitation is achieved by fedding the indication signal into the excitation coils through the amplifier, after the specimen started to oscillate and in this way the specimen oscillates in its own resonant frequency.

In some cases the system has to be driven by external forces. The excitation coils are then fed by an R.C. oscillator with adjustable frequency. The resonant frequency is then found by varying the frequency of the R.C. oscillator until a maximum indication signal is found at a constant excitation signal.

The internal friction is determined by measuring the time that passes until the amplitude of the indication signal decreases by a factor e, after interruption of the excitation signal. Precautions are taken to keep other sources of friction and spurious signals small. In order to eliminate the main cause of spurious damping, the specimen is screwed into a heavy base, the ratio of the moments of inertia of base and oscillator being quite high. To eliminate spurious electrical damping, a switch was used which disconnects the coils from the system, connecting one side of the excitation coils to ground and indication coils to the decrement meter through a preamplifier having an input impedance of $1 \mathrm{M} \Omega$ and a Tuned amplifier (see fig. 9). It was possible by means of this system to measure a damping as low as $\mathrm{C}^{-1}=7 \cdot 10^{-6}$ of a $\mathrm{Cu} 20$ at \% Au polycrystalline specimen, vibrating in torsional oscillations. With this specimen the extra damping of the air was measured, i.e., the damping of the specimen vibrating in torsional oscillations when the apparatus is not evacuated, and it was found to be $Q^{-1}=2 \cdot 10^{-5}$. 
In order to measure the effects as a function of plastic deformation, the deformation is increased stepwise and after each step resonant frequencies and damping in flexural and torsional oscillations are measured.

Polycrystalline specimens and single crystalline specimens of $<001>$ and $<111>$ orientation, which remain circular during deformation, have only one resonant frequency in torsion and one in bending. single crystal specimens with their axis in all other orientations have two resonant frequencies (ground tones) in flexural oscillations and two or three resonant frequencies in torsion. All resonant frequencies in torsion are measured without changing the position of the magnet with respect to the coils.

The frequency with lowest damping is found by using self-excitation, while the others are found by use of the R.C. oscillator.

It is known that elliptic specimens have different resonant frequencies according to whether the bending is in the thin or thick direction, but there is still no adequate explanation for the fact that there is more than one resonant frequency in torsion. It was found, that both resonant frequencies in flexure can be measured, if the magnetic axis (iv-S) is in an intermediate position between the thinest and thickest direction of the specimen. It is possible to predict the directions of the axes of the cross-section ellipse of the specimen after extension by determining the primary slip direction. The orientations in all directions were therefore determined by use of Laue $x$-ray photographs and then the screws were soldered in such a manner that the $N-S$ axis of the magnet should be in the correct direction.

In order to avoid amplitude dependent effects, the oscillation amplitude is kept constant $\left(\simeq 10^{-6}\right)$. After each deformation the amount of elongation or torsion is given by the change of position of the manipulation bar. This position is found by turning the manipulation bar slowly until it is seen on the oscilloscope that the oscillations are just stopping.

The measure of torsional deformation is expressed as the relative 
elongation of a spiral line on the specimen surface at an angle of $45^{\circ}$ to the axis. This criterion gives as a measure for torsional deformation $\varepsilon=\sqrt{1+\frac{r \theta}{l}+\frac{1}{2}\left(\frac{r \theta}{l}\right)^{2}}-1$ and when this function is expanded in a series the first term is found to be $\frac{r \theta}{2 l}$. Although, strictly, this quantity $\varepsilon=\frac{r \theta}{2 l}$ as a measure of torsional deformation is only permissible for small deformations, following the practice in literature, it will always be used. 


\section{III}

\section{calculation of modiulus effects from experimental data}

।। I.1 $\triangle \mathrm{G}$ EFFECT

The rigidity modulus $G$ is calculated using the relations:

$$
G=\frac{8 \pi \ell ! f^{2}}{r^{4}}
$$

for a specimen with a circular cross-section (Hearmon (1946)) ${ }^{\bullet}$ ano

$$
G=\frac{4 \pi \ell \mid f^{2}}{\left(\frac{a^{3} b^{3}}{a^{2}+b^{2}}\right)}
$$

for a specimen with an elliptic cross-section (Timoshenko $E$ Goodier (1970) p. 299) in which:

$\ell=$ length of the specimen between the screws (in $\mathrm{mm}$ ),

$I=$ moment of inertia of the magnet and screw with respect to the specimen axis. The mass of the specimen $(0,6 \mathrm{gr})$ is neglected with respect to the mass of the load (magnet and screw $14 \mathrm{gr}$ )

$f=$ the resonant frequency

$r=$ radius of the cross-section

$a=$ short half-axis of the cross-section ellipse

$b=$ long half-axis of the cross-section ellipse.

- This expression is actually correct only for isotropic materials like polycrystalize specimens, however we will use it also for single crystal specimens, with the understonding that the rigidity modulus $G$ calculated in this way is an average of the different $G^{\prime} s$ in the different directions perpendicular to the specimen axis. 
We assume that during plastic deformation the volume remains constant. With this assumption we can calculate the change of the radius, after an extension. For a specimen that remains circular:

$$
r_{x}^{2}=r_{0}^{2} \frac{l_{0}}{l_{x}}
$$

the indices 0 and $x$ refer to the undeformed and deformed specimen respectively.

For a specimen that changes from a circular to an elliptic crosssection during extension:

$$
a_{x}^{2}=r_{0}^{2} \frac{l_{0}}{\alpha_{x}^{l} x}
$$

where $\alpha_{x}=b_{x} / a_{x}$. The change of the rigidity modulus for a specimen that remains circular is then found to be:

$$
\Delta G / G=\frac{G_{x}-G_{0}}{G_{0}}=\frac{G_{x}}{G_{0}}-1=\frac{l_{x} f_{x}^{2} r_{0}^{4}}{l_{0} f_{0}^{2} r_{x}^{4}}-1
$$

and by use of relation $(3-2)$ we get:

$$
\Delta G / G=\frac{l_{x}^{3 p^{2}}}{l_{0}^{3 p^{2}}}-1
$$

in which $P=\frac{1}{f}$ ( $P$ is the period of one oscillation).

For a specimen that changes from a circular into an elliptic crosssection the change of the modulus is:

$$
\Delta G / G=\frac{e_{x} f_{x}^{2} r_{0}^{4}\left(a^{2}+b^{2}\right)}{2 l_{0} f_{0}^{2} a^{3} b^{3}}-1
$$


and by use of relation $(3-2 A)$ we get:

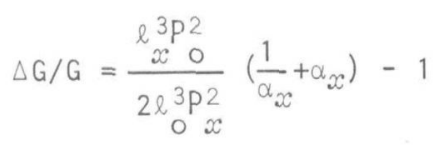

The modulus effect $\Delta G / G$ is negative. This means that in $(3-4 A)$ the first term on the right hand side is positive and $<1$. As the correction factor $1 / 2\left(1 / \alpha_{x}+\alpha_{x}\right) \geqslant 1$ and $\Delta G / G$ values always 1 ie between 0 and -1 , it follows that the corrected values of $|\Delta G / G|$ are smaller than the uncorrected ones.

It will be shown in the next section that $\alpha_{x}=b_{x} / a_{x}$ can be calculated from the two resonant frequencies found in flexural oscillations, so that the $\Delta G / G$ effect can also be calculated for a specimen changing from a circular to an elliptic cross-section during plastic extension.

There are, however, more problems with respect to torsional oscillations of deformed single crystals in random orientation: 1) Goens (1932) and Brown (1940) have given a solution to the equations of Voigt (1910) and have shown that with the exception of symmetric orientations, there are no pure torsional or flexural oscillations, but a torsion-flexure coupling in vibration experiments. Therefore, for a correct value of the absolute modulus, a correction factor must be used (as calculated by Goens for ex.). However, as we are interested only in the relative change of the elastic moduli of one specimen, as a function of plastic deformation, we shall ignore this correction, as the change of the correction factor by deformation is negligible.

2) Another problem is the anisotropy of the single crystal, namely the dependence of the elastic moduli on the orientation in which they are measured. The dependence of the modulus on the orientation of the axis is important because it is expected that the orientation of the axis of most crystals will change during plastic extension and also that certain parts of the specimen will have new orientations, as a result of mechanical twinning 
(see section V.3). Such a change of the orientation will result in a purely "crystallographic" modulus effect, for which has to be corrected if the "physical" modulus effect due to the dislocations introduced during deformation has to be determined.

For Young's modulus the problem is easily solved as it can be shown that the dependence of $E$ on orientation for cubic crystals is:

$$
\frac{1}{E}=S_{11}-2\left(S_{11}-S_{12}-\frac{1}{2} S_{44}\right)\left(\alpha^{2} \beta^{2}+\beta^{2} \gamma^{2}+\gamma^{2} \alpha^{2}\right) .
$$

$\alpha, \beta, \gamma$ are the direction cosines of the specimen axis with respect to the cube axes.

For the shear modulus, G, the problem is more complicated. If in a single crystal, a shear stress is applied on a certain plane, the resulting shear strain, depends on the direction of the shear stress in that plane.

The shear modulus is therefore dependent also on the direction of the applied shear-stress and not only on the plane on which it acts. When a cylindrical specimen is loaded in torsion, in planes perpendicular to the axis, the shear stress has everywhere the direction perpendicular to the radius. It can be shown that the shear modulus measured in this way is the harmonic average of the direction dependent shear modulus, when the polar angle varies from 0 to $2 \pi$. It is clear that this average has to be calculated so that the result will depend only on the orientation of the specimen axis. A formula calculated in this way has been presented by Van Bueren (1961):

$$
\frac{1}{G}=S_{44}+4\left(S_{11}-S_{12}-\frac{1}{2} S_{44}\right)\left(\alpha^{2} \beta^{2}+\beta^{2} \gamma^{2}+\gamma^{2} \alpha^{2}\right)
$$

It can be seen that the formulae for $E$ and $G$ are similar and whereas in the $<001>$ orientation the modulus of rigidity $G$ has the largest value the modulus of Young, E, has the smallest value. 

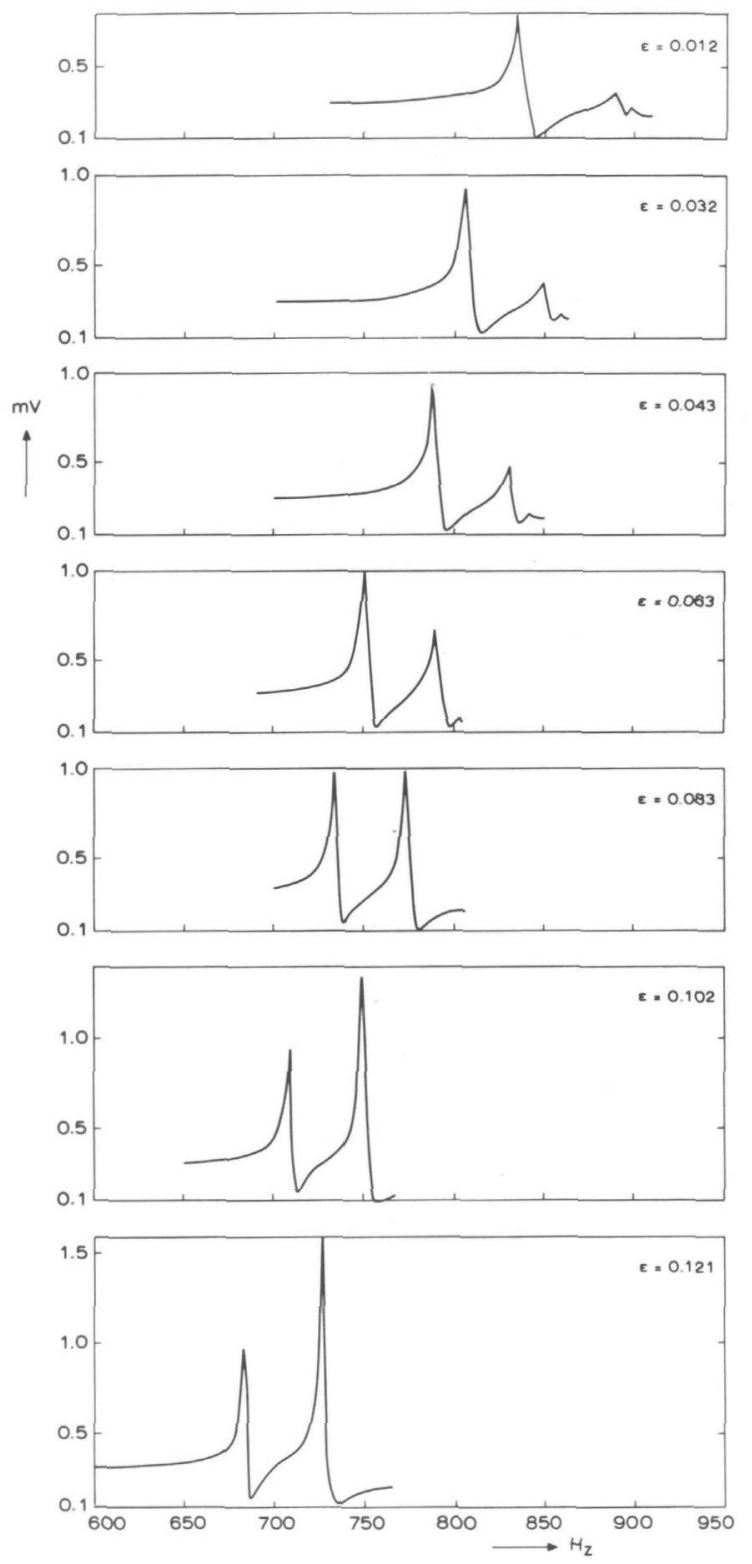

Fig. 10 - Indication signal as function of frequency at a constant excitation signal of $250 \mathrm{mV}$ from a specimen of orientation NO. 1 after different degrees of extension.

30 
It is also easy to show that in the $<111>$ orientation the roles are reversed and the modulus of rigidity $G$ is a minimum whereas Young's modulus $E$ is a maximum.

3) The most serious problem is, however, the following. With the exception of the symmetric orientations $<001\rangle$ and $\langle 111\rangle$, either two or three resonant frequencies are found in torsional vibrations of copper single crystal specimens. An example is shown in fig. 10. In this experiment the excitation signal from the R.C. oscillator was kept constant at $250 \mathrm{mV}$. The indication voltage is given in fig. 10 as a function of the frequency of the vibration for various values of the degree of plastic extension $\varepsilon$. Two resonant frequencies clearly show up. Up to $\varepsilon \simeq \delta \%$ the first resonant peak is the largest but for larger deformations the second peak is larger.

When measured in self-excitation, in this particular case, up to $\varepsilon \simeq 8 \%$ the lower resonant frequency is found, whereas for $\varepsilon>8 \%$ the specimen vibrated in the higher resonant frequency. Six specimens of this particular orientation (No. 1 see fig. 24) were tested. In two cases the frequency transition took place at $\varepsilon \simeq 8 \%$ and in four cases at $\varepsilon \simeq 12 \%$. This means that at the transition strain an apparent discontinuous change in $G$ takes place.

The transition from one resonant frequency to another one, in self-excitation measurements, did only occur in specimens of certain orientations. In the other orientations two or three resonant frequencies were always observed, but the same one shows up in self-excitation in the range of plastic deformations investigated. Fig. 11 shows the three $\Delta G$ effects as calculated with formula (3-4A) from the three different resonant frequencies in torsion, of a specimen oriented about $5^{\circ}$ from the $<001>$ orientation. For comparison we have also plotted the $\Delta G$ effect of a $<001>$ oriented specimen in which case only one resonant frequency in torsion was found along with the respective $\Delta E$ effects. The $\Delta E$ effects show $a$ remarkable resemblance and as a consequence we would expect that 
also the $\Delta G$ effect of the two specimens will not differ much. We see that the curve $\Delta G / G$ I is close to the $\Delta G / G$ curve of the $<001>$ specimen. The curve $\Delta G / G I$ is calculated from the resonant frequency found with self-excitation.

Therefore, although we do not know the reason for the presence of more than one resonant frequency in torsion, we shall assume that (with the exception of orientations which have a transition as in fig. 10) the "main frequency" found in self-excitation reflects the shear modulus $G$ as represented in formula (3-1). The modulus effect $\Delta G$ is calculated from the change in this "main frequency".
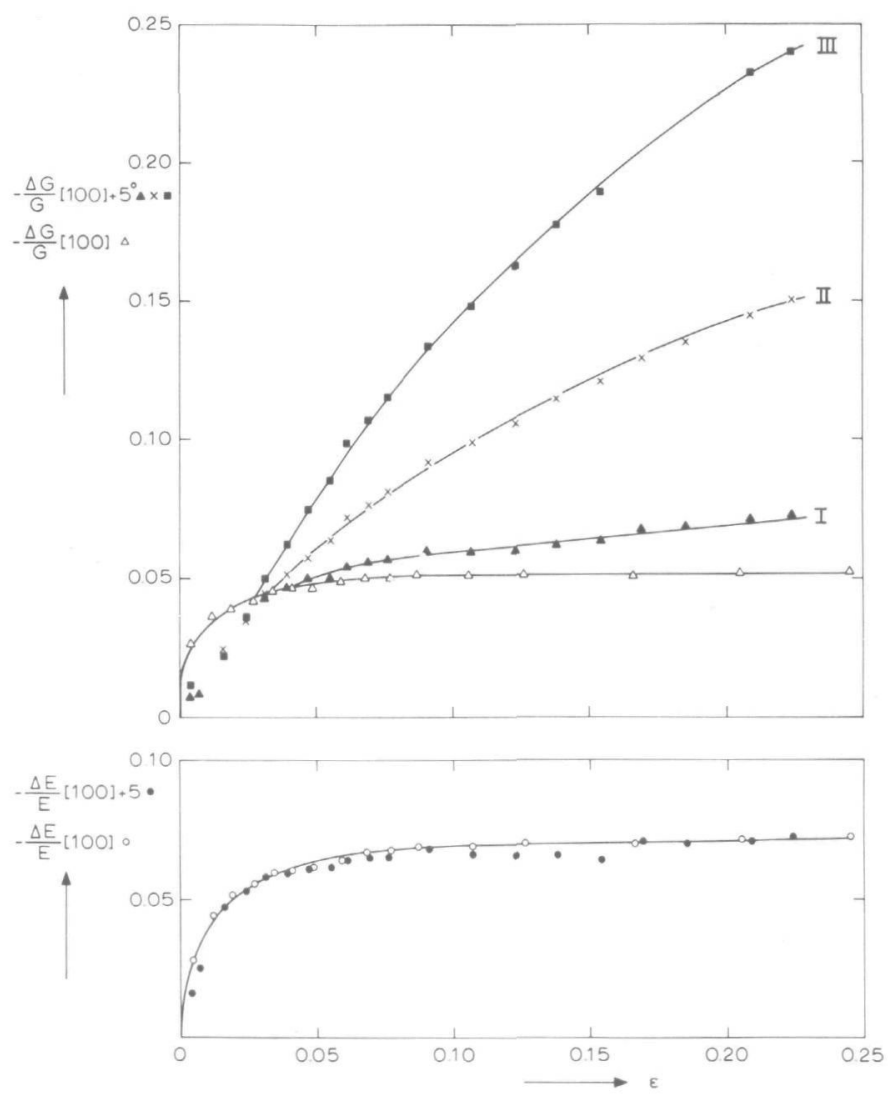

Fig. 11 - A comparison between 3 different $\Delta G$ effects calculated from the 3 different resonant frequencies in a specimen $5^{\circ}$ from [100] and the $\Delta G$ effect of a [100] specimen, as weit as the $\Delta E$ effect of both specimens. 
Young's modulus $E$ is calculated using the formula derived by A. Brouwer (1965) relating the modulus to the period of flexural oscillation and in which the mass of the specimen $(\simeq 0.6 \mathrm{gr})$ is neglected with respect to the mass of the load (magnet and screw $14 \mathrm{gr})$.

$$
E J=\frac{l m}{2 P^{2}}\left[\delta^{2}+\delta l+\frac{l^{2}}{3}+\frac{1}{m}+\sqrt{\left(\delta^{2}+\delta l+\frac{l^{2}}{3}+\frac{1}{m}\right)^{2}-\frac{l^{2} I}{3 m}}\right]
$$

$\mathrm{J}=$ moment of inertia of the cross-section,

$m=$ mass of the magnet and screw,

$\delta=$ distance of center of gravity of magnet and screw to its connecting place with the specimen,

$1=$ moment of inertia of the magnet and screw with respect to its center of gravity.

To simplify the notation of formula $(3-6)$ we define:

$$
B=\delta^{2}+\delta l+\frac{l^{2}}{3}+\frac{1}{m}+\sqrt{\left(\delta^{2}+\delta l+\frac{l^{2}}{3}+\frac{1}{m}\right)^{2}-\frac{l^{2} 1}{3 m}}
$$

then the change of Young's modulus after extension becomes:

$$
\Delta E / E=E_{x} / E_{0}-1=\frac{l_{x}^{P_{0} J_{O}{ }^{B} x}}{l_{0}{ }_{0}{ }^{2} J_{x}{ }^{B}{ }_{0}}-1
$$

in which the indices 0 and $x$ refer to the undeformed and deformed specimens respectively.

The value of $m$ was found by weighing and $\delta$ by direct measurement of the distance from the place of equilibrium to the connecting place magnet and screw with the specimen. I was taken as an average of two values: one found by the physical pendulum method and the second by calculation. Although the difference between the two values 
was about $20 \%$ it does not introduce a big error in the $\Delta E / E$ calculation as a variation of $20 \%$ in I yields only a change of $0.2 \%$ in $\triangle E / E$ after an extension of $30 \%$.

The undeformed specimens were rods with a circular cross-section for which $J_{0}=\pi r_{0}^{4} / 4$ (Sommerfeld (1964)). For specimens that remain circular (polycrystalline, <001> and <111>) formula (3-7) becomes, by use of relation $(3-2)$ :

$$
\Delta E / E=\frac{l_{x 0^{3} p^{2}} B^{3}}{l_{0}^{3}{ }_{0}^{2} B_{0}}-1 .
$$

When, as a result of plastic extension, the cross-section of the specimen changes from a circular to an elliptic one, we use the fact that the resonant frequency in bending is different when measured in the thin (a) or thick (b) direction (Kohlrausch (1960)). In a thin rod, vibrating in flexural oscillations, there is only a simple extension or compression (Landau \& Lifshitz (1959)) so that the strain is always in the axial direction and we are measuring the same $E$, whether the bending is in the thin or thick direction, the difference in resonant frequencies being a consequence only of the different moments of inertia of the cross-section in the respective directions.

It is assumed that after deformation, the cross-section becomes an ellipse. The moment of inertia of the cross-section is in the thin (a) direction:

$$
J_{a}=\iint x^{2} d s=\frac{\pi a b^{3}}{4}
$$

and in the thick (b) direction:

$$
J_{b}=\iint y^{2} d s=\frac{\pi a^{3} b}{4}
$$


Substituting these values in $(3-7)$ we obtain:

$$
(\Delta E / E)_{L}=\frac{l_{x} P_{0}^{2} r^{4} B_{x}}{\ell_{0} P^{2} a b^{3} B_{0}}-1
$$

and

$$
(\Delta E / E)_{H}=\frac{e_{x O_{0}{ }^{2} r^{4} B_{x}}}{\ell_{O} P_{H}^{2} a^{3} b B_{0}}-1 .
$$

$P_{L}$ and $P_{H}$ are the periods of the resonant frequencies measured in the thin (a) and thick (b) directions respectively.

As we have argued that there is no difference in $E$, whether it is measured in the thin or thick direction, we equate formulae (3-9) and $(3-9 A)$ and find the following relation $b / a=P_{H} / P_{L}=\alpha$. After each experiment $a$ and $b$ were measured in a microscope with a precision of $\pm 0.005 \mathrm{~mm}(\simeq 0.2 \%)$ and their ratio was compared with the ratio of the last two values of $P_{H} / P_{L}$ measured. The agreement was always good, the difference being of the same order of magnitude as the error in measuring the dimensions after deformation.

Substituting for $\alpha$ in $(3-2 A)$ we obtain:

$$
a_{x}^{2}=r_{0}^{2} \frac{l_{0} P_{L}}{l_{x} P_{H}} .
$$

Using again the notation $b / a=\alpha$ and substituting relation $(3-10)$ in formula (3-9), we obtain a relation between the change in Young's modulus and the two resonant frequencies in bending:

$$
\Delta E / E=\frac{l_{x}^{3 P^{2} B_{x}}}{l_{0}^{3} P_{0} P_{H} B_{0}}-1
$$

That means that for an elliptic cross-section, when there are two different resonant frequencies in flexural oscillations, their 
geometric mean has to be taken.

In order to verify the accuracy of these formulae, the following tests were made:

III.2.1 Variation of the elastic modulus during plastic deformation of one specimen (check whether the equating of $(\triangle E / E)_{L}$ and $(\Delta E / E)_{H}$ is justified)

A $<145>$ oriented specimen, which according to the model of Schmid (Mark, Polanyi and Schmid (1932)) should deform about 52\% by gliding in only one slip system, was deformed, stepwise, in extension about $28 \%$ and during the process the period of the two resonant frequencies $\left(P_{L}\right.$ and $\left.P_{H}\right)$ in flexural oscillations were measured as a function of deformation.

After the experiment it was found that $b_{x}=r_{0}$ as was expected for glide in one slip system and $a_{x} \simeq r_{0} l_{0} / l_{x}$ as it should, proving that the assumption that the volume remains constant is valid. Substituting these values in (3-9) and (3-9A) we obtain two independent formulae for $\triangle E / E$ :

$$
\begin{aligned}
& (\Delta E / E)_{L}=\frac{{ }_{x}^{{ }^{2} P_{O}^{2} B_{x}}-1}{l_{O}^{2 P^{2} B_{0}}-1} \\
& (\Delta E / E)_{H}=\frac{l_{x}^{4} P_{0}^{2} B_{x}}{l_{O}^{4} P_{H}^{2} B_{O}}-1 .
\end{aligned}
$$

The result of calculating $\triangle E / E$ with these formulae is shown in fig. 12 . It is seen that between an extension of 0.06 and 0.16 the two curves fit very well, whereas for other deformations there is only a small discrepancy, which may be partially a result of the inaccuracy in measuring the length. This can be made plausible as follows: Fig. 13 shows two specimens soldered in screws. The solder has crept upwards by about $0.4 \mathrm{~mm}$, reducing the length of the vibrating specimen by a similar amount. As the length of the specimen has been 


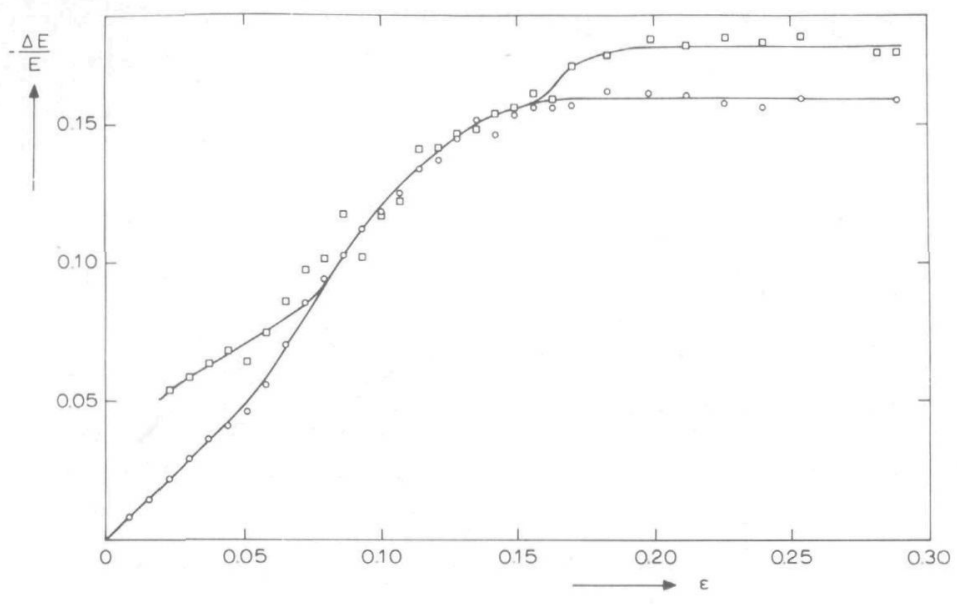

Fig. $12-\Delta E$ effect calculated from the eigenfrequency in the thin $\left(P_{L} O\right)$ and thick $\left(P_{H}\right.$ 口) direction of a <145> oriented single crystal.

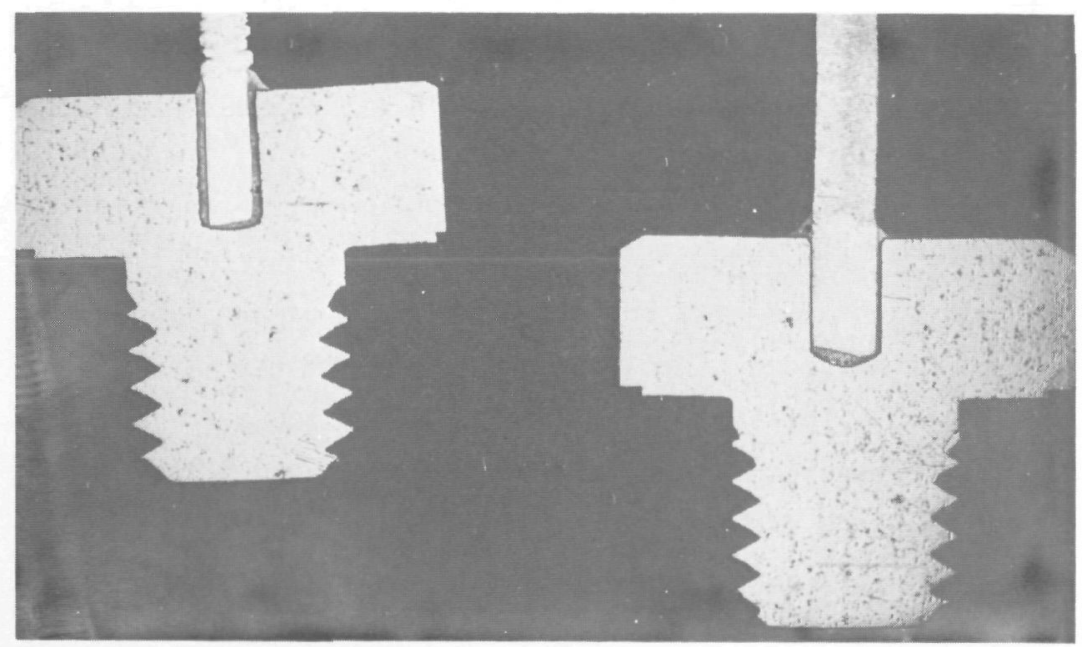

Fig. 13 - Two specimens soldered in screws. 
measured from screw to screw, this has to be corrected by $\Delta l \simeq 0.4 \mathrm{~mm}$, both in the deformed and undeformed state. It follows easily that in this case the value of $l_{x} / l_{0}$ for $\varepsilon \simeq 0.20$ has to be reduced by about 0.004 . Substituting this value in $(3-12)$ and $(3-12 \mathrm{~A})$ it follows that $-(\Delta E / E)_{H}$ is larger than $-(\Delta E / E)$ by about 0.008 , in agreement with the result of fig. $12\left[-(\Delta E / E)_{H}\right.$ is reduced by 0.016 and $-(\Delta E / E)_{L}$ by $0.008]$. For low strains $(\varepsilon<0.05)$ this correction is negligible; in this range the discrepancy has to be ascribed to the elongation measurement, especially to the inaccuracy of the first measurement at the start of plastic extension. Because the influence of $l_{x} / l_{0}$ is the smallest in $-(\Delta E / E)$ L this value seems to be the most reliable in the low strain region.

III.2.2 Comparison of the elastic constants of different undeformed specimens (<111> orientation)

Resonant frequencies in torsion and bending were measured of a number of $<111>$ oriented specimens, As reference the specimen $S_{Q}$ with the lowest internal friction was taken. The difference of the moduli $G$ and $E$ of the other specimens with respect to $S_{Q}$ was then computed by means of equations $(3-3)$ and $(3-7)$. The results are shown in table 1 .

It is interesting to note that the average value of $\Delta G / G$ and $\Delta E / E$ compared to the reference specimen $S_{Q}$ is negative. This had to be expected, because $S_{Q}$ is the specimen with the lowest internal friction and therefore, the lowest contribution of grown in dislocations to the modulus effect (Granato and Lücke (1956)). It has been shown in irradiation experiments that the contribution of grown in dislocations to the modulus effect is of the order of a few percent indeed (Thomson and Holmes (1956)).

It is concluded that the absolute measurements of the elastic moduli reproduce within a few percent. These deviations are probably due to three causes: the inaccuracy of the measurement of length of the specimens, small deviations of the specimen axes from the $\langle 111\rangle$ orientation and differences in initial dislocation density. 
In our experiments, where we are interested only in the relative changes of the moduli, due to plastic deformation of one and the same specimen, the accuracy will be even better.

\section{Table I}

\begin{tabular}{|c|c|c|c|c|}
\hline \multicolumn{2}{|c|}{ Specimen No. } & \multirow{2}{*}{$\frac{\Delta G / G}{-0.012}$} & \multicolumn{2}{|l|}{$\Delta \mathrm{E} / \mathrm{E}$} \\
\hline & 90804 & & -0.015 & \\
\hline & 90806 & +0.016 & -0.025 & \\
\hline & 90807 & -0.004 & +0.022 & \\
\hline & 90813 & -0.021 & -0.027 & \\
\hline & 90827 & -0.030 & -0.038 & \\
\hline & 91028 & -0.020 & -0.024 & \\
\hline & 91216 & -0.010 & +0.017 & \\
\hline & 100121 & -0.008 & -0.015 & \\
\hline & 100423 & -0.020 & -0.031 & \\
\hline & 100511 & +0.027 & +0.021 & \\
\hline & 100519 & -0.020 & -0.015 & \\
\hline & 100520 & -0.009 & -0.037 & \\
\hline & 100521 & +0.008 & +0.024 & \\
\hline \multirow{8}{*}{$\left(s_{Q}\right)$} & 100601 & 0 & 0 & mean $\Delta G / G=-0.005$ \\
\hline & 100817 & +0.029 & +0.014 & standard dev. $=0.017$ \\
\hline & 100902 & +0.005 & -0.015 & mean $\Delta E / E \quad=-0.009$ \\
\hline & 100914 & -0.025 & -0.031 & standard dev. $=0.021$ \\
\hline & 101005 & -0.010 & -0.019 & \\
\hline & 110121 & +0.003 & +0.004 & \\
\hline & 120329 & +0.008 & +0.006 & \\
\hline & 120419 & -0.001 & -0.015 & \\
\hline
\end{tabular}


III.2.3 Specimens of different orientations

It is possible to calculate a $\Delta E$ of specimens of different orientations with respect to the <111> orientation, in which $E$ is maximal, $(\operatorname{see}(3-5))$.

We calculate:

$$
\Delta E_{i}=\frac{E_{i}}{E_{<111>}}-1
$$

in which $E_{i}$ is Young's modulus of a specimen with a random orientation $\langle h k l>$.

From the theory of elasticity it follows that:

$$
E_{i}=\frac{1}{s_{11}^{<h k l>}} \text { and } s_{11}^{\langle h k l\rangle}=S_{11}-2 V \frac{h^{2} k^{2}+k^{2} l^{2}+l^{2} h^{2}}{\left(h^{2}+k^{2}+1^{2}\right)^{2}}
$$

in which $V=\mathrm{S}_{11}-\mathrm{S}_{12}-\frac{1}{2} \mathrm{~S}_{44}$. It must be pointed out that relation $(3-14)$ is the same as $(3-5)$ only written in an other form.

The stiffness constants for $\mathrm{Cu}$ at $80 \mathrm{~K}$ were taken from the results of Overton and Gaffney (1955) and from them the compliance constants were calculated using the relations:

$$
\begin{aligned}
& S_{11}=\frac{c_{11}+C_{12}}{\left(c_{11}-c_{12}\right)\left(c_{11}+2 c_{12}\right)} ; S_{12}=-\frac{c_{12}}{\left(c_{11}-c_{12}\right)\left(c_{11}+2 c_{12}\right)} \\
& S_{44}=\frac{1}{c_{44}},
\end{aligned}
$$

and were found to be: $\mathrm{S}_{11}=1.388, \mathrm{~S}_{12}=-0.576, \mathrm{~S}_{44}=1.235$ in units of $10^{-12} \mathrm{~cm}^{2} /$ dyne.

By using these values of the compliance constants, E was calculated for specimens of the different orientations by use of relation $(3-14) . \Delta E_{i}$ was then calculated by use of relation (3-13) and the results are given in table $I I$. The measured value of $\Delta E_{i}$ was found using relation $(3-7)$ in which $\mathrm{P}_{x}$ is the period of the resonant 
frequency of the $i$ orientation and $P_{O}$ is the period of the resonant frequency of the $<111>$ oriented specimen $S_{Q}$, used as reference in table I.

There is a fair agreement between the calculated and measured values of the modulus, the difference being of the same order of magnitude as in table 1 . The cause of the deviations is probably also the same.

\section{Table II}

$$
\Delta E_{i}=\frac{E_{i}}{E_{<111>}}-1
$$

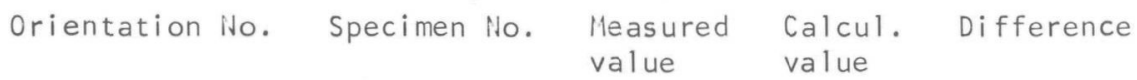

\begin{tabular}{ccccc}
\hline$<11>$ & 100601 & 0 & 0 & 0 \\
$<001>$ & 91223 & -0.627 & -0.652 & +0.025 \\
$<011>$ & 110817 & -0.299 & -0.319 & +0.020 \\
1 & 110310 & -0.610 & -0.630 & +0.020 \\
2 & 110319 & -0.523 & -0.538 & +0.015 \\
3 & 110601 & -0.066 & -0.059 & -0.007 \\
4 & 110510 & -0.183 & -0.185 & +0.002 \\
5 & 110726 & -0.303 & -0.312 & +0.009 \\
6 & 110525 & -0.538 & -0.565 & +0.027 \\
7 & 120307 & -0.453 & -0.429 & -0.024 \\
8 & 120418 & -0.417 & -0.435 & +0.018 \\
10 & 120131 & -0.606 & -0.621 & +0.015 \\
\hline
\end{tabular}




\section{extension of copper single crystals}

There are two mechanisms of plastic deformation: slip and mechanical twinning. Mechanical twinning will be the subject of section V.3 and in this chapter we will deal only with plastic deformation by slip.

Polycrystalline specimens deform (at least macroscopically) homogeneously under the action of an uniaxial stress and a circular cross-section remains circular after extension. The cross-section of a single crystal specimen becomes elliptic after an extension, because the deformation takes place by crystal planes slipping over one another, resembling a sheared pack of cards. Fig. 14 shows schematically the process of deformation by slip in single crystals and in fig. 15 a deformed single crystal is shown on which the slipped areas appear as steps on the surface of the crystal. In fig. 14 it is also seen that during deformation the orientation of the axis rotates towards the slip direction.

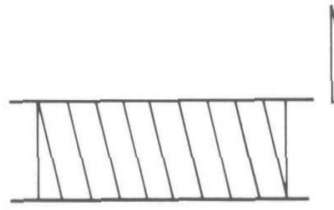

(a)

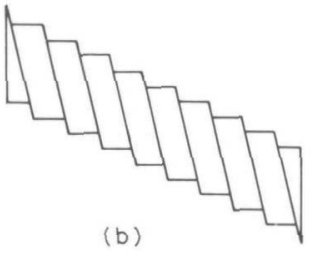

(b)

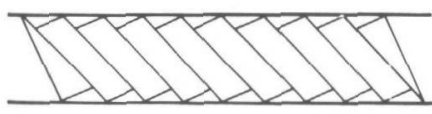

(c)

Fig. 14 - Schematic representation of slip and the accompanying rotation of the axis oxientation in extended single crystals.

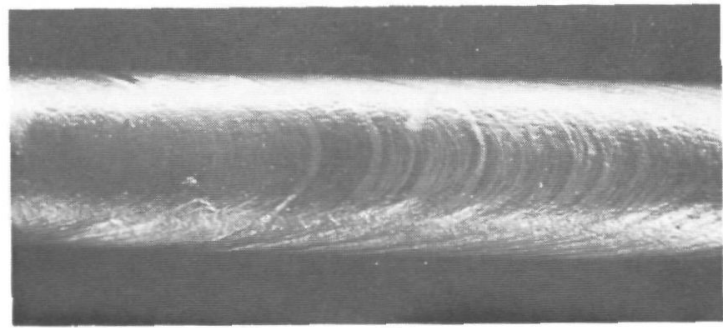

Eig. 15 - An extended single crystal of copper. 
Copper has a face centered cubic ( $f c c$ ) structure and it slips only on $\{111\}$ planes (slip planes) and in the $\langle 110\rangle$ directions (slip directions). A particular combination of a slip plane and a slip direction is called a slip system. In fcc there are 4 slip planes and 3 slip directions on each plane so that there are 12 slip systems in total.

In general only one and occasionally two slip systems appear to operate at the start of slip (if we ignore the symmetrical orientations $<001>$ and $\langle 111>$ ). This experimental result was explained by H. Mark et al (1922) and Taylor \& Elam (1923, 1925). They assumed that in each metal there is a definite shear stress $\tau_{c}$ at which the planes can slip over one another. When the applied stress $\sigma$ is resolved along all twelve slip systems, that one where the resolved value of $\sigma$ first equals $\tau_{c}$ will be the operative system. $\tau_{c}$ is called the critical resolved shear stress for slip. The value of $\tau_{c}$ is very sensitive to the impurity content and density of crystal imperfections.

The angles used in resolving $\sigma$ are shown in $\mathrm{fig}$. 16. The normal on the slip plane is $B C$. The angle between the normal to the slip plane $B C$ and the specimen axis $B A$ is $\varphi$. The angle between the slip direction BF and the specimen axis BA is $\lambda$.

The area of the slip plane is $S / \cos \varphi$ ( $S$ is the area of the cross-section) and the shear stress on the slip plane in the direction of slip will be $\tau_{r}=\frac{F}{S} \cos \theta \cos \lambda$.

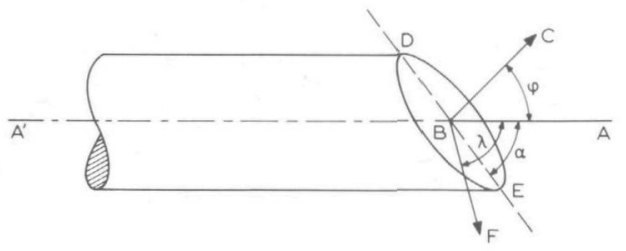

Fig. 16 - The angles used in resolving o. 
The factor $\cos \varphi \cos \lambda$ is called the Schmid factor. When $\tau_{r}$ is equal to the critical shear stress $\tau_{c}$ slip will start. Thus the slip system which will operate is that for which the Schmid factor is a maximum. It follows that the onset of slip in a crystal depends on the orientation of its crystallographic axes with respect to the direction of the applied stress, which in our case is the specimen axis.

The orientation of the axis of a single crystal specimen is conveniently represented using a stereographic projection, as for example point $P$ on fig. 17. It is then easy to predict which slip system will operate at the start of plastic deformation as we can calculate for every orientation which slip system has the largest Schmid factor.

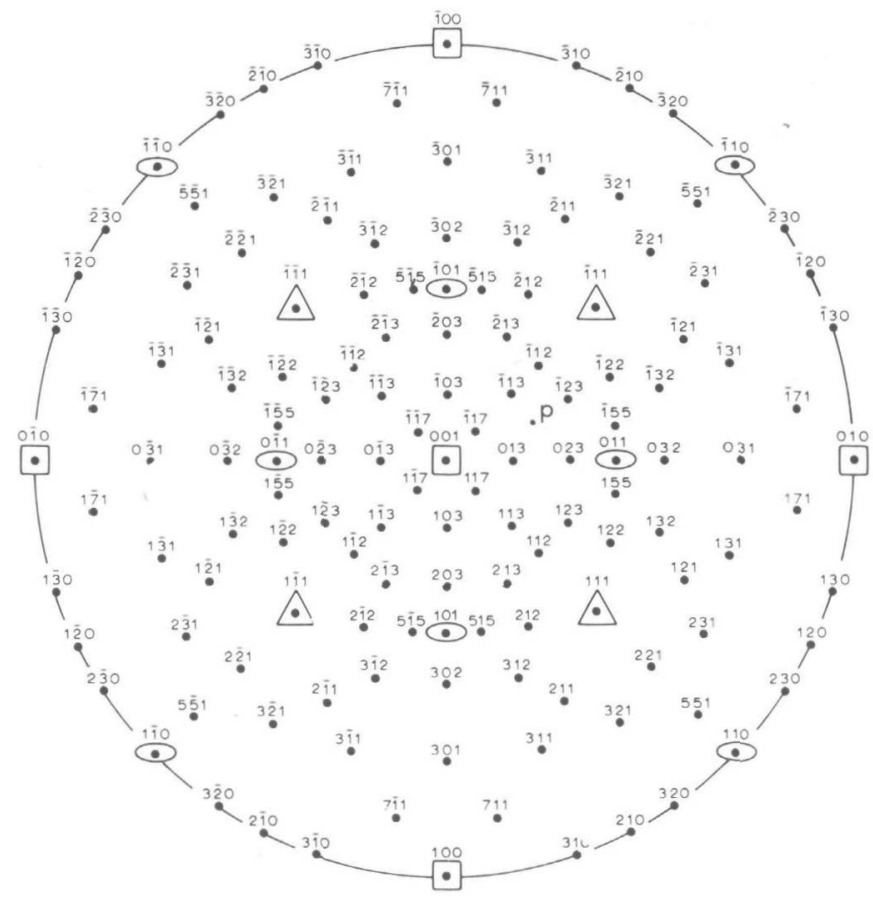

Fig. 17 - Standard (001) projection for cubic crystals. 


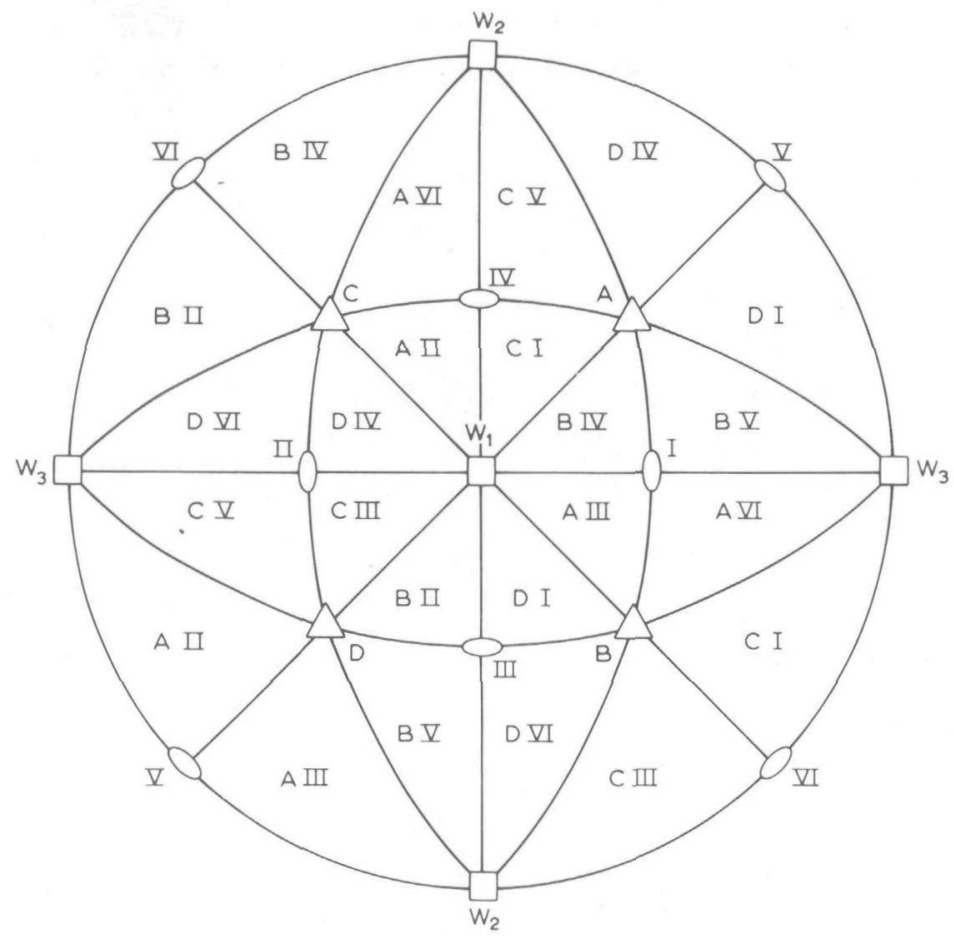

Fig. 18 - Choice of the operative slip system for extension of fec crystats. A-D poles of the slip planes. I-VI slip directions.

Fig. 18 gives the results of such a calculation made by Clarebrough and Hargreaves (1959).

It is not necessary, however, to use the whole standard projection, for the axis of the specimen may be referred to the three neighbouring poles of $\{001\}\{011\}$ and $\{111\}$ planes. If poles of these three types are joined by great circles, there results for the cubic system a pattern of 24 equivalent "triangles". It is now standard practice to use the triangle marked by the poles of the (001) (011) and (i11) planes for plotting the specimen axis. This triangle is called the standard triangle. 
This system, using the standard triangle, permits the adoption of consistent names for the four planes on which slip may take place, identifying them unambiguously with respect to the direction of stress. We will use the terminology introduced by Rossi and Mathewson (1950) which is illustrated in fig. 19 and is also used extensively in literature.

The ideal behaviour of a crystal in tension is to start slipping on the "primary" system indicated in fig. 19 i.e. (111) [101] for an orientation of the direction of stress in the standard triangle. The result of such slip is that the axis of the crystal rotates in such a way that the stress direction moves towards the slip direction. After a certain deformation the orientation of the axis must reach the [001]-[111] boundary. For this orientation the primary system (111) [101] and the conjugated system ( $\overline{1} \overline{1} 1)$ [011] are equally favoured. Further deformation of the crystal occurs by "double slip" on these two systems with a rotation of the direction of stress, along the line of symmetry, towards [1112] (Taylor E Elam (1925)).

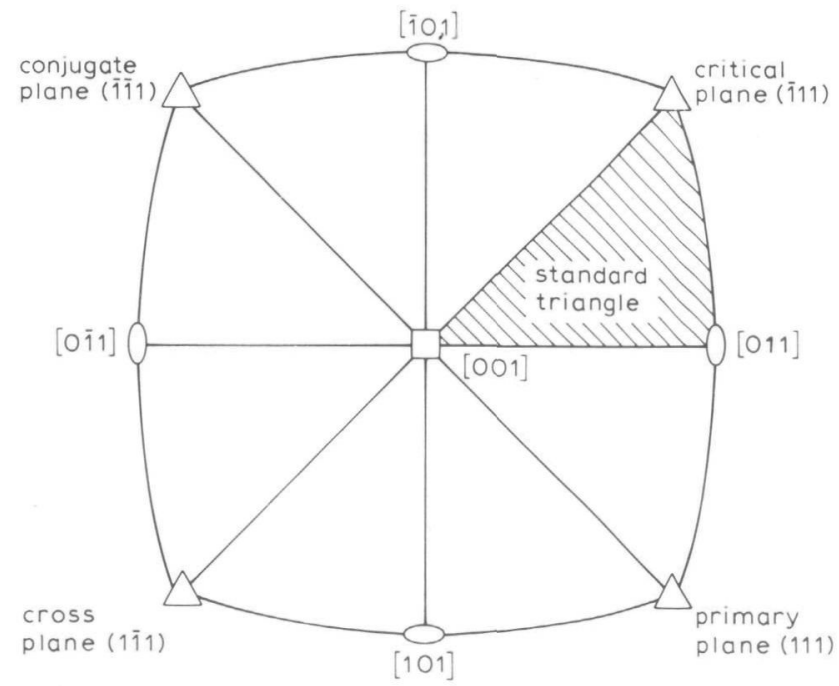

Fig. 19 - Terminology for the slip planes in fec crystals as introduced by Rosi and Mathewson (1950). 
In the following a method will be outlined to calculate the change in orientation of the specimen axis as a function of plastic extension. It will be assumed that the behaviour is ideal, as just described.

In single slip, according to Penning (1971), we can calculate the rotation of the orientation of the specimen's axis in the following manner (see fig. 20).

We define the following unit vectors:

slip direction

initial orientation of the axis

axis orientation after deformation pole of slip plane

$$
\begin{aligned}
& \vec{p}(P \vec{i} ; Q \vec{j} ; R \vec{k}) \\
& \vec{a}(A \vec{i} ; B \vec{j} ; C \vec{k}) \\
& \overrightarrow{a^{\prime}}\left(A^{\prime} \vec{i} ; B^{\prime} \vec{j} ; C^{\prime} \vec{k}\right) \\
& \vec{h}(H \vec{i} ; K \vec{j} ; L \vec{k})
\end{aligned}
$$

The origin of the coordinate system is taken at a point of the specimen that remains unchanged after an extension. An arbitrary point $\vec{r}$ has a distance $\vec{r} \cdot \vec{h}$ to the slip plane through the origin. If a shear $\gamma$ occurs on the slip system the point $\vec{r}$ will shift over a distance $\gamma(\vec{r} \cdot \vec{h})$ in the direction of $\vec{p}$. The new position $\vec{r}^{\prime}$, of the points is hence: $\vec{r}^{\prime}=\vec{r}+\gamma(\vec{r} \cdot \vec{h}) \vec{p}$.

In general, the lengths of $\vec{r}$ and $\vec{r}^{\prime}$

Fig. 20 - Vectors of slip in single crystals. are unequal, so that an elongation $\varepsilon$ takes place with:

$$
\varepsilon=\left(\left|\vec{r}^{\prime}\right|-|\vec{r}|\right) /|\vec{r}| \text {. }
$$

In section V.2 it wizl become apparent that in practice deviations from this idealized behaviour occur. 
Taking $\vec{r}$ in the direction of the axis, we find at once:

$$
(1+\varepsilon) \vec{a}^{\prime}=\vec{a}+\gamma(\vec{a} \cdot \vec{h}) \vec{p} .
$$

The strain, $\varepsilon$, is found by taking the modulus squared of both sides of $(4-1)$ :

$$
(1+\varepsilon)^{2}=1+2 \gamma(\vec{a} \cdot \vec{h})(\vec{a} \cdot \vec{p})+\gamma^{2}(\vec{a} \cdot \vec{h})^{2} .
$$

By solving $y$ from (4-2) for a given $\varepsilon$ the new axis $\vec{a}^{\prime}$ can be calculated from equation (4-1).

Equation (4-1) can also be written in three separate equations for the three direction cosines of the vector $\vec{a}^{\prime}$ :

$$
\begin{aligned}
& A^{\prime}=\frac{A+P(\vec{a} \cdot \vec{h})_{\gamma}}{1+\varepsilon} \\
& B^{\prime}=\frac{B+C(\vec{a} \cdot \vec{h})_{\gamma}}{1+\varepsilon} \\
& C^{\prime}=\frac{C+P(\vec{a} \cdot \vec{h})_{\gamma}}{1+\varepsilon} .
\end{aligned}
$$

If we trace the orientation of the specimen axis, calculated according to this model after different amounts of deformation in single slip, on a stereographic projection we will see that all lie on the great circle connecting the initial orientation with the slip direction.

When we want to calculate the amount of deformation needed until $\vec{a}^{\prime}$ is on the symmetry line [001]-[111], we use the fact that in that case the vector $\langle 110\rangle$ which will be called $\vec{b}$ is perpendicular to $\vec{a}$ ' and as a consequence $\vec{a}^{\prime} \cdot \vec{b}=0$.

Substituting $(4-1)$ for $\vec{a}^{\prime}$ we get:

$$
\vec{a} \cdot \vec{b}+\gamma(\vec{a} \cdot \vec{h})(\vec{p} \cdot \vec{b})=0
$$


and

$$
\gamma(\vec{a} \cdot \vec{h})=-\frac{\vec{a} \cdot \vec{b}}{\vec{p} \cdot \vec{b}}
$$

Substituting this result in $(4-2)$ we get:

$$
\left(1+\varepsilon_{b}\right)^{2}=1-2(\vec{a} \cdot \vec{p}) \frac{\vec{a} \cdot \vec{b}}{\vec{p} \cdot \vec{b}}+\left(\frac{\vec{a} \cdot \vec{b}}{\vec{p} \cdot \vec{b}}\right)^{2} .
$$

So far we have assumed that for a deformation $\varepsilon<\varepsilon_{b}$ there is only single slip and for a deformation $\varepsilon>\varepsilon_{b}$, the deformation will continue by "double slip"i.e. by simultaneous slip on two systems, but in such a manner that the orientation will remain on the [001][1111] line. In this case, as was shown by Schmid and Boas (1968 p.67) we can use formulae (4-1, A, B, C) of single slip also for "double slip", but in place of the "primary" slip direction we have to use the resulting slip direction, which in our case is [i12] and a suitable slip plane which we choose to be the $(1 \overline{1} 1)$.

This calculation of the change of orientation as a function of plastic extension can easily be adapted for electronic computation and in our case a Hewlett Packard Electronic Calculator 9100B was used.

If we want to evaluate only the amount of deformation in single slip $\varepsilon_{b}$ then a much simpler method can be used (see fig. 21). $\vec{a}=$ initial orientation;

$\vec{a}^{\prime}=$ orientation after a deformation;

$\varepsilon_{b}=l_{x} / l_{0}-1$;

$g=$ the length of the longest line on the slip plane in the slip direction;

$d_{0}=$ is the diameter of the undeformed specimen $\left(=2 r_{0}\right)$;

$d_{x}=2 a=$ short diameter of the cross section ellipse of the deformed specimen. 
As we assume that there is only single slip and the volume is constant, then from relation $(3-2 A)$ we have:

$$
a=r_{0} \frac{l_{0}}{l_{x}}=\frac{d_{x}}{2} \text { (because in single slip } b=r_{0} \text { ). }
$$

From fig. 21 we see that $g=\frac{d_{0}}{\sin \theta_{0}}$ and after deformation

$$
\begin{aligned}
& \sin \theta_{x}=\frac{d_{x}}{g}=\frac{d_{0}}{g} \cdot \frac{l_{0}}{l_{x}}=\frac{l_{0}}{l_{x}} \sin \theta_{0} \\
& \frac{l_{0}}{l_{x}}=\frac{\sin \theta_{x}}{\sin \theta_{0}}
\end{aligned}
$$

This calculation is made in practice in the following manner: The initial orientation $P$ is plotted on a stereographic projection. A Wulff's net is placed on the stereographic projection so that the point $P$ and the slip direction [ $[01]$ are on the same meridian. Then $\theta_{0}$ and $\theta_{x}$ can be read off directly. In fig. 22 the initial orien-
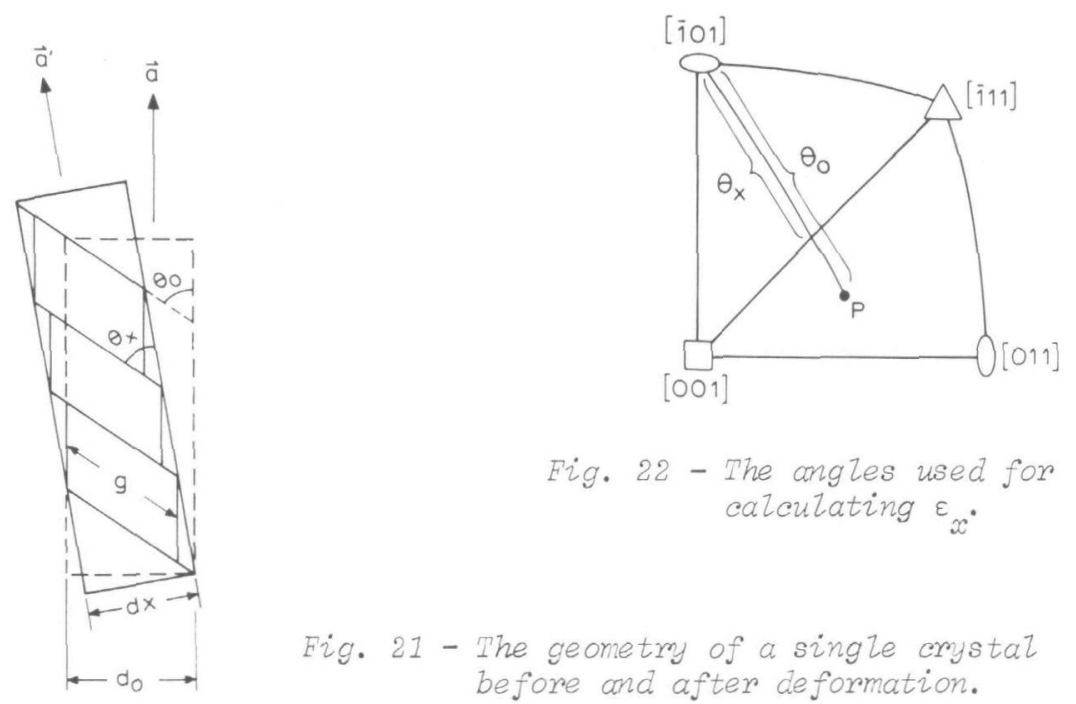

$$
\begin{gathered}
\text { Fig. } 22 \text { - The angles used for } \\
\text { calculating } \varepsilon_{x} \text {. }
\end{gathered}
$$

Fig. 21 - The geometry of a single crystal before and after deformation. 
tation $P$ and the two angles $\theta_{0}$ and $\theta_{x}$ are shown. Inserting $\theta_{0}$ and $\theta_{x}$ in $(4-4)$ we can calculate $e_{x} / l_{0}$ which corresponds to a rotation of the axis so that it lies on the [001]-[ī11] line.

The result is the same when we use either form of calculation and equation (4-4) can also be obtained directly from equation (4-3) 


\section{experimental results}

\section{1 THE STRESS-STRAIN CURVE}

\section{V.1.1 Introduction}

The work hardening behaviour of fcc metal single crystals deformed in tension has received considerable attention in the literature. Stress-strain relations in such crystals together with studies of surface slip markings, electron-microscopy etc., have led to several dislocation models of deformation and work hardening.

In the present work, the multiplication of dislocations and the change of their effective length was investigated by measuring the change of their elastic moduli and internal friction as a function of plastic deformation. In order to make it possible to relate the results of the present investigation to the former ones, stressstrain curves of the copper single crystals used in the investigation were measured.

The results showed several differences with those reported in literature. The possible origin of these deviations will be discussed in this section.

The stress-strain curves of copper single crystals can, in general, be divided into three distinct stages (fig. 23).

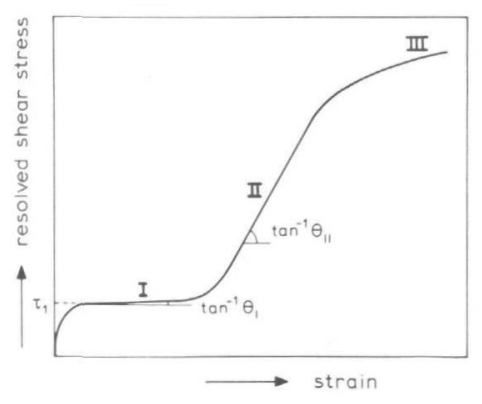
Fig. 23 - Schematic curve of resolved shear stress vs strain of a fec single cmystal.


The three stages can be briefly described as follows:

STAGE I : called "easy glide", immediately follows the onset of plastic flow and is characterized by a low but constant work hardening rate denoted $\theta_{1}$.

STAGE II : called the "linear hardening" region has also a constant work hardening coefficient, denoted $\theta_{1}$, but the rate of hardening is much higher than in STAGE $I$.

STAGE III: called the "parabolic hardening" region is characterized by a work hardening rate which decreases continuously with increasing strain, until fracture occurs, or the deformation continues by mechanical twinning.

In addition to $\theta_{1}$ and $\theta_{1}$, there are also other parameters characterizing the stress-strain curve: $\tau_{0}, \tau_{\mid}, \varepsilon_{\mid}, \varepsilon_{\mid l}$ and $\varepsilon_{t}$. $\tau_{0}=$ the value of the resolved shear stress at which there is at first a significant departure from the elastic line;

$\tau_{1}=$ the intersection of the extrapolated "easy glide" line with the stress axis;

$\varepsilon_{1}=$ the strain at which the extrapolated "easy glide" line intersects the extrapolated "linear hardening" line. It is cus tomary to denote the part of the curve up to $\varepsilon$, as the "easy glide" region;

$\varepsilon_{\mid l}=$ the strain at which there is a significant departure from a linear relation between stress and strain;

$\varepsilon_{t}=$ the strain at which the specimen fractures or the deformation continues by mechanical twinning.

All these parameters are influenced by a number of variables: orientation, temperature, way of loading, purity, extraneous deformation, etc. For a detailed account on the influences of these variables see: Clarebrough and Hargreaves (1959) Nabarro et al. (1964), Mitchell (1964), Hirsh and Mitchell (1967).

In recent years, it has been shown that another variable, the initial dislocation density $\rho_{0}$, has an influence on the initial part 
of the stress-strain curve (Washburn and Murty 1967, Hildebrand 1972). In the course of the present investigation, the internal friction $Q^{-1}$, which is an indirect indication of $\rho_{0}$, has been measured on all specimens, but in some specimens of intermediate initial damping, $\rho_{0}$ has been measured by etch pit counting and found to be $\simeq 10^{3} \mathrm{~cm}^{-2}$.

\section{V.1.2 Experimental results}

The orientations of the copper single crystal specimens are given in fig. 24. In this figure the [1]12] orientation is also marked

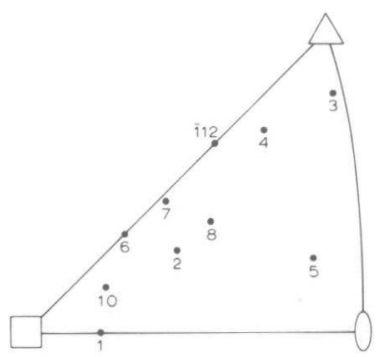

Fig. 24 - The axis orientation of the specimens used in the experiments. as it plays an important role in the direction of the rotation of the tensile axis during extension (see chapter IV). In addition to these orientations, specimens oriented in the $\langle 001\rangle$, $<011>$ and $<111>$ directions and some which deviate up to $5^{\circ}$ from them were also extended. The deformation was carried out at liquid nitrogen temperature (78K).

In fig. 25 one curve of each orientation is presented and also the curve of a specimen oriented approximately $5^{\circ}$ from the $\langle 011\rangle$. The inexact $\langle 001\rangle$ and $\langle 111\rangle$ are not presented because they have the same character as the true symmetric orientations and only the work hardening rate decreases as a function of misorientation. The misoriented $\langle 011\rangle$ are, on the other hand, fundamentally different from the $\langle 011\rangle$. Whereas the stress-strain curve of the specimen $5^{\circ}$ from the $\langle 011\rangle$ is similar to the one of orientation No. 5 which is about $10^{\circ}$ from the $\langle 011\rangle$, the curve of the $\langle 011\rangle$ is different. Although in this case two linear regions can be distinguished, the ratio of their slopes $\theta_{1} / \theta_{1}$ is about 1.5 

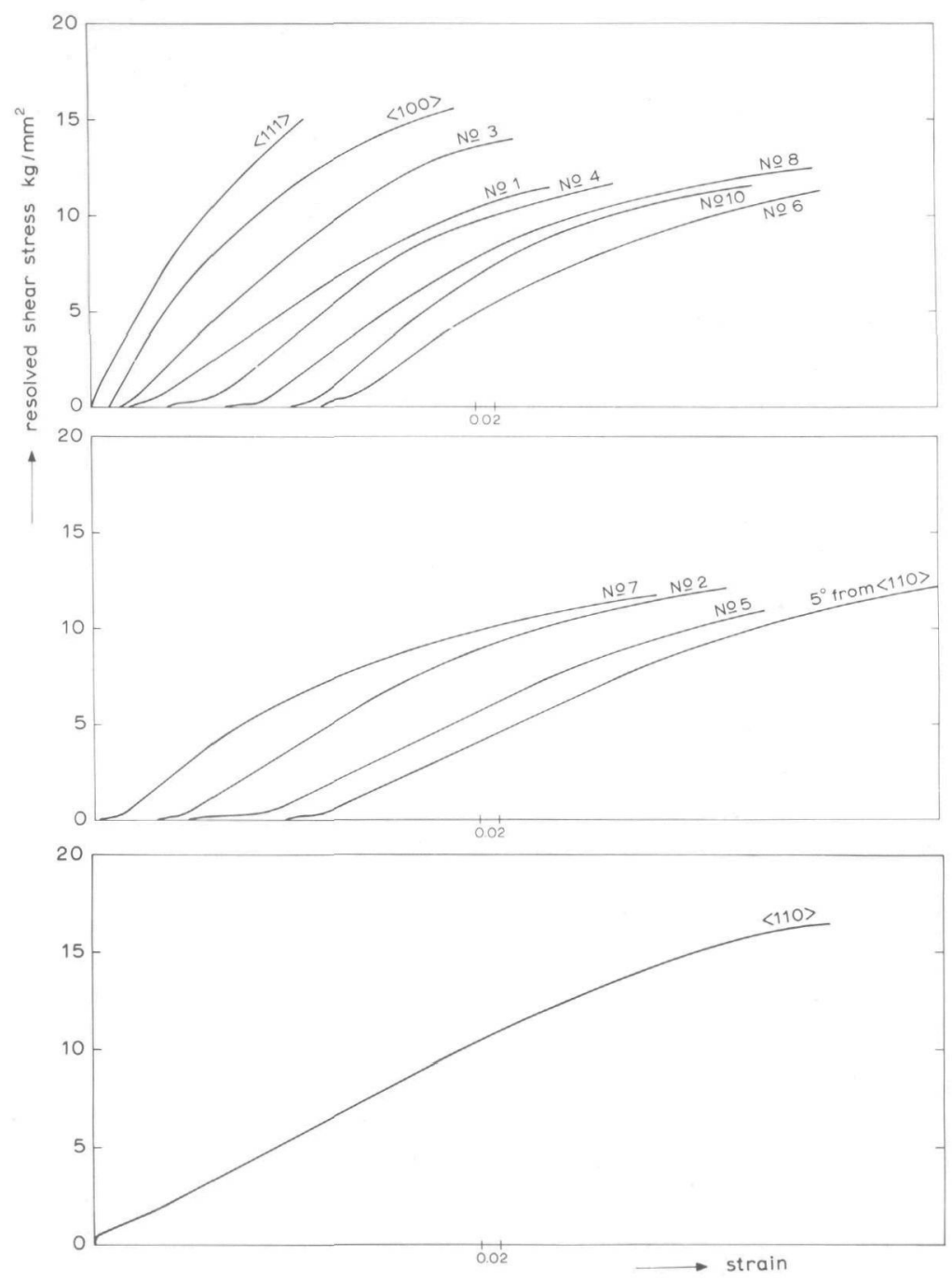

Fig. 25 - Resolved shear stress-strain curves of the specimens with axis orientations presented in fig. 24. 
to be compared to 5-10 in all other crystals investigated. On the other hand the equivalent of $\tau_{1}$ is larger by a factor of 5-10 than in other orientations.

Fig. 26 demonstrates that a relation exists between the extent of "easy glide" and the initial damping. Two specimens of orientation No.5, cut from the same long single crystal, were extended. One, marked a, had been heated for 48 hours at $1050^{\circ} \mathrm{C}$ in vacuo and then cooled down slowly, whereas the second, marked b had received no heat treatment. The specimen, which had originally an internal friction of $Q^{-1}=5 \cdot 10^{-4}$ was heat treated together with another specimen of orientation No. 10. After the heat treatment, it was found that the internal friction of the specimen of orientation No. 10, which was used in elastic measurements, was reduced by a factor 2.5. As the internal friction of the specimen of orientation No. 5 which was used in the extension experiment, was not measured, it was assumed that it was reduced also with a factor 2.5. The second pair of specimens, of orientation No. 2 were cut from different long single crystals and had initial dampings of $1 \cdot 10^{-4}$ and $2.5 \cdot 10^{-4}$ for specimens of curves marked $a$ and $b$ respectively.

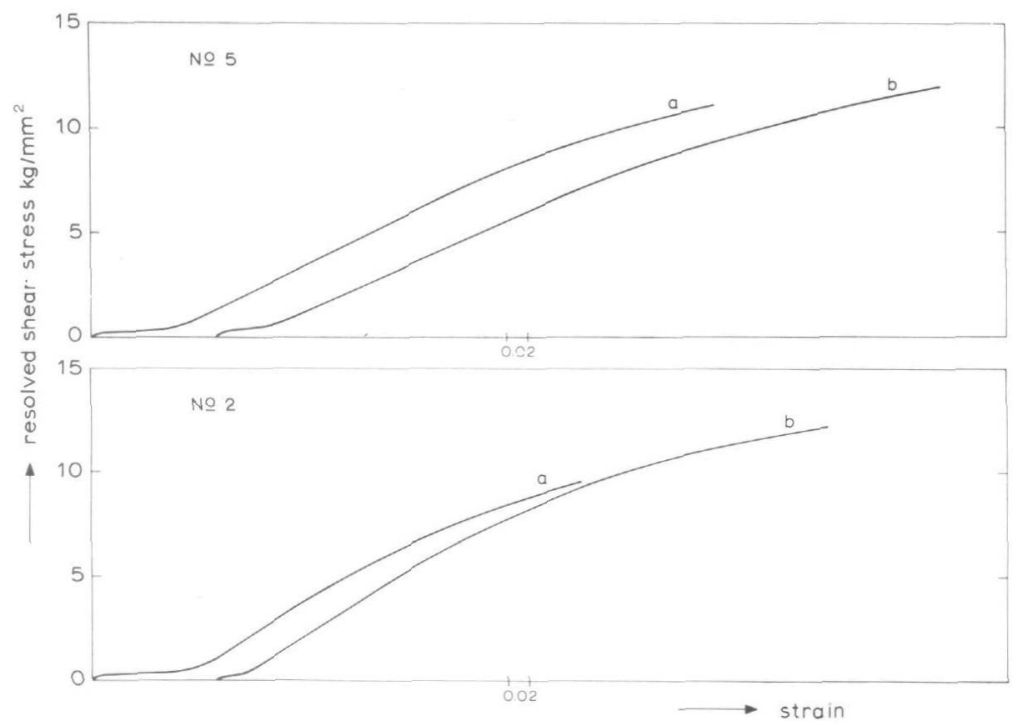

Fig. 26 - The relation between the extent of "easy glide" and initial damping. 
Table III

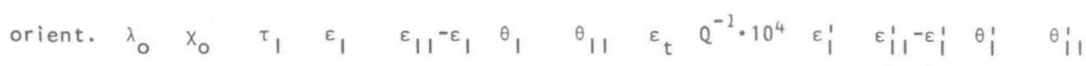

\begin{tabular}{|c|c|c|c|c|c|c|c|c|c|c|c|c|c|}
\hline 1 & $46^{\circ}$ & $48^{\circ}$ & $\begin{array}{l}.17 \\
.10\end{array}$ & $\begin{array}{l}.021 \\
.016\end{array}$ & $\begin{array}{l}.13 \\
.13\end{array}$ & $\begin{array}{r}7.6 \\
11.2\end{array}$ & $\begin{array}{l}34.4 \\
34.7\end{array}$ & $\begin{array}{l}.44 \\
.50\end{array}$ & $\begin{array}{l}3.6 \\
5.1\end{array}$ & $\begin{array}{l}.044 \\
.035\end{array}$ & $\begin{array}{l}.35 \\
.35\end{array}$ & $\begin{array}{l}3.6 \\
5.3\end{array}$ & $\begin{array}{l}17.4 \\
17.5\end{array}$ \\
\hline 2 & $37^{\circ}$ & $53^{\circ}$ & $\begin{array}{l}.22 \\
.15\end{array}$ & $\begin{array}{l}.103 \\
.031\end{array}$ & $\begin{array}{l}.08 \\
.08\end{array}$ & $\begin{array}{l}2.1 \\
5.0\end{array}$ & $\begin{array}{l}33.3 \\
32.3\end{array}$ & $\begin{array}{l}.47 \\
.59\end{array}$ & $\begin{array}{l}1.0 \\
2.5\end{array}$ & $\begin{array}{l}.209 \\
.064\end{array}$ & $\begin{array}{l}.22 \\
.25\end{array}$ & $\begin{array}{l}1.0 \\
2.4\end{array}$ & $\begin{array}{l}15.5 \\
16.0\end{array}$ \\
\hline 3 & $38^{\circ}$ & $63^{\circ}$ & $\begin{array}{l}.13 \\
.13\end{array}$ & $\begin{array}{l}.015 \\
.018\end{array}$ & $\begin{array}{l}.06 \\
.09\end{array}$ & $\begin{array}{l}15.0 \\
13.0\end{array}$ & $\begin{array}{l}50.5 \\
47.7\end{array}$ & $\begin{array}{l}.41 \\
.40\end{array}$ & $\begin{array}{l}6.0 \\
5.0\end{array}$ & $\begin{array}{l}.042 \\
.051\end{array}$ & $\begin{array}{l}.20 \\
.40\end{array}$ & $\begin{array}{l}5.3 \\
4.7\end{array}$ & $\begin{array}{l}18.4 \\
18.0\end{array}$ \\
\hline 4 & $36^{\circ}$ & $60^{\circ}$ & $\begin{array}{l}.16 \\
.14\end{array}$ & $\begin{array}{l}.048 \\
.031\end{array}$ & $\begin{array}{l}.13 \\
.18\end{array}$ & $\begin{array}{l}3.9 \\
5.9\end{array}$ & $\begin{array}{l}41.0 \\
39.8\end{array}$ & $\begin{array}{l}.47 \\
.44\end{array}$ & $\begin{array}{l}1.0 \\
1.0\end{array}$ & $\begin{array}{l}.116 \\
.074\end{array}$ & $\begin{array}{l}.30 \\
.30\end{array}$ & $\begin{array}{l}1.6 \\
2.4\end{array}$ & $\begin{array}{l}17.5 \\
16.3\end{array}$ \\
\hline 5 & $49^{\circ}$ & $45^{\circ}$ & $\begin{array}{l}.17 \\
.16 \\
.15 \\
.18 \\
.19 \\
.23\end{array}$ & $\begin{array}{l}.082 \\
.055 \\
.051 \\
.023 \\
.038 \\
.047\end{array}$ & $\begin{array}{l}.24 \\
.22 \\
.24 \\
.08 \\
.28 \\
.24\end{array}$ & $\begin{array}{r}2.9 \\
3.7 \\
2.6 \\
10.5 \\
4.1 \\
3.0\end{array}$ & $\begin{array}{l}25.0 \\
25.4 \\
24.1 \\
27.0 \\
22.8 \\
22.8\end{array}$ & $\begin{array}{l}.60 \\
.60 \\
.58 \\
.62 \\
.66 \\
.70\end{array}$ & $\begin{array}{l}2.0 \\
3.4 \\
3.4 \\
9.0 \\
3.0 \\
4.0\end{array}$ & $\begin{array}{l}.167 \\
.115 \\
.106 \\
.048 \\
.080 \\
.098\end{array}$ & $\begin{array}{l}.50 \\
.60 \\
.55 \\
.52 \\
.60 \\
.55\end{array}$ & $\begin{array}{l}1.4 \\
1.8 \\
1.2 \\
4.9 \\
2.0 \\
1.4\end{array}$ & $\begin{array}{l}13.8 \\
13.6 \\
13.1 \\
13.5 \\
12.2 \text { bl.str. } \\
12.2 \text { bl.str. }\end{array}$ \\
\hline 6 & $34^{\circ}$ & $57^{\circ}$ & $\begin{array}{l}.24 \\
.24\end{array}$ & $\begin{array}{l}.036 \\
.033\end{array}$ & $\begin{array}{l}.08 \\
.08\end{array}$ & $\begin{array}{l}7.4 \\
7.6\end{array}$ & $\begin{array}{l}37.9 \\
37.1\end{array}$ & $\begin{array}{l}.47 \\
.52\end{array}$ & $\begin{array}{l}1.0 \\
1.0\end{array}$ & $\begin{array}{l}.079 \\
.073\end{array}$ & $\begin{array}{l}.28 \\
.28\end{array}$ & $\begin{array}{l}3.4 \\
3.7\end{array}$ & $\begin{array}{l}17.6 \\
17.3\end{array}$ \\
\hline 7 & $32^{\circ}$ & $59^{\circ}$ & $\begin{array}{l}.09 \\
.06\end{array}$ & $\begin{array}{l}.024 \\
.037\end{array}$ & $\begin{array}{l}.10 \\
.09\end{array}$ & $\begin{array}{l}6.0 \\
2.7\end{array}$ & $\begin{array}{l}38.9 \\
36.1\end{array}$ & $\begin{array}{l}.58 \\
.61\end{array}$ & $\begin{array}{l}8.0 \\
7.0\end{array}$ & $\begin{array}{l}.054 \\
.079\end{array}$ & $\begin{array}{l}.32 \\
.18\end{array}$ & $\begin{array}{l}2.6 \\
1.2\end{array}$ & $\begin{array}{l}17.0 \\
17.2\end{array}$ \\
\hline 8 & $35^{\circ}$ & $56^{\circ}$ & $\begin{array}{l}.21 \\
.23\end{array}$ & $\begin{array}{l}.020 \\
.013\end{array}$ & $\begin{array}{l}.12 \\
.14\end{array}$ & $\begin{array}{l}7.0 \\
6.9\end{array}$ & $\begin{array}{l}34.3 \\
33.0\end{array}$ & $\begin{array}{l}.56 \\
.60\end{array}$ & $\begin{array}{l}2.4 \\
4.7\end{array}$ & $\begin{array}{l}.046 \\
.028\end{array}$ & $\begin{array}{l}.32 \\
.22\end{array}$ & $\begin{array}{l}3.1 \\
3.2\end{array}$ & $\begin{array}{l}14.8 \\
15.6\end{array}$ \\
\hline 10 & $39^{\circ}$ & $53^{\circ}$ & .11 & .020 & .09 & 9.7 & 41.7 & .48 & 4.4 & .043 & .30 & 4.5 & 19.4 \\
\hline$\langle 100\rangle$ & & & - & - & $\begin{array}{l}.04 \\
.06\end{array}$ & - & $\begin{array}{l}84.9 \\
78.5\end{array}$ & $\begin{array}{l}.28 \\
.36\end{array}$ & $\begin{array}{l}6.0 \\
6.0\end{array}$ & - & $\begin{array}{l}.10 \\
.10\end{array}$ & - & $\begin{array}{l}35.4 \\
32.4\end{array}$ \\
\hline$\langle 111\rangle$ & & & $\begin{array}{l}- \\
- \\
-\end{array}$ & $\begin{array}{l}- \\
- \\
-\end{array}$ & $\begin{array}{l}.08 \\
.04 \\
.03 \\
.06\end{array}$ & $\begin{array}{l}- \\
- \\
-\end{array}$ & $\begin{array}{l}97.8 \\
96.2 \\
97.3 \\
93.9\end{array}$ & $\begin{array}{l}.23 \\
.21 \\
.26 \\
.23\end{array}$ & $\begin{array}{l}7.0 \\
7.0 \\
7.0 \\
9.0\end{array}$ & $\begin{array}{l}- \\
- \\
-\end{array}$ & $\begin{array}{l}.30 \\
.22 \\
.15 \\
.30\end{array}$ & $\begin{array}{l}- \\
- \\
-\end{array}$ & $\begin{array}{l}26.7 \\
26.4 \\
26.6 \\
25.4\end{array}$ \\
\hline $5^{\circ}$ from & $\langle 110\rangle$ & & $\begin{array}{l}.11 \\
.13\end{array}$ & $\begin{array}{l}.030 \\
.040\end{array}$ & $\begin{array}{l}.16 \\
.24\end{array}$ & $\begin{array}{l}2.7 \\
4.9\end{array}$ & $\begin{array}{l}24.5 \\
23.9\end{array}$ & $\begin{array}{l}.58 \\
.58\end{array}$ & $\begin{array}{l}4.0 \\
4.0\end{array}$ & $\begin{array}{l}.048 \\
.093\end{array}$ & $\begin{array}{l}.40 \\
.50\end{array}$ & $\begin{array}{l}1.1 \\
2.1\end{array}$ & $\begin{array}{l}12.6 \\
12.5\end{array}$ \\
\hline$\langle 110\rangle$ & & & $\begin{array}{r}1.22 \\
.88 \\
.63\end{array}$ & $\begin{array}{l}.060 \\
.060 \\
.060\end{array}$ & $\begin{array}{l}.30 \\
.26 \\
.30\end{array}$ & $\begin{array}{l}12.1 \\
17.9 \\
19.2\end{array}$ & $\begin{array}{l}19.7 \\
25.9 \\
26.3\end{array}$ & $\begin{array}{l}.72 \\
.70 \\
.94\end{array}$ & $\begin{array}{l}4.0 \\
4.0 \\
4.0\end{array}$ & & & & \\
\hline
\end{tabular}


In table 111 the work hardening characteristics of the extended specimens are presented. In this table in columns 5-9 strain was defined as $\Delta l / \ell$ and the corresponding work hardening coefficients are $\theta_{1}$ and $\theta_{1}$. In order to allow a comparison with data from the literature, in columns 11-14 the resolved shear strain $\varepsilon^{\prime}$ is used and the corresponding work hardening coefficients are $\theta ;$ and $\theta i$.

The resolved shear strain cannot be found experimentally but must be calculated by making certain assumptions. The standard assumption is that a single crystal will deform by single slip in the primary system until its axis orientation reaches the [001]-[ $\overline{1} 11]$ line, then it will continue by double slip in such a way that the orientation remains on that $l$ ine and rotates towards the $[\overline{1} 12]$. As will be shown in the next section, this last assumption is contrary to the experimental evidence and even deviations from single slip in the first part of the deformation have been demonstrated by Ahlers and Haasen (1962) and Mitchell and Thornton (1964).

In literature, where these assumptions are made, the manner of calculation, especially in the region of double slip is not reported explicitly. In the present work the value of $\varepsilon^{\prime}$, in single slip, was calculated using the usual relation (see Honeycombe (1968) p. 23 formula 2.5) but for double slip $1+\frac{1}{2}\left(\varepsilon-\varepsilon_{b}\right)$ was substituted for $\ell_{x} / l_{0}$ and the value thus obtained was multiplied by two and added to $\varepsilon_{b}^{\prime}$. ( $\varepsilon_{b}$ and $\varepsilon_{b}^{\prime}$ are the values for strain in single slip). When these values of $\varepsilon^{\prime}$ were introduced a smooth curve of $\sigma$ as a function of $\varepsilon^{\prime}$ was obtained and no discontinuity as reported by Mitchell and Thornton (1963) was observed.

For the $<111>$ and $<001>$ specimens multiple slip was assumed in 6 and 8 slip systems respectively. Therefore in place of $\ell_{x} / l_{0}$, $1+\frac{1}{6}\left(l_{x} / l_{0}-1\right)$ and $1+\frac{1}{8}\left(l_{x} / l_{0}-1\right)$ was used and from the obtained value the resolved shear strain was determined by multiplying it by 6 or 8 respectively. We think that in these two cases this procedure is indeed correct as will be argued later on.

In table III only values of $\tau$, are given because the manner of recording does not permit a reasonable precision in evaluating $\tau_{0}$. 
The initial damping given in table III was not measured directly on the deformed specimen but on a second one, cut from the same long single crystal and which was used for measurements of the elastic moduli. In one case, the first specimen of orientation No. 5 the specimen received a heat treatment and $\mathrm{C}_{0}^{-1}$ was assumed as described earlier (specimen marked a in fig. 26).

\section{V.1.3 Conclusions}

From the values given in table III, some conclusions about the properties of the stress-strain curve of the copper single crystals used in the present research can be drawn:

\section{V.1.3.1 Effect of orientation}

For specimens with approximately the same values of $Q_{0}^{-1}, \varepsilon_{1}$ decreases as the orientation approaches the [001]-[ㅍ1] line as was found also by other investigators. It was found, however, contrary to the prediction (Friedel (1955)) and earlier reports (see for example Cup and Chalmers (1954)) that a specimen with an axis orientation on the [001]-[ī11] line had also an easy glide region. This is demonstrated by specimens of orientation No. 6 which is on the [001]-[111] line as can be seen from the $x$-ray photograph, made with the rotating specimen methode, in fig. 39. It can be seen that on the $\langle 220\rangle$ ring there is a single reflection on the equator, showing that the axis makes an angle of $90^{\circ}$ with the $\langle 110\rangle$ i.e. is on the [001]-[ī11] line. The only specimens which were found to have no easy glide region, the $<001>$ and $<111>$ orientations, had an initial damping of 6 or $7 \cdot 10^{-4}$ and it was not possible to grow a single crystal in these orientations with a lower initial damping.

\section{V.1.3.2 Effect of initial damping}

Specimens of one orientation (No. 5) of which a number, with different, $\mathrm{C}_{0}^{-1}$, were extended show an increase in $\varepsilon_{1}$ for a decrease in initial damping a result which is also demonstrated in fig. 26 . A same trend is visible for the other orientations in table 111 and 
seems to be found also by Argon and Brydges (1968) (increasing $\varepsilon_{\text {}}$ for decreasing $\rho_{0}$ )

\section{V.1.3.3 The rate of hardening in stage II}

$\theta_{1}$ shows the same dependence on orientation as reported in 1 iterature i.e. low values near the $\langle 011\rangle$ which increase when the orientation approaches the <001> or <111> corner. The values of $\theta$ i) (computed by use of the resolved shear strain) are comparable with the results of other investigators (see e.g. Rossi (1954), Diehl (1956, Suzuki (1956), liitchell (1962)).

\section{V.1.3.4 The symmetric orientations <001> and <111>}

The linear hardening of $\langle 001\rangle$ and $\langle 111\rangle$ oriented specimens is not mentioned in literature but as can be seen in fig. 25 and table 111 , stage 11 has also been observed in specimens of these orientations. It must be mentioned that even a small bending or torsion during mounting results in the dissappearance of the linear stage. It is our opinion that only in the case of these two orientations, the calculation of the amount of resolved shear strain is correct, as the specimens of these orientations remain perfectly circular and do not change their orientation during plastic extension. Von Mises (1928) has shown that for a crystal to undergo a general homogeneous strain by slip, at least five slip systems must operate and only these two orientations which have more than 5 slip systems with the same Schmid factor remain circular and do not change their orientation (see fig. 31 and 33). It was also found that the rate of hardening $\theta$ of the <001> specimen is higher than of the <111> specimen as expected because the <001> has more slip systems operating at the same time than the $\langle 111\rangle$ specimen.

\section{V.1.3.5 The <011> orientation}

The stress-strain curve of the $<011>$ oriented specimen is different as was expected, because this specimen deforms almost from the beginning also by mechanical twinning (Weiner 1972) without serra- 
tions on the stress-strain curve. This behaviour is different from the other specimens which start to deform by slip only and where, later on, the start of mechanical twinning is audible and also visible on the stress strain curve by the onset of serrations.

\section{V.1.3.6 The influence of $p_{0}$ on $\theta_{I I}$}

The last two specimens of orientation No. 5 in table III which have a block-structure i.e. subgrain boundaries and therefore a higher initial dislocation density, show a rate of hardening $\theta_{1}$ lower by about 10-15\% than the other specimens. This result is not surprising as it was found that in crystals prestrained in an other glide system, causing an increase of dislocation density on them, $\theta_{11}$ is reduced (see Jackson and Bazinsky (1967), Washburn and Murty $(1967))$.

\section{V.2 THE CHANGE IN ORIENTATION OF COPPER SINGLE CRYSTALS AS A RESULT OF PLASTIC EXTENSIOIN}

\section{V.2.1 Introduction}

There can be two kinds of change of orientation as a result of plastic deformation of copper single crystals:

1) A change in orientation of a small part of the crystal as a result of twinning.

2) A continuous change in orientation of the whole crystal as a result of slip.

Mechanical twinning will be discussed in section V.3 so in this section only the change of orientation as a result of slip will be treated.

The change in orientation plays an important role in the interpretation of the experimental results on the change of the elastic moduli during plastic deformation of single crystals. l'hen the orientation of the axis of the specimen changes, $E$ and $G$ also change and there can be measured a "crystallographic effect" even if there is 
no dislocation multiplication.

In chapter IV, the formulae relating elongation, amount of glide shear and amount of lattice rotation for crystals deforming in "single slip" followed by "double slip" under tension have been developed. With formula $(4-1)$ the orientation after a certain extension can be calculated and then with formula (3-13) Young's modulus E for this orientation can be found. The result of such a calculation, for the orientations used, relating the "crystallographic" change in E with strain, is given in fig. 29 (with the exception of orientation No. 5 that changes along a line $E=$ const).

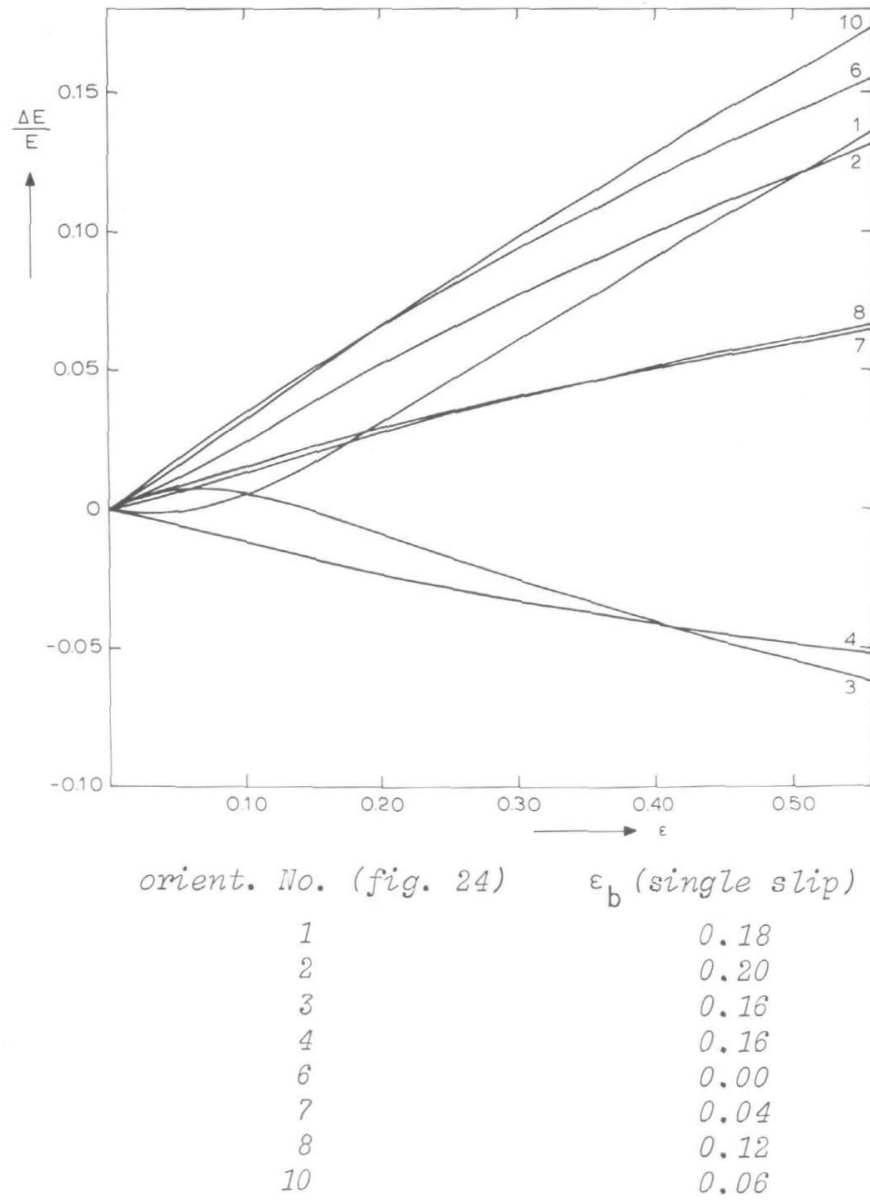

Fig. 29 - The "cmystazlographic" $\Delta E$ effect as a function of strain. 
In the figure are also given the calculated strains in single glide i.e. until the axis orientation is on the [001]-[111] line. As can be seen, for some orientations, this "crystallographic effect" is quite large.

As can be easily shown from (3-5), the change in $E$ is dependent on the angle between the axis orientation and the <001> orientation. In single glide, when the crystal orientation moves towards the $[001]-[\overline{1} 11]$ symmetry line, the change of the angle between the axis orientation and the $<001>$ is small and the corresponding changes in $E$ and $G$ are a few percent at most (see fig. 29). When the orientation has arrived at the symmetry line, further deformation is expected to take place by double slip. As a consequence the orientation should move along the symmetry line, and this should cause rather large changes in the elastic constants. It will be shown, however, that in our experiments the behaviour is contrary to this expectation. After arrival on the symmetry line, only minor changes of orientation were observed, and the corresponding changes of $E$ and $G$ can be neglected.

\section{V.2.2 X-ray methods}

Before we present the experimental results, we want to explain the choice of the rotating specimen $x$-ray method and then introduce some concepts about this method which will be used in the presentation.

\section{V.2.2.1 The choice of the method}

The simplest method used to determine the axis orientation of a single crystal is the Laue $x$-ray method, and for undeformed specimens we have used this method extensively. However, when the crystal is deformed, the number of spots decreases and they are also smeared out, because strong spots become "streaks" and weak ones disappear, so that we lose precision. For severely deformed crystals we do not get any significant spots on the photographic film. 
This effect is a consequence of the bending of the lattice planes. To understand this effect, it is easy to compare the Laue method to the reflection of visible light by a mirror. If the lattice simply rotates during deformation then the Laue patterns, made after deformation, will merely show a change in orientation but will remain sharp. On the other hand, if the lattice is bent or twisted, the Laue spots will become smeared out into streaks, becaúse of the continuous change in orientation of the reflecting planes, just as a spot of light reflected by a flat mirror, becomes elongated when the mirror is curved.

We have found that the spots become extremely blurred only when the axis orientation approaches the [001]-[111] symmetry line and disappear completely when the orientation is on this line.

By means of the rotating specimen $x$-ray method using monochromatic radiation, we get always reflections, even from severely deformed crystals. In the latter case, the spots are quite large, a fact that reduces the precision of determining the orientation. However, if we want to determine only the change in orientation, when the axis is on the $[001]-[\overline{1} 11]$ line, it will be shown that in this case we get also quite accurate results.

\section{V.2.2.2 Some concepts about the rotating specimen method}

When an x-ray photograph of a polycrystalline copper wire, is made with the rotating specimen method, using monochromatic radiation we get the familiar Debye-Scherrer rings.

Each ring is formed by the reflections of only one set of planes and because there are crystalites in almost every orientation, we get almost a continuous line. In fcc metals we get reflections only from planes with all indices either odd or even and no reflections from planes with mixed indices. In fig. 30 we see an x-ray photograph of a copper polycrystalline specimen, made with the rotating specimen method, using $K_{\alpha}$ radiation of copper, on which the different rings are marked. The last two rings (from $\{133\}$ and $\{240\}$ planes) are double because, although we use a nickel filter, we get 
also $K_{\beta}$ radiation which differs only slightly in wave length from $K_{\alpha}$, but for the higher indices this is enough to be seen.

The line of intersection between the film and a plane containing the $x$-ray beam and perpendicular to the axis of rotation, will be called the equator (see fig. 30).

When we make an $x$-ray photograph, with the same method, of a single crystal then we will get distinct spots on the film, only where a particular set of planes will, for an instant, make the correct Bragg angle for reflection of the monochromatic incident beam.

All the spots on the equator are from sets of planes parallel to the axis. The spots not on the equator, are distributed symmetrically about it, because every plane reflecting on a point below the equator will reflect on an equidistant point above it, when rotated $180^{\circ}$.

In the camera we used, the equator is not in the middle of the film, so we get more reflections below the equator than above it. The length of the film (only half the circumference of the camera) is $125 \mathrm{~mm}$ and the heigth is $65 \mathrm{~mm}$.

From a single crystal we would expect only a limited number of spots on each ring, below or above the equator: 4 spots on the $\{111\}$ and $\{222\}$ rings, 3 on the $\{200\}$ and $\{400\}$ rings, 6 on the $\{220\}$ ring etc. (see fig. 44). This number of spots is a maximum as the number of reflections is equal to the number of differently oriented but crystallographically equivalent planes. If two or more planes of this set make the same angle with the axis, then they give reflections on the same place on the $\mathrm{film}$ and so reduce the number of spots. There will also be no reflection from a plane that makes such an angle with the axis that during rotation the Bragg law is never satisfied. This is shown clearly in fig. 5, where there are three spots on the $\{111\}$ ring from an imperfect oriented <111> crystal and in fig. 6 (of a $<111>$ oriented specimen) it can be seen that from the three spots we get only one spot. There is no fourth spot on the $\mathrm{film}$ on the $\{111\}$, ring because one $\{111\}$ plane is perpendicular to the axis, and the angle with the $x$-ray beam does not satisfy the 
Bragg law.

As we use the convention that all axis orientations are marked in the standard triangle (see fig. 19 page 46) we can identify unambiguously all the reflections. The two reflections nearest to the equator on the first ring are from the (1 $\overline{1} 1$ ) plane (see for ex. fig. 34) and for a [i 12 ] orientation there is only one reflection on the equator (see for ex. fig. 38) as this orientation lies on the (111) plane. When the axis orientation is on the symmetry line then the reflections from the (220) (the third ring) plane are also on the equator (giving only one spot). This last fact enables us to see whether, after a certain deformation, the orientation has reached the symmetry line $[001]-\left[\begin{array}{ll}1 & 1\end{array}\right]$.

\section{V.2.3 Experimental results}

Fig. 31 is an $x$-ray photograph, made with the rotating specimen method, of a deformed <111> specimen and by comparing it with fig. 6 it can be seen that the place of the spots has not changed showing that the orientation has not changed. The spots are, however, smeared out as a result of the bending of the reflecting planes after deformation. A specimen having an axis some $5^{\circ}$ from the $\langle 111\rangle$ orientation, like the one in fig. 5, has after a deformation of $15 \%$ the same orientation as the more perfect oriented one since we get the same $x$-ray photograph as in fig. 31 .

A $<001>$ oriented specimen ( $\mathrm{fig}$. 32) has, after an extension of $\simeq 20 \%$ still the same orientation and in this case the spots are smeared out even more than in the <111> photograph (fig. 33). This effect is not a result of exposure time and for deformation $>10 \%$ almost independent of $\varepsilon$ for $\langle 111\rangle$ and $\langle 001\rangle$, and in other orientations, it is independent of $\varepsilon$ only after reaching the $[001]-[\overline{1} 11]$ line. Fs a consequence it seems plausible to ascribe the bigger spots of the $<001>$ orientation to an extra bending of the planes as the $<001>$ orientation has eight primary slip systems and the $\langle 111\rangle$ only six slip systems. 
$X$-ray photographs made with the rotating specimen method of:

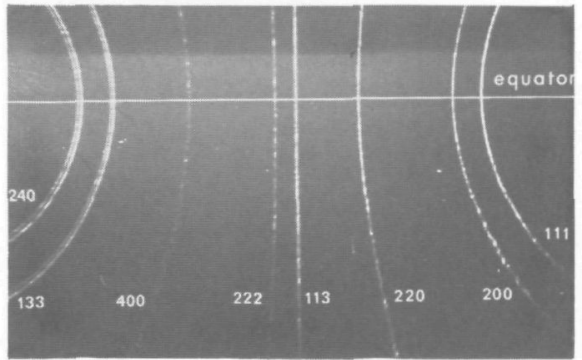

Fig. 30 - Polyorystalline speoimen undeformed.

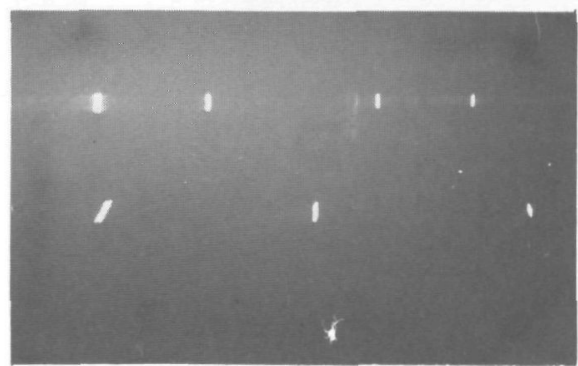

Fig. 32 - <001s speoimen undeformed.

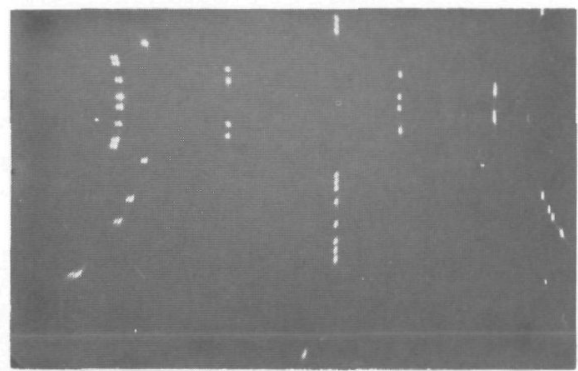

Fig. 34 - Approximately 4 from <001> unde formed.

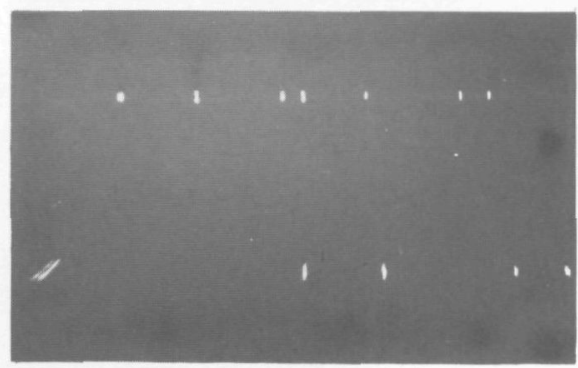

Fig. 36 - <011> specimen undeformed.

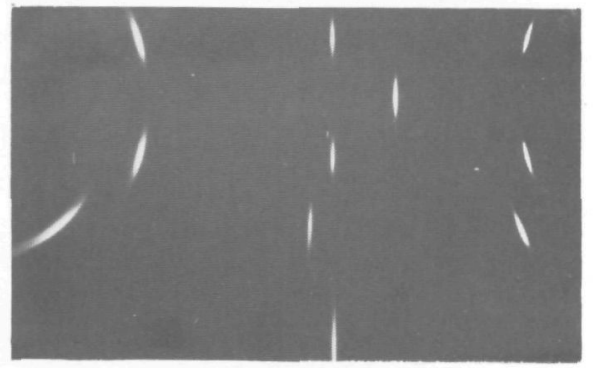

Fig. 31 - <111〉 specimen deformed $\simeq 15 \%$.

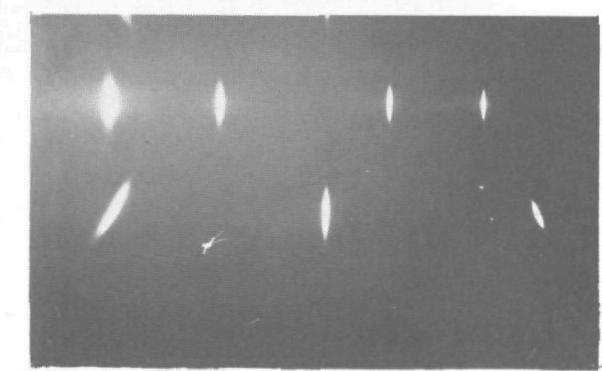

Fig. 33 - <001> specimen deformed $\simeq 20 \%$.

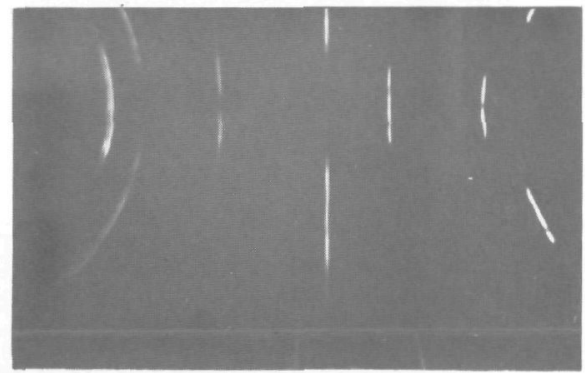

Fig. 35 - The same orientation deformed $\approx 20 \%$.

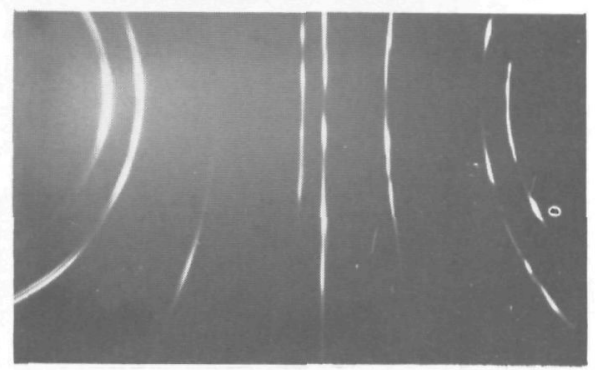

Fig. $37-\langle 011\rangle$ specimen deformed $\simeq 6 \%$. 


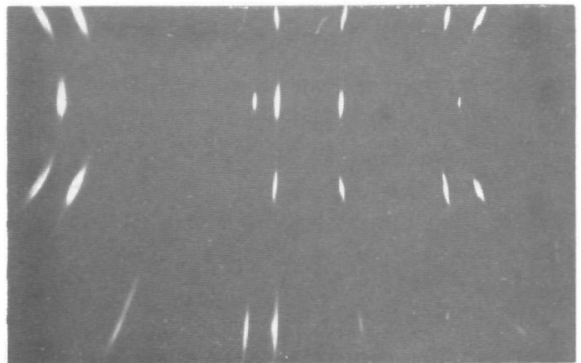

Fig. $38-5^{0}$ from <011> deformed $\approx 60 \%$.

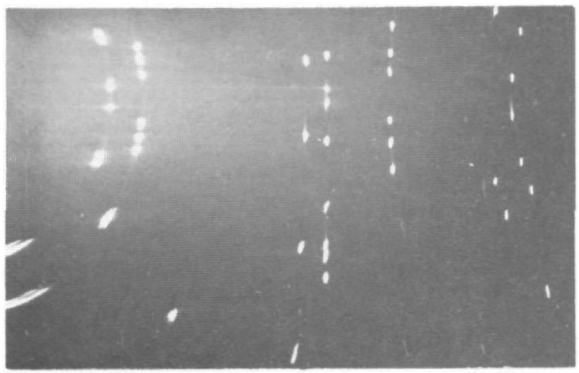

Fig. 41 - Orientation No. 4 undeformed.

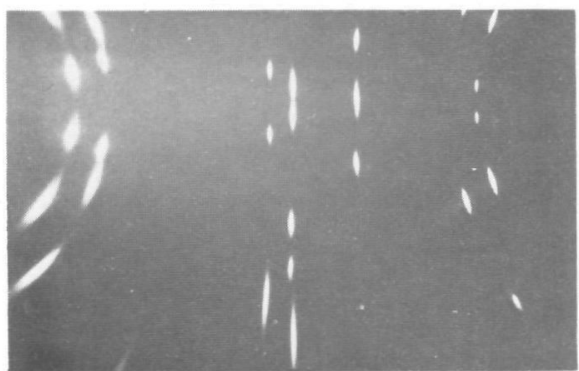

Fig. 42 - Orientation No. 4 deformed $\simeq 37 \%$.

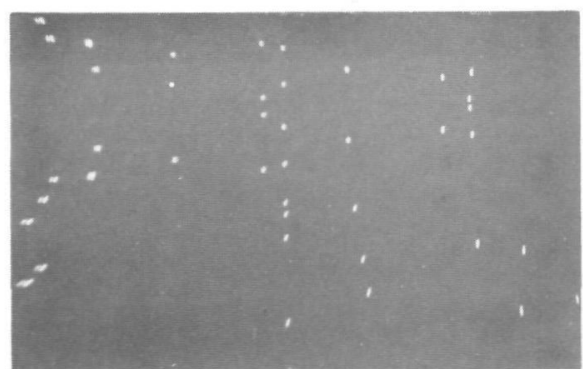

Fig. 44 - Specimen $1 \frac{32^{\circ}}{0}$ from $<145>$ undeformed.

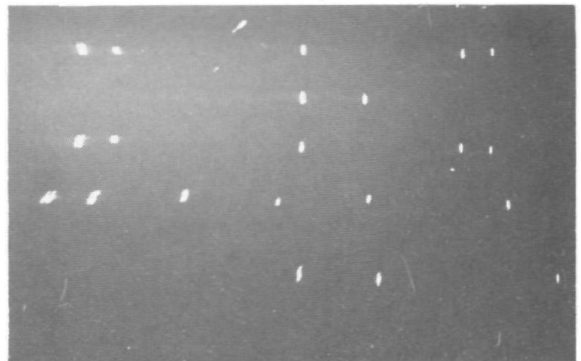

Fig. 39 - Orientation No. $6 \quad(<114>)$ undeformed.

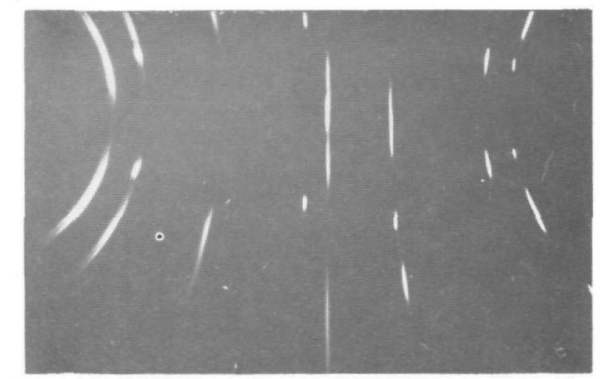

Fig. 40 - Orientation No. 6 deformed $\simeq 31 \%$.

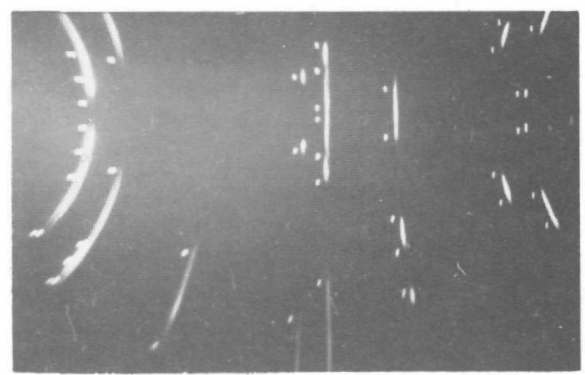

Fig. 43 - Orientation No. 8 undeformed and deformed $\simeq 50 \%$.

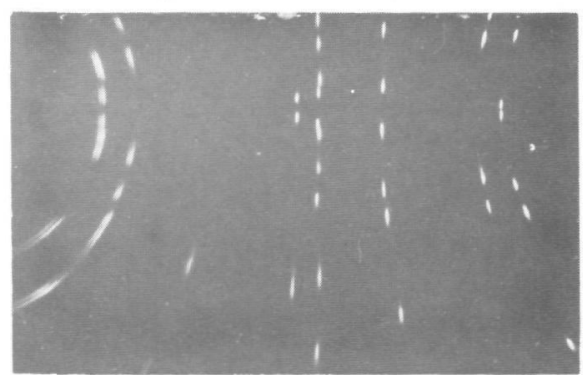

Fig. 45 - The same omientation as in fig. 44 deformed $28 \%$. 
A specimen $\simeq 4^{\circ}$ from the $<001>$ orientation (fig. 34 ) shows after an extension of $\simeq 20 \%$ that its axis orientation has probably not changed as the smeared out spots cover the initial spots. This result is probably because even in the case of the misoriented <001> specimen more slip systems are active at the same time, and the amount of slip on each of them is, contrary to the inexact $<111\rangle$, about the same so that the orientation of the axis does not change.

The <011> specimen (fig. 36) starts to deform by mechanical twinning almost from the beginning of the extension (Weiner (1972)) as can also be seen from fig. 37. A specimen $5^{\circ}$ from the $\langle 011\rangle$ orientation deforms probably mostly by slip on the primary system, since after an extension of about $60 \%$ the orientation is [1 12 ] as can be seen in fig. 38. The same result is obtained with a specimen of orientation Wo. 5 (which is [ $\overline{145}$ ] as can be seen in fig. 3) i.e. after an extension of $\simeq 50 \%$ its axis is also in the [112] orientation since an $x$-ray photograph made with the rotating specimen method is the same as in fig. 38. Both these specimens twin somewhat, only in the necked region. These two orientations $\left(5^{\circ}\right.$ from $\langle 011\rangle$ and Wo. 5) have no "crystallographic effect" since the orientation moves along a line where $E$ is constant.

A specimen of orientation No. 6 ([ $\overline{1} 14])$ which is on the symmetry line [001]-[ī11] (see fig. 39) should deform by slip on two systems and its orientation should move towards [112]. After an extension of $\simeq 31 \%$ the orientation is almost the same (see fig. 40 ) since the distance between the reflections of the (11i1) plane (the two spots nearest to the equator on the first ring) is almost the same as in the $x$-ray photograph of the undeformed specimen (fig. 39). If this specimen would have changed its orientation according to "double slip", this distance would have changed from $16.3 \mathrm{~mm}$ to $12.3 \mathrm{~mm}$ (in the original photograph which has a size double of that reproduced here). It is also interesting to observe that these spots (from the $(1 \overline{1} 1)$ plane) remained small showing that this plane is very little twisted or bent. This is probably due to the fact that this plane makes an angle of $76^{\circ}$ with the axis and there is almost no 
shear stress on it. This is of course a favourable result since it permits to fix the distance between these two particular spots with a reasonable precision, and this distance measures the movement of the axis orientation on the $[001]-[\overline{1} 11]$ line, towards the $[\overline{1} 12]$. The same result can be seen for orientation No. 4 (fig. 41 and 42) which should move towards the [i112] from the other direction (see fig. 24) and then the distance between the two (11i1) spots would have changed from $6.5 \mathrm{~mm}$ to $4.7 \mathrm{~mm}$ (in the original photograph). In fig. 43 two photographs, one of a deformed and one of an undeformed specimen of orientation No. 8, have been superposed and displaced latterally. It is easy to see that the spots of the reflections of the $(1 \overline{1} 1)$ and $(2 \overline{2} 2)$ planes have not changed their positions after an extension of $\simeq 50 \%$. In all these photographs it can be seen that the axis orientation of the deformed specimens is on the [001][111] line as on the $\{220\}$ ring there is one spot on the equator. Finally two x-ray photographs are presented (fig. 44 and 45) of a specimen oriented $1 \frac{1}{2}^{\circ}$ from the $\langle 145\rangle$, one in the undeformed state and one after an extension of $28 \%$. It can be seen that al though the spots from the deformed specimen are a little bit bigger than from the undeformed one, they are smaller than the spots from reflections from specimens of other orientations which, after the same strain, have changed their orientation so that their axis orientation is on the $[001]-[\overline{1} 11]$ line, whereas this orientation must be extended $\simeq 50 \%$ to reach this line. From the two spots on the $\{220\}$ ring nearest to the equator the angle to the $[001]-[111]$ line can be found and in this case it was $\simeq 5^{\circ}$. From the fact that the size of the spots is small in comparison to those of other orientations, it can be concluded that the planes from which these beams were reflected are less twisted or bent. This result is in good agreement with the expectation that this orientation should deform by gliding mainly in one slip system up to $50 \%$ extension. There is also another deviation from the simple model of Schmid worth reporting. The rule of Schmid can be summed up as follows: the slip system with the largest Schmid factor will operate and 
when two slip systems have the same factor they will operate at the same time. In the latter case the axis orientation will rotate in such a way that the angle with both slip directions will decrease. Orientation No. 1 is on the symmetry line [001]-[011] (see fig. 24) and according to this model should deform by double slip. As a result of the double slip the axis orientation of this specimen should rotate towards [001]. What actually happens is that only one slip system is chosen although not always over the whole length of the specimen. It is possible that one part of the specimen deforms according to one slip system and another part according to a second system. This effect is easily seen as after deformation the crosssection ellipse of one part is rotated with respect to the other. of the six specimens of this orientation that were extended only two have chosen one slip system over the whole length of the specimen. Only the results of these two specimens are presented in this thesis.

\section{V.2.4 Summary and conclusions}

According to the model describing the deformation of single crystals by single slip followed by "double slip" as outlined in chapter IV, appreciable changes in orientation should occur as a function of extension. If these changes in orientation will take place, then an appreciable "crystallographic" $\Delta E$ effect will occur which has to be substracted from the measured effect in order to find the "physical" effect as a result of dislocation multiplication.

By use of the rotating specimen $x$-ray technique it was found that the axis orientation changes so that it is after a certain deformation on the $[001]-[\overline{1} 11]$ line, but the change in orientation along this line as a result of "double slip" is only a small fraction of the predicted one or absent at all. This fact could be determined as the spots from the $(1 \overline{1} 1)$ reflections are quite small after deformation, and permit a reasonable precision in measuring the distance between them (and the angle between the [1i1] pole and the axis orientation). 
By careful analyzing the results obtained with $x$-rays it was concluded that there are even small deviations from the change in orientation as predicted by single slip. This result was also reported by Ahlers and Haasen (1962) and Mitchell and Thornton (1964).

It was found from these changes in orientation that the "crystallographic" effect is at most $2 \%$ so that this correction will be ignored.

\section{V.3 MECHANICAL TWINNING}

\section{V.3.1 Introduction}

Since Blewitt et all (1954, 1955) have reported that copper single crystals can deform, at low temperature, by mechanical twinning, every investigation on plastic deformation of copper single crystals has to consider also this mechanism.

In the course of this investigation, some new experimental results were found, concerning the role of mechanical twinning in the deformation process of copper single crystals. The influence of twinning on necking and fracture was also investigated. Deformation in torsion gives rise to helical grooves on the surface of all crystals investigated. The results indicate a relation between these grooves and mechanical twins. As a consequence of these results, the possibility that mechanical twinning is a mode of deformation that starts when the possibilities to deform by slip are exhausted, will be discussed in this section.

\section{V.3.2 Results and discussion}

\section{V.3.2.1 Deformation by elongation}

In fig. 46 the relation between the orientation of the specimen axis and the occurrence of twinning at $78 \mathrm{~K}$ is shown. Twinning occurs in a wider range of orientations than indicated by Blewitt et al. (1954) for copper at 78K. Twinning prior to necking is observed if 


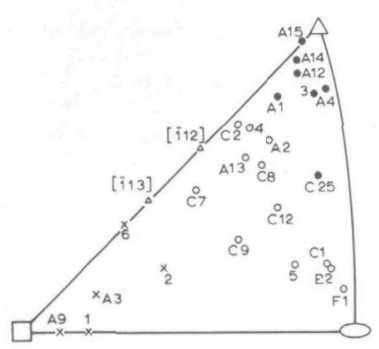

$x \quad$ No twinning observed

- Twinned before necking

- Twinned after necking

Fig. 46 - Orientation dependence of mechanical twinning in copper single crystals after deformation in tension.

the specimen axis is near $<111>$. In other cases twinning only took place after necking, in a way described by Suzuki \& Barrett (1958). In this case only part of the specimen contains twins. The nearer the initial orientation is to <111> the larger is the part of the specimen containing twins.

The mode of necking and fracture of copper single crystals depends on whether twinning occurs or not. This is shown in fig. 47. In $\mathrm{fig}$. $47 a$ and $b$ the necking before fracture is shown for two crystals in which twinning was observed. Apparently necking and ultimately fracture takes place by slip on one plane, in the direction of the long axis ( $\mathrm{fig}$. 47a) or the short axis (fig. 47b) of the elliptical cross-section.

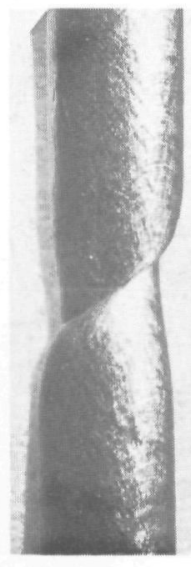

a

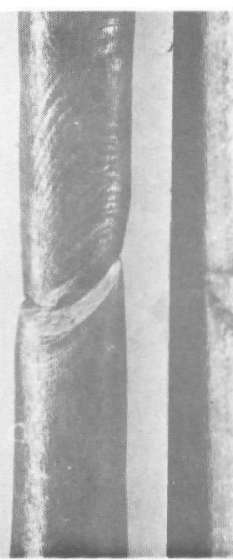

b

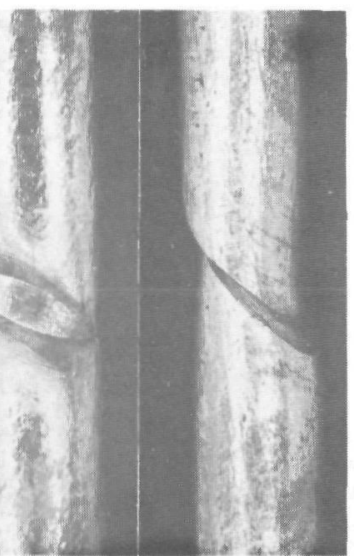

C

d

Fig. 47 - Mode of necking of copper single crystals: $a$ and $b$ are specimens deformed in tension at $78 \mathrm{~K}$ which dicl twin, c a specimen that did not twin, d <111> oriented specimen deformed in tension at $297 \mathrm{~K}$. 
The case of $\mathrm{fig}$. $47 \mathrm{a}$ occurs at $78 \mathrm{~K}$ when the orientation of the specimen axis at the start of twinning differs less than $20 \pm 2^{\circ}$ from the $<111>$. For other orientations where twinning is observed the case of fig. $47 \mathrm{~b}$ is found. At higher temperature the range of orientations where case 47 a occurs decreases.

Fig. 47c shows the necking of a specimen in which no twinning was observed. After frácture both ends of the specimens of $\mathrm{fig}$. 47a and $47 \mathrm{~b}$ show a sharp edge in contrast to the specimen of $\mathrm{fig}$. 47c of which both ends have a groove ( $\mathrm{fig}$. 48) showing that in this case fracture originated from a crack inside the crystal (cup-cup fracture).

In fig. 47d the necking of a $<111>$ specimen is shown, deformed at room temperature. Although in this case no twinning was observed, neither by audible clicks nor by serrations on the stress-strain curve the mode of necking was similar to that of fig. $47 \mathrm{~b}$ which was typical for twinned specimens. In order to elucidate this point the necked regions of the two specimens were polished and etched. The results are shown in fig. 49a for the <111> specimen deformed at room temperature and in fig. $49 \mathrm{~b}$ for the specimen of $\mathrm{fig} .47 \mathrm{~b}$. In both cases the shearing takes place in a twinned region of the specimen of about $100 \mu$ thick. Therefore the shearing in one plane is only apparent: what really seems to happen is that during necking the deformation is concentrated in one twin which in $\mathrm{fig}$. 49a and b has already a necked shape. In fig. 50 the necked regions of the specimens $47 \mathrm{a}, 47 \mathrm{c}$ and of a $<111>$ oriented specimen, deformed at $78 \mathrm{~K}$, are shown. In the necked specimen 47a ( $\mathrm{fig}$. 50a) it can be seen that also here the shearing takes place in a small region of the same size as in $49 \mathrm{~b}$ but the region appears to be polycrystalline which could be a result of repeated twinning. This puzzling result is even clearer in the necked region of the <111> oriented specimen deformed at $78 \mathrm{~K}$ (fig. 50b). In fig. $50 \mathrm{c}$ the necked region is shown of a specimen of orientation No. 2 (fig. 46) deformed at $78 \mathrm{~K}$, but which does not twin. No twins are seen but there are rows of etch pits with an accumulation of dislocations (see arrow) where a small cavity will 


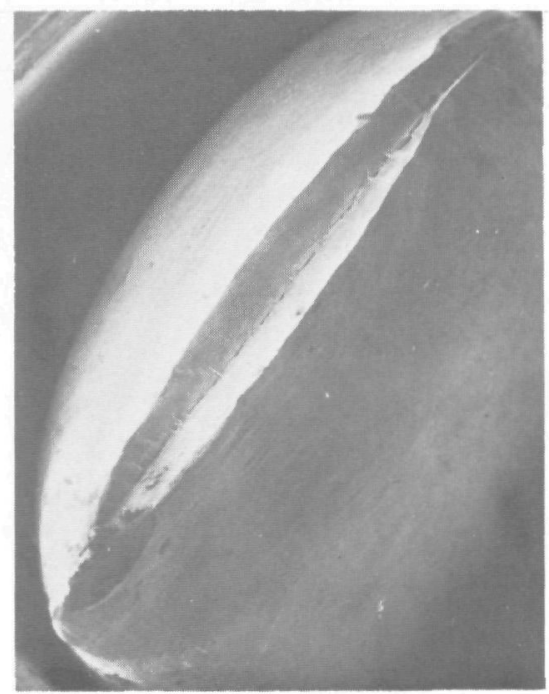

Fig. 48 - The groove on an end of a fractured specimen that did not twin made with a scanning electron microscope.

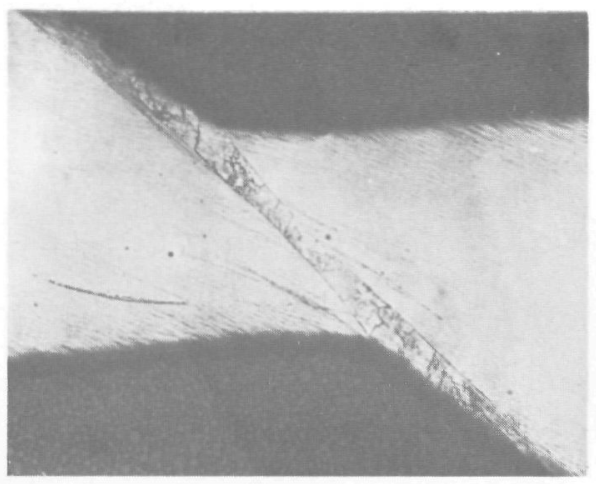

a

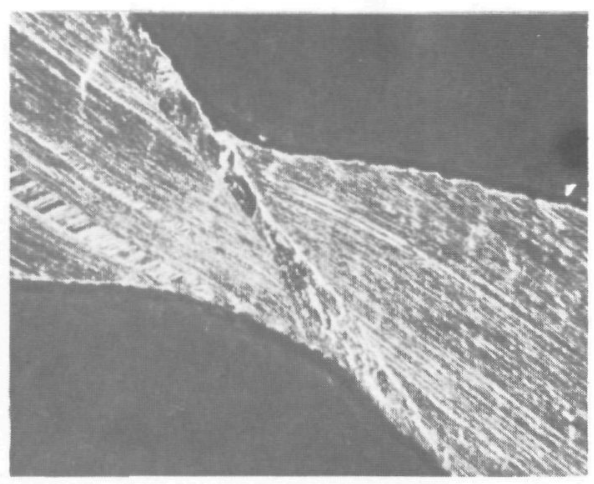

b

Fig. 49 - Necked regions of specimens of fig. $47 \mathrm{~b}$ and $d$ after polishing and etching. 


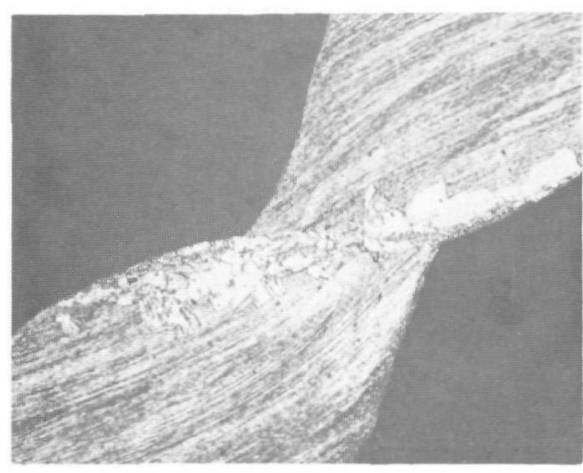

a

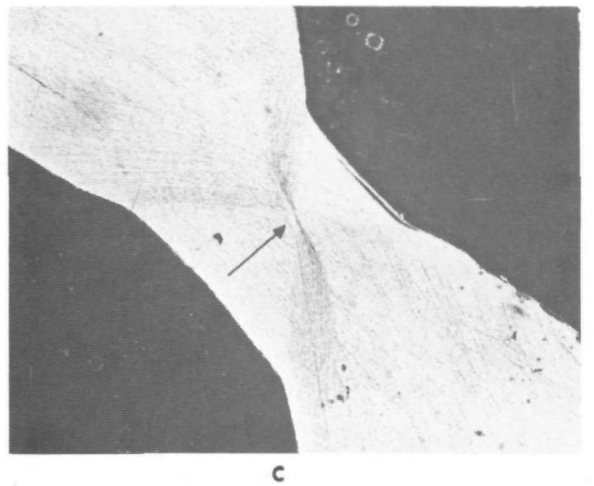

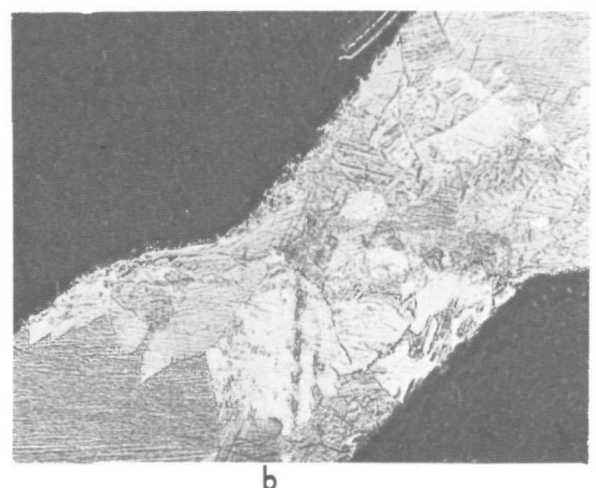

Fig. 50 - Necked regions of specimens of fig. 47a, $c$ and $a<111>$ oriented specimen deformed at $78 \mathrm{~K}$.

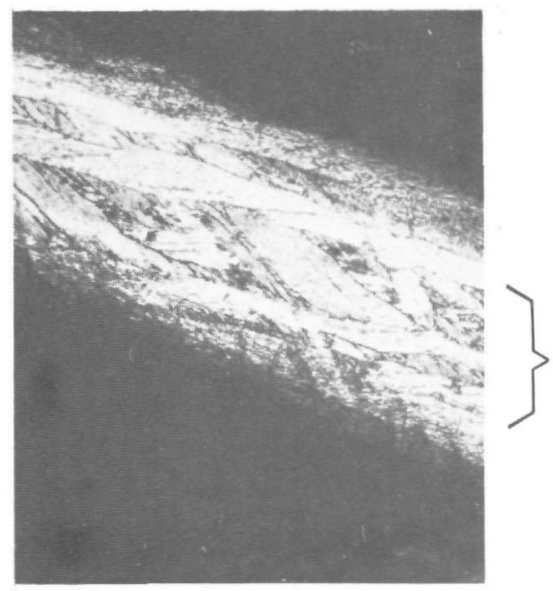

a

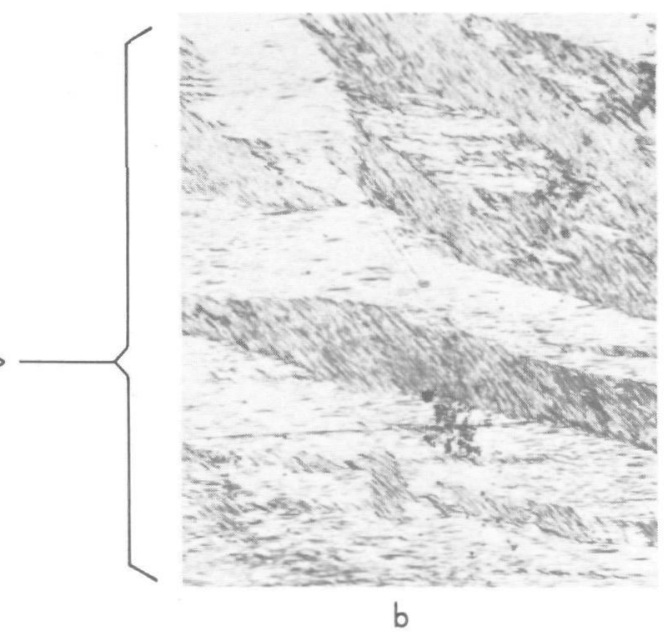

Fig. 51 - A deformed <011> specimen after polishing and etching in two magnifications $50 \times(a)$ and $200 \times(b)$. 
probably form resulting ultimately in the groove of fig. 48 .

Obviously it is not correct to say that the $\langle 111\rangle$ specimen does not twin at room temperature, because it fractures within the very first twin formed. In this context is it interesting that $\langle 111\rangle$ oriented specimens deformed at $78 \mathrm{~K}$ start to twin at a strain of $24 \pm 2 \%$ whereas $<111>$ oriented specimens deformed at room temperature, fracture at a strain of $24 \pm 2 \%$. In the light of the preceding section this should be expressed as follows: both at $78 \mathrm{~K}$ and at room temperature twinning starts at the same degree of deformation. In the former case, deformation continues by twinning whereas in the later case, fracture occurs at the first twin. The correspondence of the strain where twinning starts at $78 \mathrm{~K}$ and the strain where fracture occurs at room temperature is neither fortuitous nor typical for <111> oriented crystals as is shown in table IV: it is roughly valid in all crystals investigated.

Table IV.

Orient. No. of Starts to twin after a Starts to neck after a specimen (fig.46) deformation of $\%$ at $78 \mathrm{~K}$ deformation of $\%$ at $24^{\circ} \mathrm{C}$

\begin{tabular}{|c|c|c|}
\hline$<111>$ & $\begin{array}{l}25.6 \\
23.0 \\
22.8\end{array}$ & $\begin{array}{l}24.0 \\
24.5\end{array}$ \\
\hline 5 & $\begin{array}{l}66.0 \\
67.6 \\
60.0 \\
62.0 \\
65.0\end{array}$ & $\begin{array}{l}66.3 \\
64.0\end{array}$ \\
\hline 3 & $\begin{array}{l}30.9 \\
33.4 \\
32.1\end{array}$ & 28.0 \\
\hline 4 & $\begin{array}{l}46.5 \\
43.8\end{array}$ & 40.0 \\
\hline$A_{2}$ & $\begin{array}{l}46.7 \\
54.2 \\
42.3\end{array}$ & 47.2 \\
\hline
\end{tabular}


It should be noted that the values of strains given in table IV are rather sensitive to strain rate and therefore the strain values in table IV have been taken at about the same strain rate; approximately $1 \% / \mathrm{min}$.

The results on <011> oriented crystals are somewhat exceptional. During deformation at $78 \mathrm{~K}$ and at room temperature no audible clicks nor serrations on the stress-strain curve were observed. Nevertheless, twins appear to be present in the deformed specimen, as could be shown in different ways. A picture of a specimen, polished on a $\{110\}$ plane (parallel to the axis) and etched, after deformation is shown in $\mathrm{fig}$. 51. The straight boundaries of $\mathrm{fig}$. 51 a are interpreted as twin boundaries and in fig. 51b the traces of the $\{111\}$ planes (that are perpendicular on the $\{110\}$ ) can be seen to make an angle of $\simeq 56^{\circ}$, being the angle between the $\langle 111\rangle$ and the $\langle 115\rangle$, which is the transformed $\{111\}$ plane in the twinned region. Further a grazing incidence $x$-ray photograph was made of both sides of an undeformed specimen and of the same specimen deformed $3 \%$ in tension at $78 \mathrm{~K}$. In the latter (fig. 52) there are reflections (identified on the photograph) which do not, fit the pattern of the <011> oriented specimen as do the other reflections. By identifying them, it is found that they $\mathrm{fit}$ in a pattern that shows the axis orientation to be $\langle 114\rangle$, the twin orientation of $\langle 110\rangle$.

After some deeper etching on a polished $\{111\}$ plane, triangular etch pits appear, which are each others mirror immage at both sides of a twin boundary. In fig. 53 one etch pit on a twin boundary is shown, $10.000 \times$ magnified. The mirror line is seen clearly between two triangular bottoms which are $\{111\}$ planes in the original lattice and twinned crystal. The angle between these planes was measured in the following manner: when the specimen is looked at perpendicular to the initial $\{111\}$ plane, the right triangle is equilateral. Then the specimen was tilted until the left triangle was equilateral, the angle between these two positions was $40^{\circ}$ as expected for a twin transformation.

After $3 \%$ elongation the applied stress on the $<011\rangle$ crystal was 


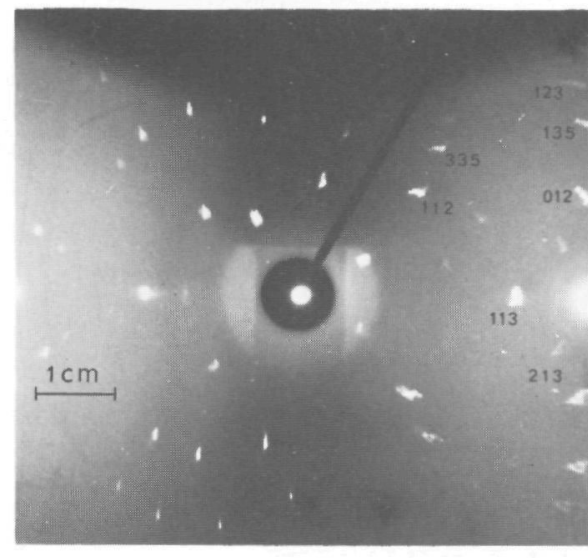

Fig. 52 - Laue X-ray photograph of a twinned <011> specimen.

Fig. 53 - Etch pit on a twin boundary made with a scanning electron microscope 10.000x.

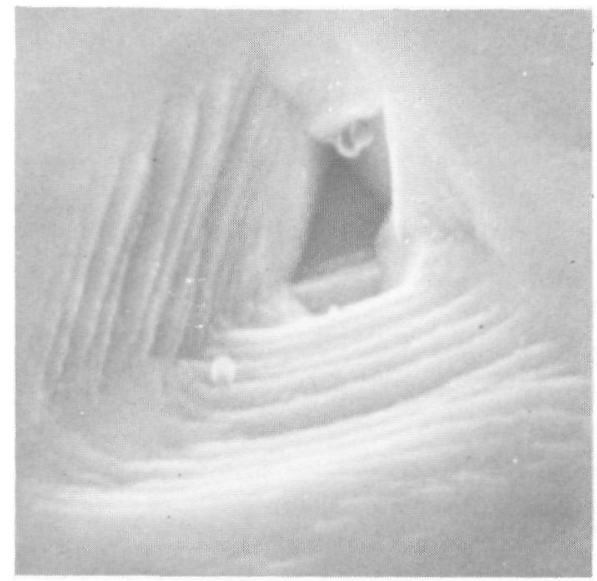

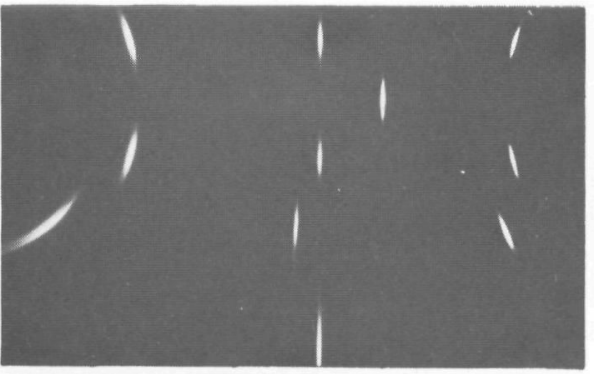

a

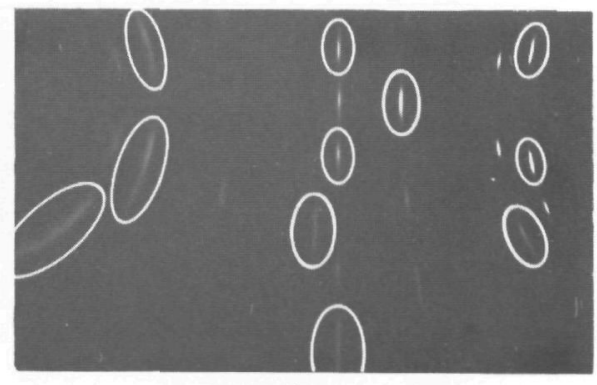

b

Fig. 54 - X-ray photographs of deformed <111> specimens without (a) and with (b) twins. 
$1 \mathrm{~kg} / \mathrm{mm}^{2}$ corresponding to a C.R.S.S. of $0.4 \mathrm{~kg} / \mathrm{mm}^{2}$. This is at least one order of magnitude smaller than the stress where twinning starts in the other crystals investigated and the value of $15.2+0.58 \mathrm{~kg} / \mathrm{mm}^{2}$ given by Thornton and Mitchell (1962). This corroborates Cahn's statement that "there is no such a thing as a critical shear stress for twinning" (Cahn (1964)).

Finally a method that was used to check if twins are present in the specimen, after deformation, using $x$-ray techniques will be demonstrated. Fig. 54 shows two x-ray photographs, made with the rotating specimen method of two deformed $<111>$ oriented specimens, one without and one with deformation twins. Fig. $54 a$ is an x-ray photograph of a $<111\rangle$ specimen where the deformation was stopped before the start of mechanical twinning. It can be seen that the number and place of the reflections is the same as in an undeformed specimen (compare with fig. 6, p.19) as was already mentioned (see V.2). Fig. 54b shows a photograph of a <111> specimen containing deformation twins: the <111> reflections, being the same as in fig. 54a, are encircled but there are some extra reflections from which an axis orientation can be determined which is found to be $<115\rangle$, the twin orientation of $\langle 111\rangle$. When this method is applied to specimens of other orientations, the determination of twin orientations is more complex. However, it is simple to show that mechanical twinning took place. In an x-ray photograph, made with the rotating specimen method, of a specimen in a random orientation containing twins, more reflections on one ring are found than can be expected from a single crystal (see section V.2). As the only mechanism by which a single crystal can become polycrystalline after deformation at low temperatures is mechanical twinning, that mechanism must have taken place. In order to determine the orientation of the twin, the following way is pursued: first the orientation of the specimen at the onset of twinning is calculated (see chapter IV and section V.2), then the reflections of this orientation are identified. Then the orientation of the twin of this orientation is calculated (as will be shown in chapter VI) and checked whether the 


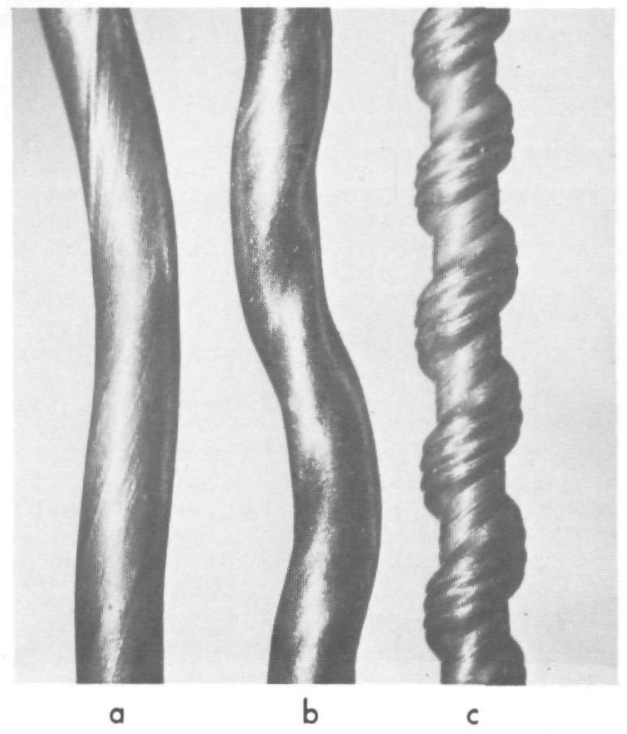

Fig. 55 - Copper single crystals deformed in torsion: $(a) \simeq 12 \%,(b) \simeq 24 \%$ and $(c) \simeq 48 \%$.

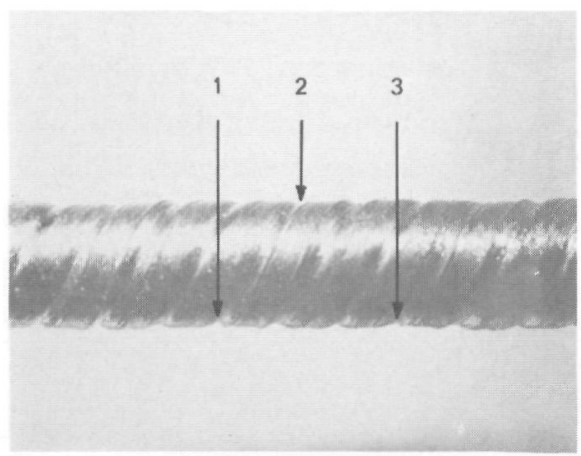

a

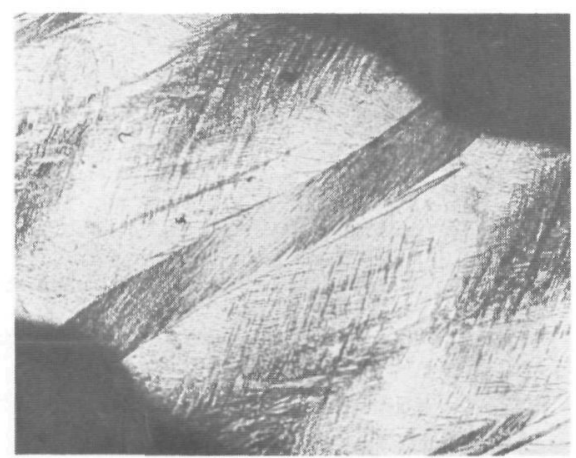

b

Fig. 56 - <111> oriented copper single crystal deformed in torsion at $78 \mathrm{~K}$.

(a) Triple grooves on the surface (between point 1 and 2 is half a pitch of the groove spiral and by doubling it the distance of a whole pitch is found). In the distance of one pitch three grooves are seen.

(b) Polished and etched, every groove corresponds with a twin. 
extra reflections correspond to these orientations.

\section{V.3.2.2 Deformation by torsion}

Deformation in pure torsion appeared to be possible for only two orientations: $\langle 111\rangle$ and $\langle 110\rangle$ (the latter only up to $\varepsilon \simeq 60 \%$ ). When a specimen is loaded in torsion, the maximum shear stress is in planes perpendicular to the axis and in planes through the axis. In a $\langle 111\rangle$ crystal one slip plane (\{111\}) is perpendicular to the axis and therefore the shearing will take place in this plane, giving rise to pure torsion. A $<110>$ oriented specimen has two $\{111\}$ planes parallel to the axis and these will be the preferred ones for slip. Specimens of all other orientations elongated during torsion up to about $5 \%$ (for $\varepsilon \simeq 60 \%$ ). With the exception of the $<001>$ specimen, all of them became helical ( $\mathrm{fig}$. 55a and b). The <001> orientation shows an intermediate behaviour: they remain straight, although they become longer and thus do not deform in pure torsion.

After a more severe deformation, helical grooves develop on the surface of specimens of all orientations ( $\mathrm{fig} .55 \mathrm{c}$ and 56a). During this process, specimens that were helical become straight again (fig. 55c); specimens that were straight remain straight as shown for the <111> orientation in fig. 56a. On closer inspection, it was observed that the groove structure depends on the specimen orientation. The $<001>$ shows a quadruple groove, i.e. four parallel helical grooves on the surface. The $\langle 111\rangle$ and $\langle 011\rangle$ orientation have triple (fig. 56a) and double grooves respectively. The number of independent grooves simply reflects the symmetry of the specimen axis: a fourfold symmetry axis $(<001\rangle)$ gives rise to a quadruple groove and so on. The remaining orientations have a surface analogous to that shown in fig. 55c: one big groove and some smaller ones. It must be pointed out, however, that in this case only the small grooves correspond with twins whereas the big groove is a result of the anisotropic deformation, analog to the ellipticity after extension. 
Fig. 56b shows the result of polishing and etching the grooved regions of a $<111>$ specimen. It is seen that the grooves correspond with twins. Analogous results have been obtained in many crystals with different orientations.

\section{V.3.2.3 Relation between twinning and strain to fracture}

In order to investigate if there exists a relation between the occurrence of twinning and a high degree of strain to fracture also for torsional deformation (as was found for extension, see table $V$, it was necessary to find a crystal that does not twin as a result of this form of deformation.

Table V

\begin{tabular}{lrrlll}
\hline Metal & $\begin{array}{c}\text { Number of } \\
\text { orient. }\end{array}$ & $\begin{array}{c}\text { temp. } \\
(\mathrm{O} C)\end{array}$ & $\begin{array}{l}\text { mode of } \\
\text { deformation }\end{array}$ & $\begin{array}{l}\text { strain to } \\
\text { fracture }(\%)\end{array}$ & $\begin{array}{l}\text { twins } \\
\text { observed }\end{array}$ \\
\hline $\mathrm{Cu}$ & 5 & -196 & extension & $70-80$ & yes \\
$\mathrm{Cu}$ & 12 & 20 & extension & $25-70$ & no \\
$\mathrm{Pb}$ & 5 & 20 & extension & $30-70$ & no \\
$\mathrm{Cu}$ & 12 & 20 & torsion & $200-300$ & yes \\
$\mathrm{Cu}$ & 2 & 250 & torsion & $200-300$ & yes \\
$\mathrm{Al}$ & 3 & 20 & torsion & $200-300$ & yes \\
$\mathrm{Pb}$ & 5 & 20 & torsion & $80-90$ & no \\
$\mathrm{Cu}$ & $1<111>$ & 20 & torsion & $400-500$ & yes \\
$\mathrm{Al}$ & $1<111>$ & 20 & torsion & $400-500$ & yes \\
$\mathrm{Pb}$ & $1<111>$ & 20 & torsion & 120 & no \\
& & & & & \\
\hline
\end{tabular}

First a copper single crystal was deformed in torsion at $250^{\circ} \mathrm{C}$. It was found, however, that even at this elevated temperature, the deformation proceeds by mechanical twinning and fracture occurs after a strain > $200 \%$.

Then $\mathrm{Al}$ and $\mathrm{Pb}$ single crystals, that have also a fcc structure and in which acoording to earlier investigators (Haasen (1958), Mitchell and Thornton (1962)) no mechanical twinning has been observed, were deformed in torsion. The result was as follows: Al single crystals deformed in torsion at room temperature fractured at 
strains of $200 \%-300 \%$ and it was found using $x$-ray techniques that they contained twins which were introduced during deformation. $\mathrm{Pb}$ single crystals fractured after strains < $100 \%$ except the $<111>$ orientation which fractured at a strain of about $120 \%$. In these crystals no twins could be detected. The results have been assembled in table $V$.

From table $V$ it may be concluded that for the deformation of fcc single crystals a connection exists between the magnitude of the strain to fracture and the occurrence of mechanical twinning.

\section{V.3.3 Summary and conclusions}

1) The mode of necking and fracture in copper single crystals deformed in tension depends on whether twinning occurs or not. In the former case fracture seems to take place by shearing over a single plane. In fact fracture occurs in a thin twinned layer.

2) In copper single crystals deformed in tension at 78K, twinning starts at about the same strain where fracture occurs when deformed at room temperature. In general in fcc crystals mechanical twinning makes possible higher strains to fracture.

3) Twins in <011> crystals were observed at an applied stress lower by an order of magnitude than found for the other orientations.

4) Deformation in pure torsion was only possible in <111> and in $<011>$ crystals, in the latter case only for $\varepsilon<60 \%$. In all other cases an additional elongation was observed.

5) After severe deformation in torsion, on the surface of all copper single crystals investigated, helical grooves were observed. If the crystal axis shows $n$-fold symmetry, then n-equivalent spirals were found. The grooves correspond with twins. 


\section{V.4 CHANGE OF THE ELASTIC MODULI AND INTERNAL FRICTION AS A}

FUNCTION OF DEFORMATION

\section{V.4.1. Introduction}

It was found, in analogy with the results of the stress-strain curves, that the change in the elastic moduli and internal friction is dependent on the initial damping of the undeformed specimen. The best way to present a series of experiments would therefore be to have specimens of different orientations with the same initial damping. This proved to be impossible to achieve, so the results of the specimens with the lowest damping of each orientation will be shown.

The value of the internal friction of the undeformed specimen given will always be the one measured in torsional oscillations as this measurement, contrary to flexural oscillations, is much less influenced by small deviations from straightness and concentricity of the specimen and magnet between the coils (see fig. 9).

The influence of mechanical twinning and recovery at room temperature on the elastic moduli was also investigated. All measurements were made at $78 \mathrm{~K}$ as at this temperature almost no recovery occurs (Blewitt et.al. (1954)). It was found that at this temperature, after an interruption of the experiment for a period of 18 hours no significant change in frequency occurred (the deviation was $<10^{-3}$ ).

\section{V.4.2. Experimental results on $\langle 001\rangle,\langle 011\rangle$ and $\langle 111\rangle$ oriented specimens}

The change of the moduli of the symmetric orientations have been measured as a function of deformation both in extension and torsion. Specimens of these orientations are the only ones remaining straight when subjected to plastic torsion. For all other orientations plastic torsion results in helix shaped specimens, which makes determination of the elastic constants from frequency measurements impossible. 


\section{V.4.2.1 Modulus effect after plastic elongation}

Fig. 57 and 58 show the change of $E$ and $G$ as a function of extension of a $\langle 001\rangle$ and $\langle 111\rangle$ oriented specimen respectively. The initial internal friction of the specimens was $Q^{-1}=5.8 \cdot 10^{-4}$ for the $<001>$ specimen and $5.4 \cdot 10^{-4}$ for the $\langle 111>$ one. After a strain of 0.18 , the $\langle 111\rangle$ oriented specimen started to deform by mechanical twinning (an effect accompanied by audible clicks) and this fact had an instantaneous effect on the change of the moduli of elasticity: $E$, after a short increase, decreases sharply and $G$ increases sharply. Later on it will be shown that this effect had to be expected. The characteristic of the effect as a result of slip alone is a sharp decrease in $E$ and $G$ after which the moduli are almost independent of strain, with only a slight tendency to increase in the case of <111> and decrease in the case of $\langle 001\rangle$.

An example of the influence of initial damping is given in fig.59 showing the $\Delta E$ and $\Delta G$ effects of a $<111>$ oriented specimen having an initial damping of $\mathrm{Q}^{-1}=7.4 \cdot 10^{-4}$. Comparison with $\mathrm{fig} .58$ yields that the changes of $E$ and $G$ are larger for larger initial damping and moreover the $\Delta E$ effect has a maximum at $\varepsilon \simeq 0.03$ (this is found in the $\Delta E$ effect of all orientations, except the $\langle 001\rangle$, where the initial damping is high). A $<111>$ oriented specimen with an initial internal friction of $Q^{-1}=10.6 \cdot 10^{-4}$ had a maximum $\Delta E$ effect of 0.10 and other specimens of this orientation had initial damping and $\Delta E$ effect values between this (the largest one) and the low one of fig. 58. The $<001>$ orientation had no maximum $\Delta E$ or $\Delta G$ effect and for larger initial damping the effects were only slightly larger.

The $\Delta E$ effect in the $\langle 011\rangle$ oriented specimens did not reproduce. In all cases a maximum was observed but the height of the maximum and the decrease of the effect varied. Fig. 60 and 61 show the two extreme cases observed. The $\Delta G$ effect was always an increasing function, reaching values between 0.20 and 0.24 . In section V.3 it has been shown that this particular orientation deforms by twinning almost from the beginning. In the discussion it will be shown that the $\Delta G$ effects are contrary to what we would expect as a result of me- 
The $\Delta E$ and $\Delta G$ effectsas a function of strain in copper single crystal deformed in extension of:

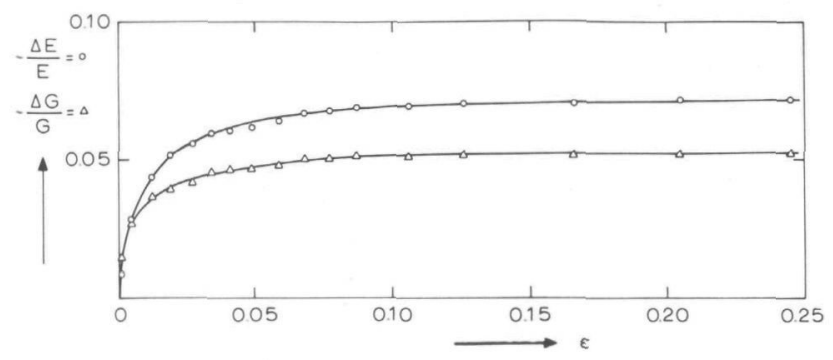

Fig. $57-<001\rangle$ orientation

$Q_{0}^{-1}=5.8 \cdot 10^{-4}$.

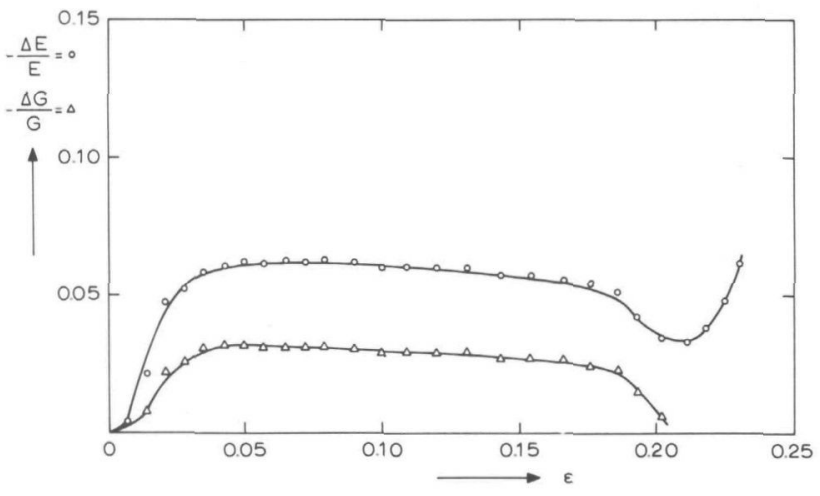

Fig. $58-<111>$ orientation

$Q_{0}^{-1}=5.4 \cdot 10^{-4}$.

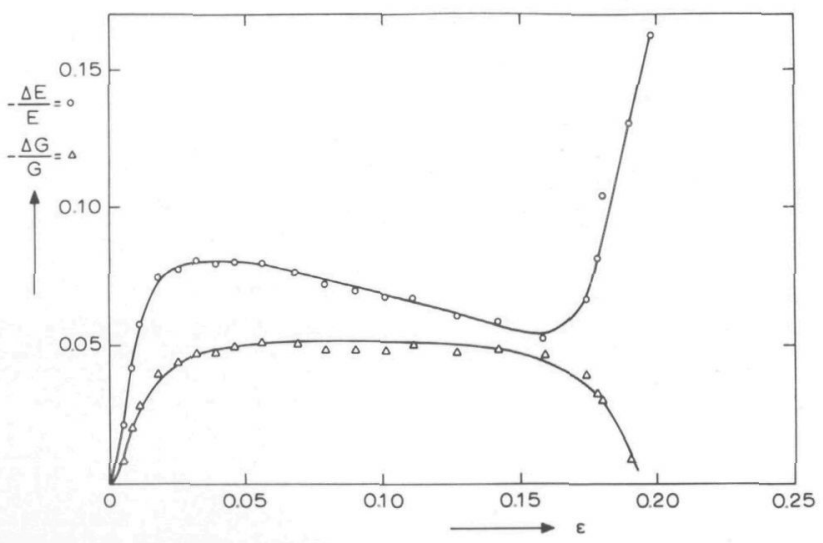

Fig. $59-<111\rangle$ orientation $Q_{0}^{-1}=7.4 \cdot 10^{-4}$. 
$\Delta E$ and $\Delta G$ effects of two $<011>$ oriented specimens.

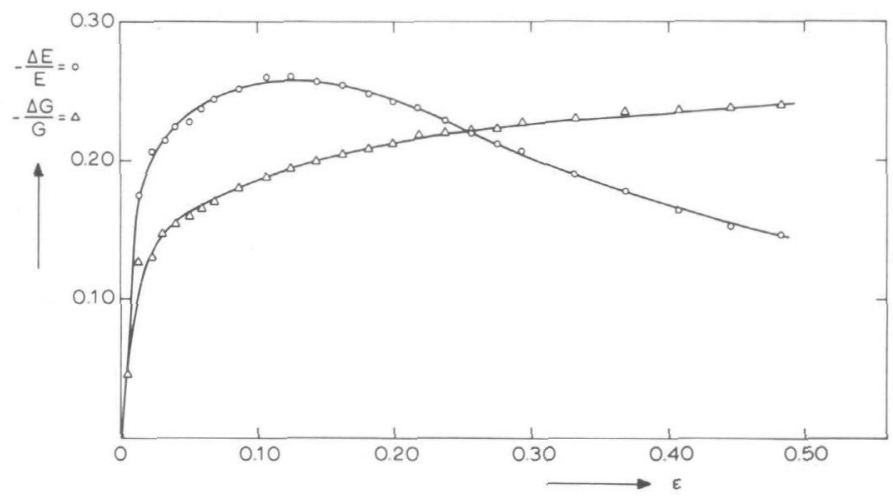

Fig. 60.

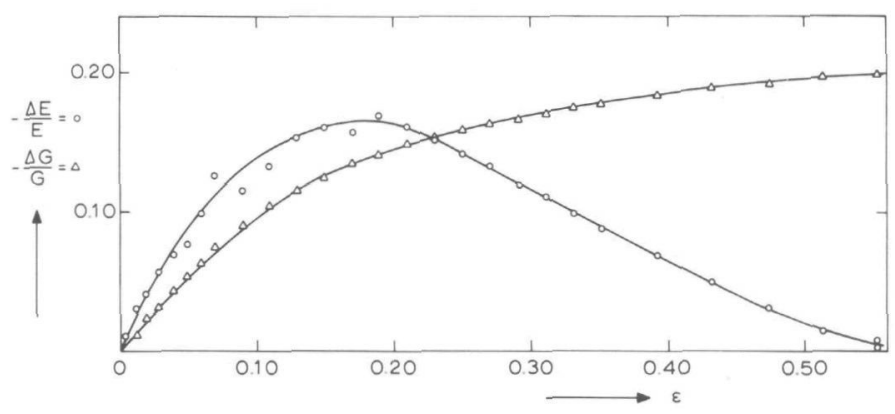

Fig. 61.

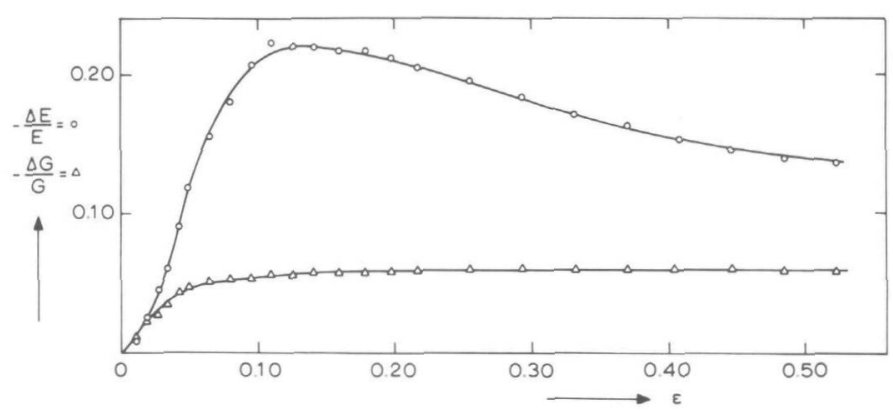

Fig. 62. $\Delta E$ and $\Delta G$ effects of a specimen $5^{\circ}$ from $\langle 011\rangle$. 
chanical twinning. The $\Delta E$ effect of a specimen $5^{\circ}$ from the $\langle 011\rangle$ is similar to the effect of the $\langle 011\rangle$ but the $\Delta G$ effect reaches after a few percent extension a limiting value of about 0.06 (see fig. 62).

\section{V.4.2.2 Modulus effect after plastic torsion}

Specimens of the three symmetrical orientations remain straight after a deformation in torsion, however, in the case of $<001\rangle$ orientation, the deformation is not a pure torsion as there is also an elongation. In the case of $\langle 111\rangle$ there is no measurable elongation during deformation in torsion. A $<011>$ oriented specimen deforms up to $\simeq 0.60$ in pure torsion, but at strains $\varepsilon>0.60$, an elongation was observed. Fig. 63 shows the elongation as a function of torsion of $\langle 001\rangle$ and $\langle 011\rangle$ oriented specimens. Up to a strain of 0.50 the elongation of the $<001>$ oriented specimen is a linear function of the strain in torsion, then the curve is flattening. In the case of $<011>$ the elongation starts only after a strain of 0.56 and is a linear function of torsional strain. After a strain of 1.50 the elongation of the $\langle 011\rangle$ is only about 0.06 . It should be pointed out that, although these curves do not reproduce very well, the character of this effect is always the same. It is important to know the exact elongation, because in the formulae for the calculation of the change of the elastic moduli as a function of deformation, the length plays an important role.

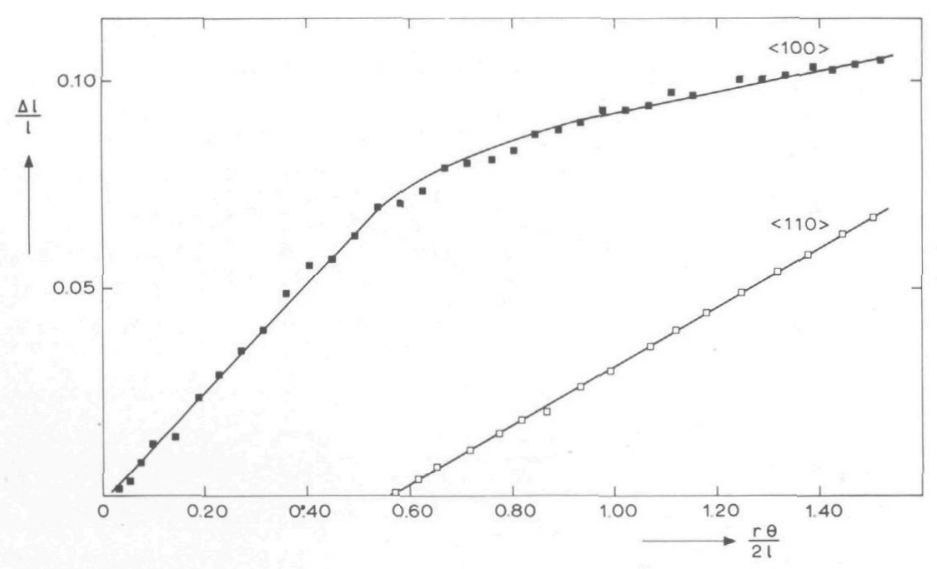

Fig. 63 Elongation as a function of plastic torsion in <100> and <110> specimens. 
$\Delta E$ and $\Delta G$ effects as a function of plastic torsion.

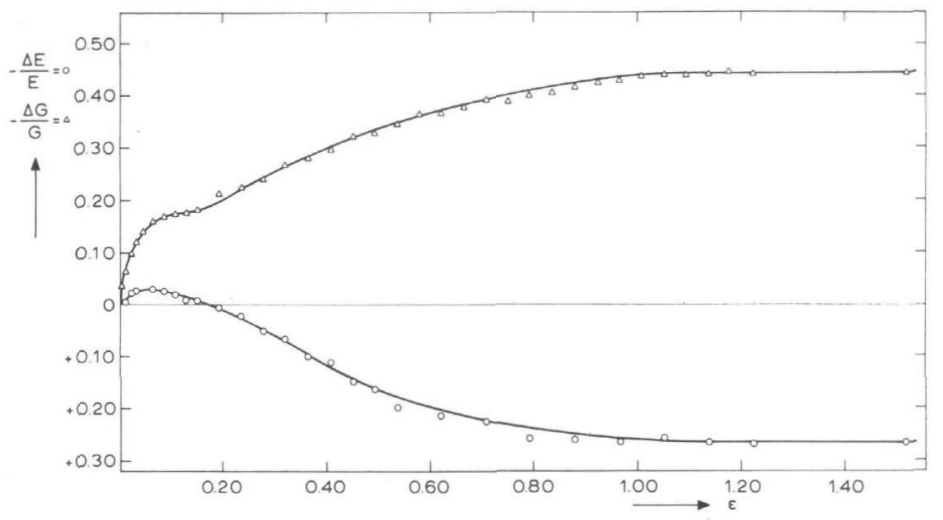

Fig. $64-<001\rangle$ orientation.

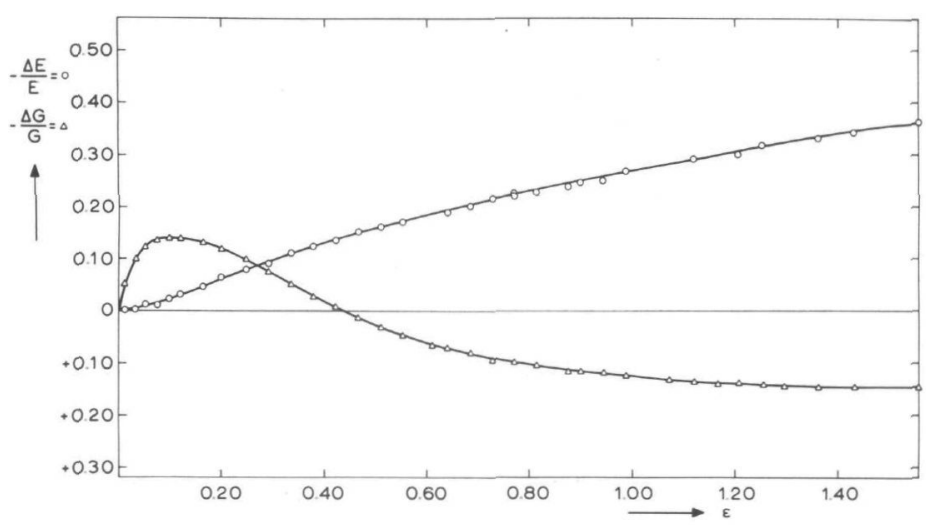

Fig. $65-\langle 111\rangle$ orientation.

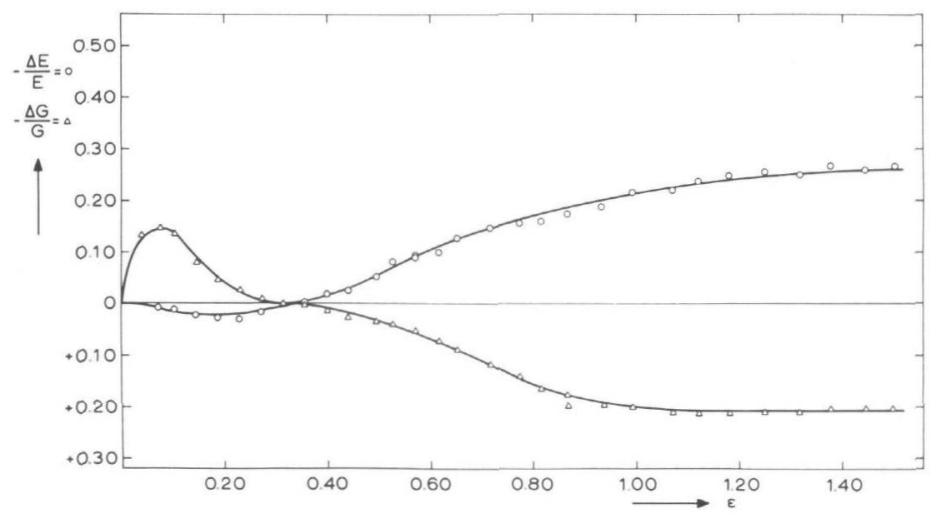

Fig. $66-<011>$ orientation. 
Fig. 64,65 and 66 show the change of $E$ and $G$ in specimens of the three symmetric orientations as a function of deformation in plastic torsion. We note the following remarkable points:

1) After a certain deformation the change in $E$ is always opposite in sign to the change in $G$, the same effect as observed in extension of $<111>$ oriented specimens once the deformation proceeds by twinning ( $\mathrm{fig} .58$ and 59 ).

2) After a certain deformation in <001> specimens, G decreases and E increases continuously, whereas in $\langle 111\rangle$ specimens the opposite is observed.

In the discussion these observations will be dealt with in more detail, but here it will be shown qualitatively that this was to be expected as a result of mechanical twinning. It was already mentioned in section 111.1 that in the $<001>$ orientation $E$ is a minimum and $G$ a maximum. Therefore, when parts of the <001> specimen change their orientation as a result of mechanical twinning, $E$ can only increase and $G$ decrease, as was found. For the $\langle 111\rangle$ orientation where $E$ is a maximum and $G$ a minimum, the reverse effect was expected and found.

The behaviour of the $\langle 011\rangle$ oriented specimen is similar to that of the <111> oriented specimen but (as in extension) also in torsion the change of $E$ does not reproduce well, as is demonstrated by fig. 66 and 67 , representing the changes of $E$ and $G$ of two <011> crystals deformed in torsion.

In torsion the initial internal friction has also an influence on the effect caused by dislocation multiplication in the part where the deformation takes place by slip only. Fig. 68 shows the change in $E$ and $G$ after deformation in torsion of a $<111>$ oriented specimen which had an initial damping of $Q^{-1}=22 \cdot 10^{-4}$ whereas the specimen presented in fig. 65 had an initial damping of $Q^{-1}=7 \cdot 10^{-4}$. It can be seen that the $\Delta G$ effect is larger in the specimen with higher initial damping, and the maximum in the $\Delta G$ curve, which is 0.20 contrary to 0.15 in the one with lower initial damping, is reached at a lower strain. 


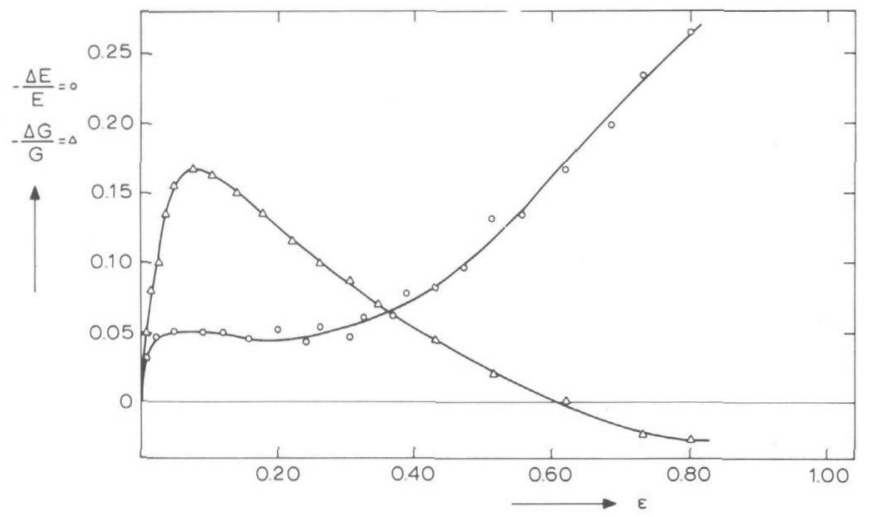

Fig. $67-\Delta E$ and $\Delta G$ effect of a <011> specimen as a function of plastic torsion.

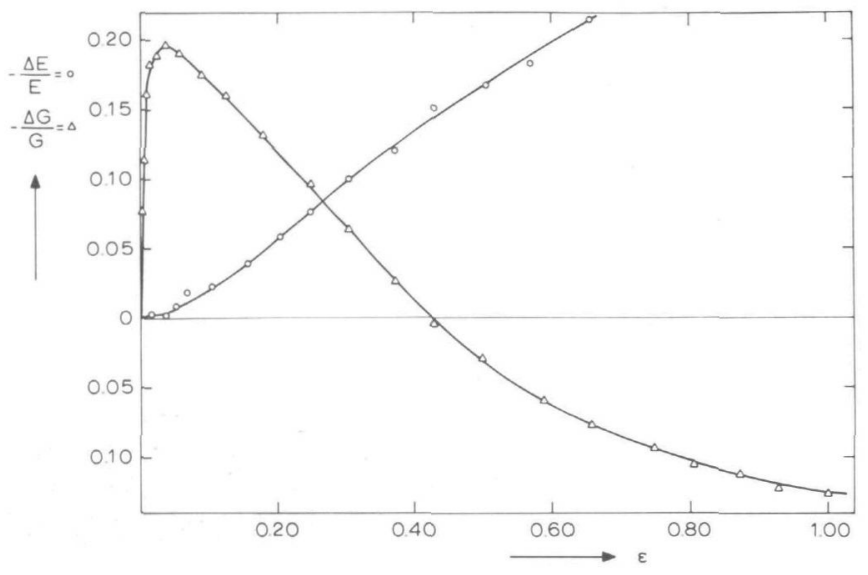

Fig. $68-\Delta E$ and $\Delta G$ effect of $\alpha<111>$ specimen as a function of plastic torsion. $Q_{0}^{-1}=22 \cdot 10^{-4}$. 
The $\Delta E$ and $\Delta G$ effects of specimens with axis orientations presented in fig. 24 .

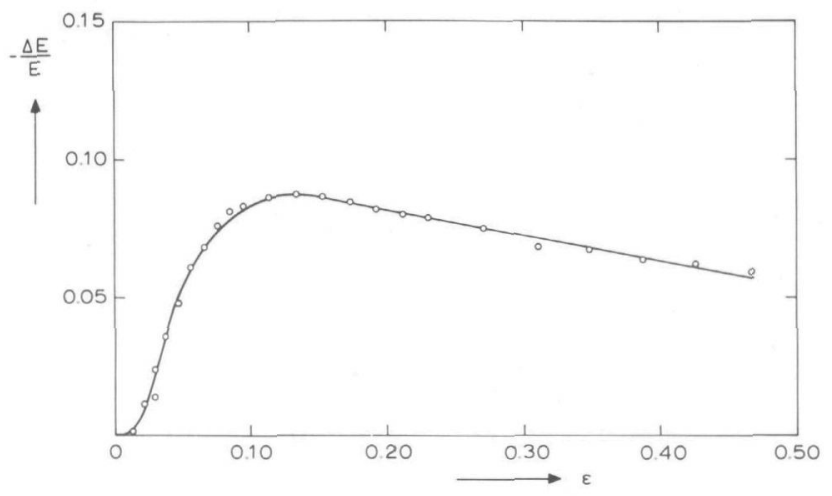

Fig. $69-$

orientation No. 1

$Q_{0}^{-1}=3.6 \cdot 10^{-4}$.

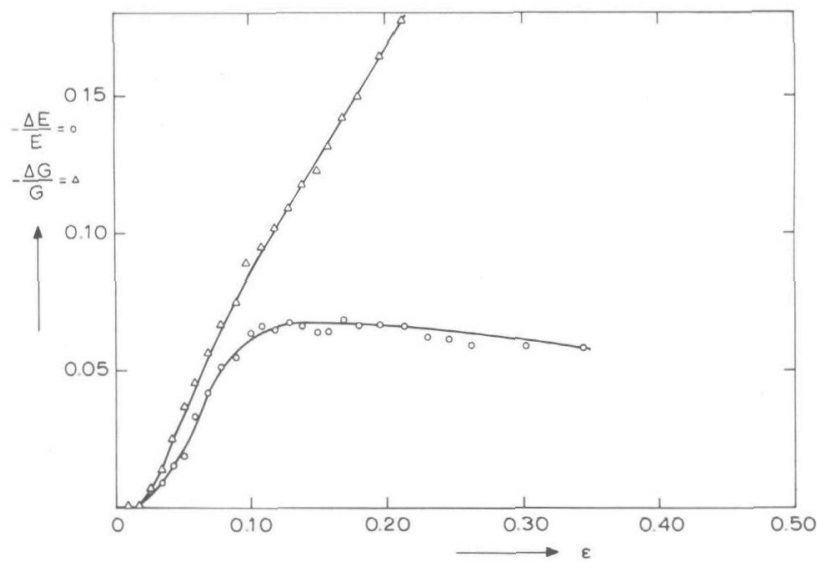

Fig. $70-$

orientation No.10

$Q_{0}^{-1}=2.4 \cdot 10^{-4}$.

Fig. $71-$

orientation No. 6 $Q_{0}^{-1}=0.9 \cdot 10^{-4}$.

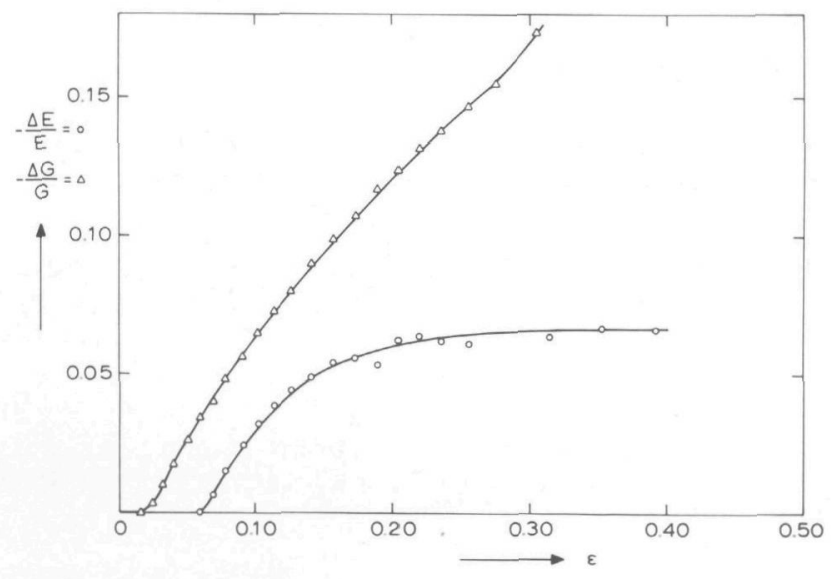




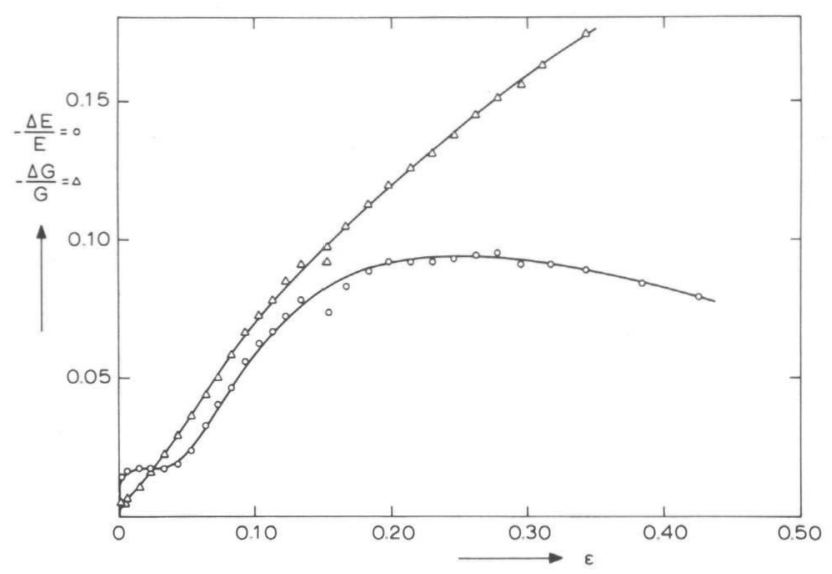

Fig. 72 orientation No. 2 $Q_{0}^{-1}=1.7 \cdot 10^{-4}$.

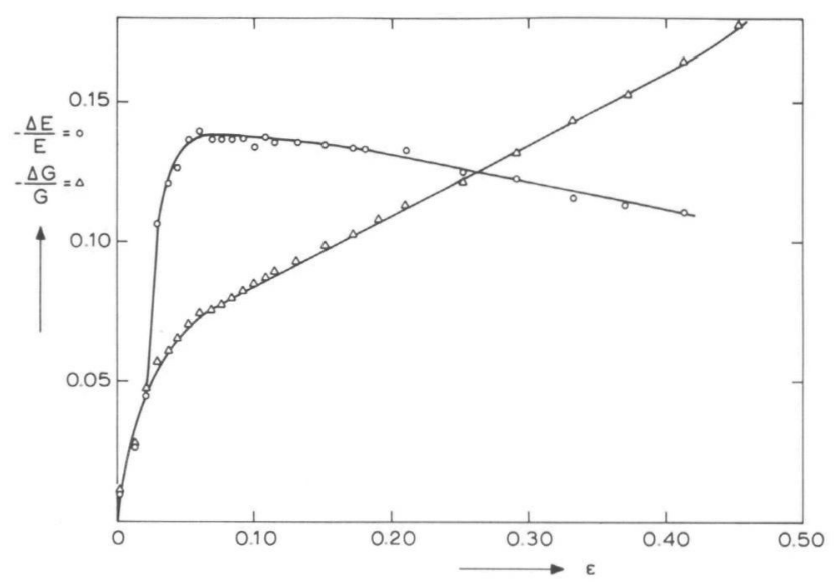

Fig. 73 -

orientation No.? $Q_{0}^{-1}=17 \cdot 10^{-4}$.

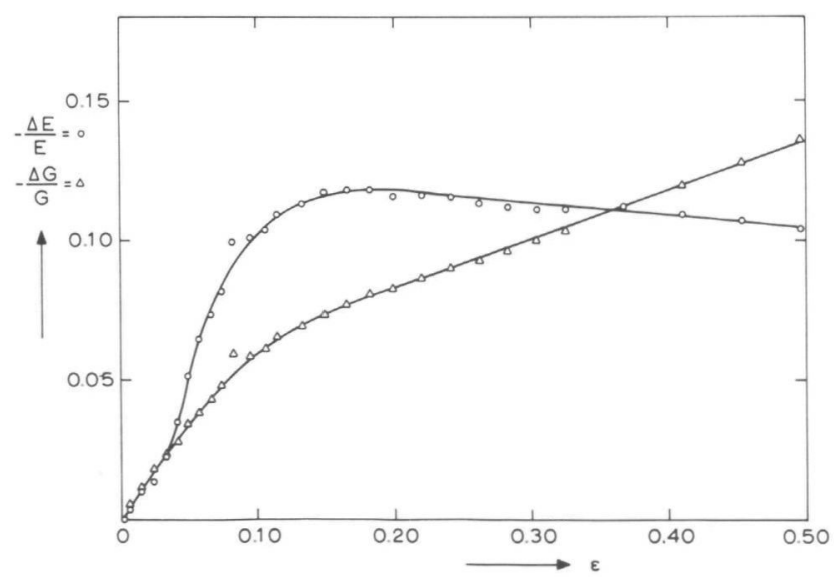

Fig. $74-$ orientation NO. 8 $Q_{0}^{-1}=2.4 \cdot 10^{-4}$. 


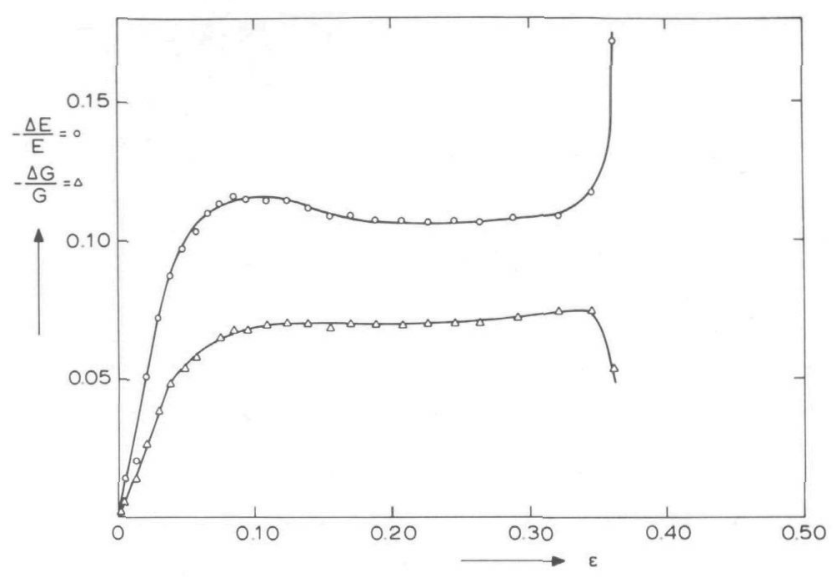

Fig. 75 -

orientation No. 3 $Q_{0}^{-1}=3.1 \cdot 10^{-4}$.

Fig. 76 -

orientation No. 4 $Q_{0}^{-1}=0.8 \cdot 10^{-4}$.

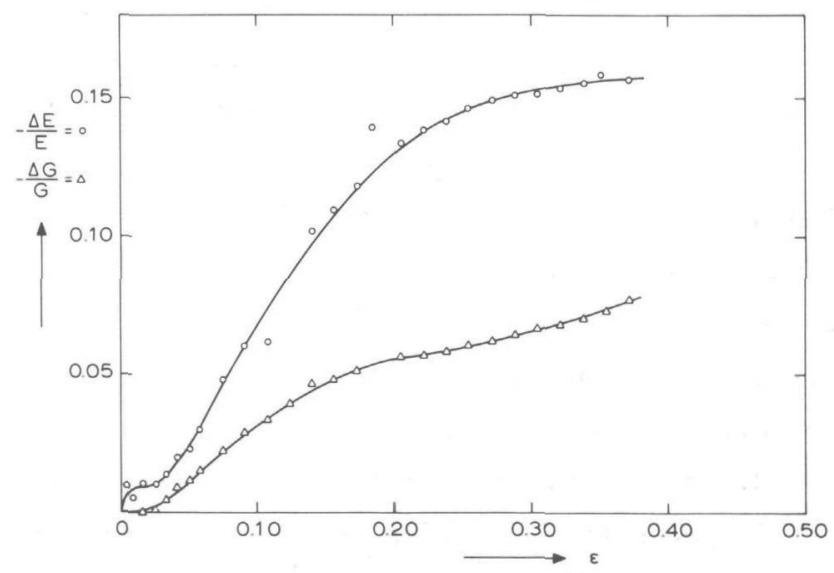

Fig. 77 -

orientation No. 5 $Q_{0}^{-1}=1 \cdot 10^{-4}$. 
V. 4.3 irodulus effect of various orientations after plastic extension

Fig. 69 through 77 present the $\Delta E$ and $\Delta G$ effects of different orientations represented in fig. 24 (orientation No. 1 only $\triangle E$ ). The results are presented in a certain order: the orientations making the smallest angle with $\langle 001\rangle$ come first and next the ones making larger angles, with the understanding that when two or three specimen axes make approximately the same angle with the <001>, the one making the smallest angle to the line [001]-[111] will be presented first. When the results are presented in this order, it is seen that the $\Delta G$ effect decreases and the $\Delta E$ effect increases as the angle between the specimen axis and <001> increases (in the same manner as $E$ and $G$ ). This is only a qualitative description when other factors, which have smaller influences on this general picture, are neglected. This point will be further discussed in chapter VI.

In fig. 75 the influence of mechanical twinning is seen after a strain of 0.34 where the familiar audible effects show that the deformation continues by twinning.

Fig. 78 demonstrates the influence of the initial damping on the $\Delta E$ effect. Three curves are presented of specimens with the same orientation (No. 5) but different initial damping. It is not simple to compare the results of specimens with different initial damping as we would expect them to have different initial dislocation densities and as a consequence different $\Delta E / E(\varepsilon=0)$ value. As all three curves reach a saturation value for $\varepsilon>0.40$ and as it is probable that after a deformation of this magnitude the influence of the initial dislocationstructure is wiped out, it was assumed that the saturation level for $\varepsilon>0.40$ is the same for all three specimens. This means that for the specimen with $\mathrm{C}^{-1}=7 \cdot 10^{-4}$ and $8 \cdot 10^{-4}$ initial modulus effect $\triangle E / E(\varepsilon=0)$ had to be assumed to be 0.038 and respectively 0.045 larger than the $\Delta E / E(\varepsilon=0)$ of the specimen with $Q^{-1}=1.10^{-4}$. Values of $\Delta E / E(\varepsilon=0)$ of this magnitude have been found in copper single crystals from irradiation experiments by Thompson et.al. (1955). 


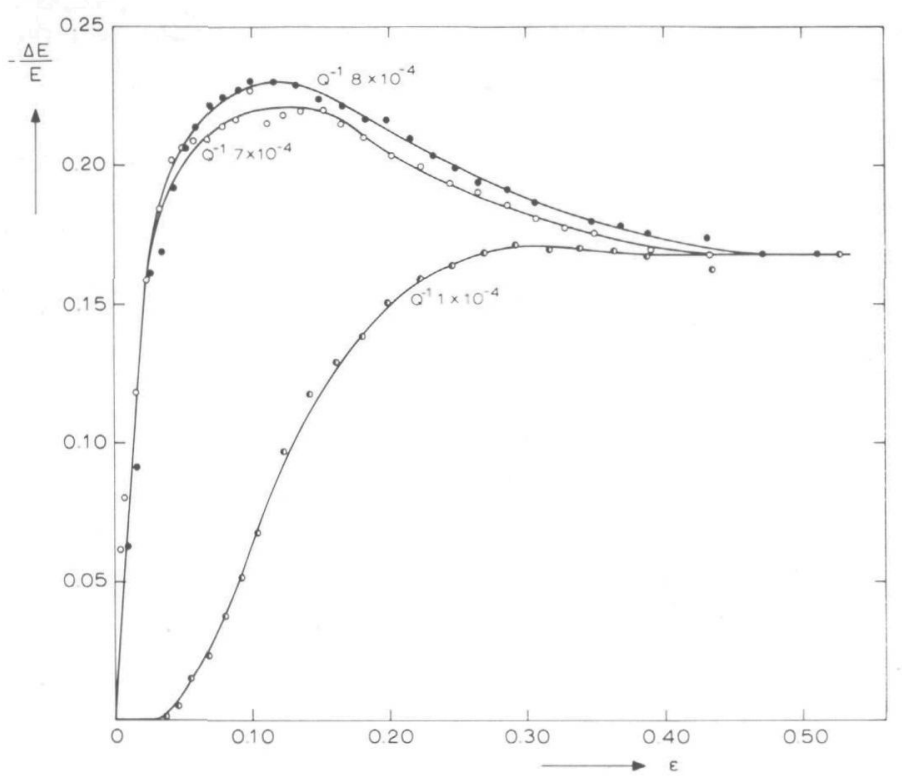

Fig. 78 - $\Delta E$ effect of three specimens of orientation No. 5 with different initial damping.

The influence of the initial damping on the $\Delta G$ effect is shown in fig. 79. The result is analogous to that on $\Delta E$ (see fig. 78).

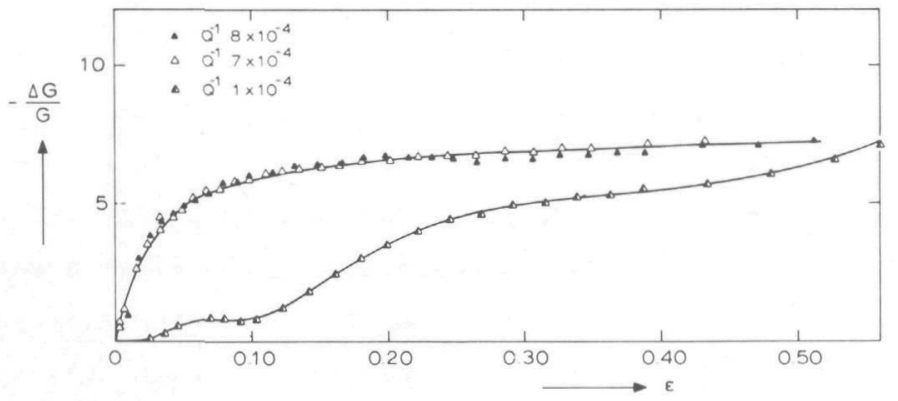

Fig. 79 - $\Delta G$ effect of three specimens of omientation No. 5 with different initial damping. 
Finally one remarkable result of the change of $E$ will be reported. Two of the specimens of orientation No. 5 with subboundaries (see fig. 2) were used in modulus measurements and the result of one is shown in fig. 80. It is seen that while the $\Delta G$ effect is similar to the one with low initial damping (compare with fig. 77 and 79), the $\triangle E$ effect is larger by a factor 3 . The initial damping was $3.10^{-4}$ and $56 \cdot 10^{-4}$ in torsion and flexure respectively. The results of the second specimen with subboundaries were similar.

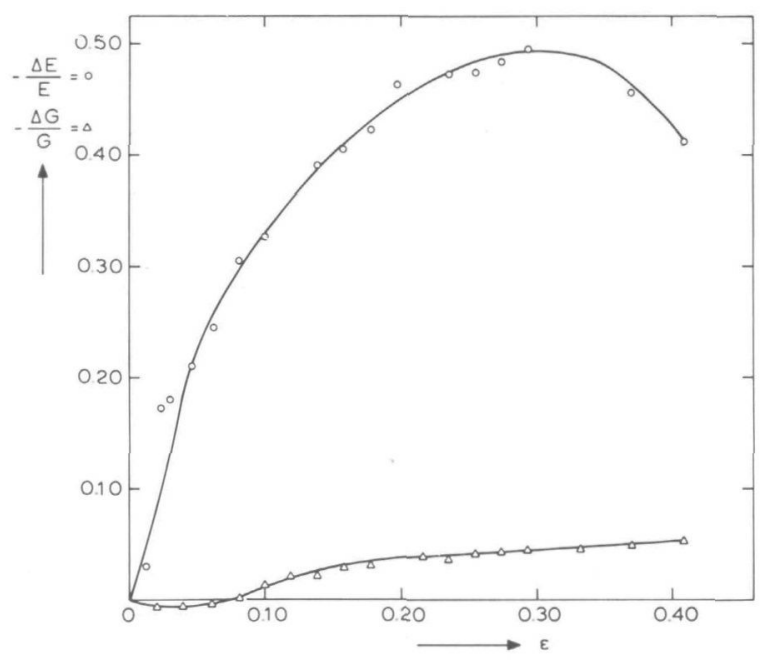

Fig. $80-\Delta E$ and $\Delta G$ effects of a specimen of orientation No. 5 with subboundaries.

\section{V.4.4 Recovery measurements}

Recovery measurements at room temperature have been made only on specimens of $\langle 111\rangle,\langle 001\rangle$ and orientation No. 3. After a certain deformation the specimens were warmed up to room temperature and kept there for about 60 hours. Then they were cooled down again to $78 \mathrm{~K}$ and the deformation and measurements were continued.

In all cases the annealing treatment results in a recovery of the modulus effects to about $25 \%$ of the value prior to annealing. 
$\Delta E$ and $\Delta G$ effects as a function of plastic extension and the influence of annealing at room temperature of specimens:

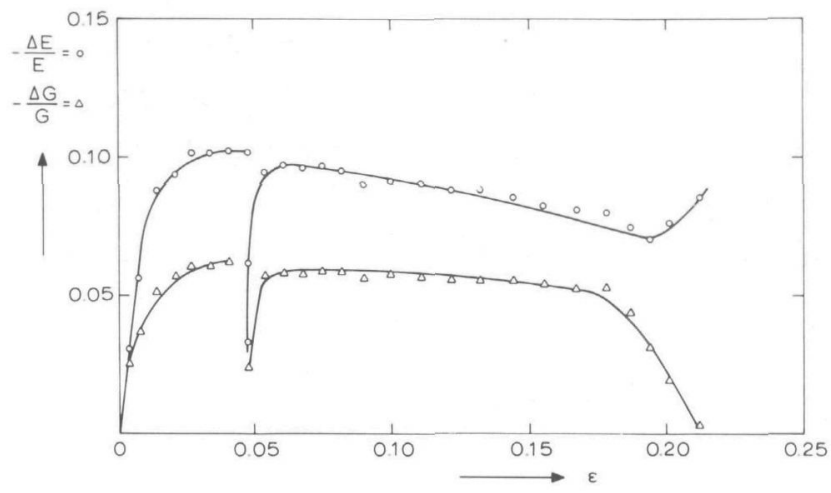

Fig. $81-\langle 111\rangle$ orientation.

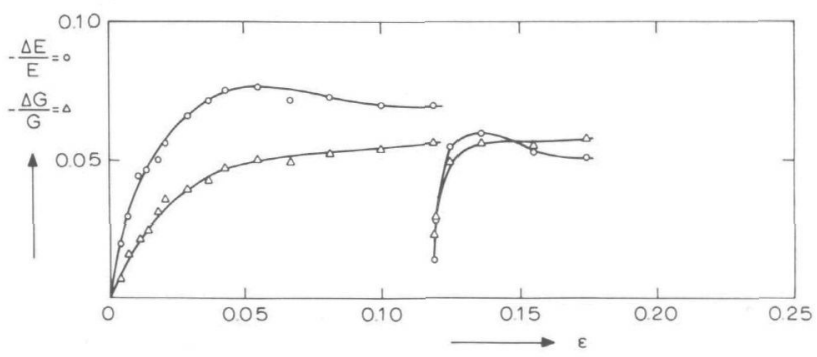

Fig. $82-<001>$

orientation.

Fig. 83 -

orientation No. 3.

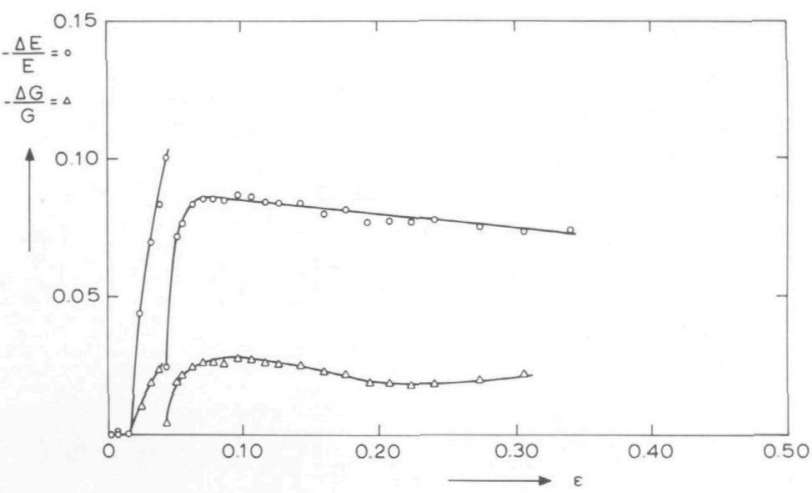


The effect of recovery is undone, partially or completely, by further deformation at $78 \mathrm{~K}$.

In the case of the $<111>$ oriented specimen, after $1 \%$ additional strain, both the $\Delta E$ and $\Delta G$ effect curves continue the course they had prior to the annealing treatment (see fig. 81). In the case of $<001>$ and orientation No. 3 the $\Delta G$ effect is continuous also, but the $\triangle E$ effect remains somewhat smaller than the value extrapolated from the pre-annealing curves (see fig. 82 and 83).

Intemal friction as a function of plastic extension in two specimens of orientation No. 5.

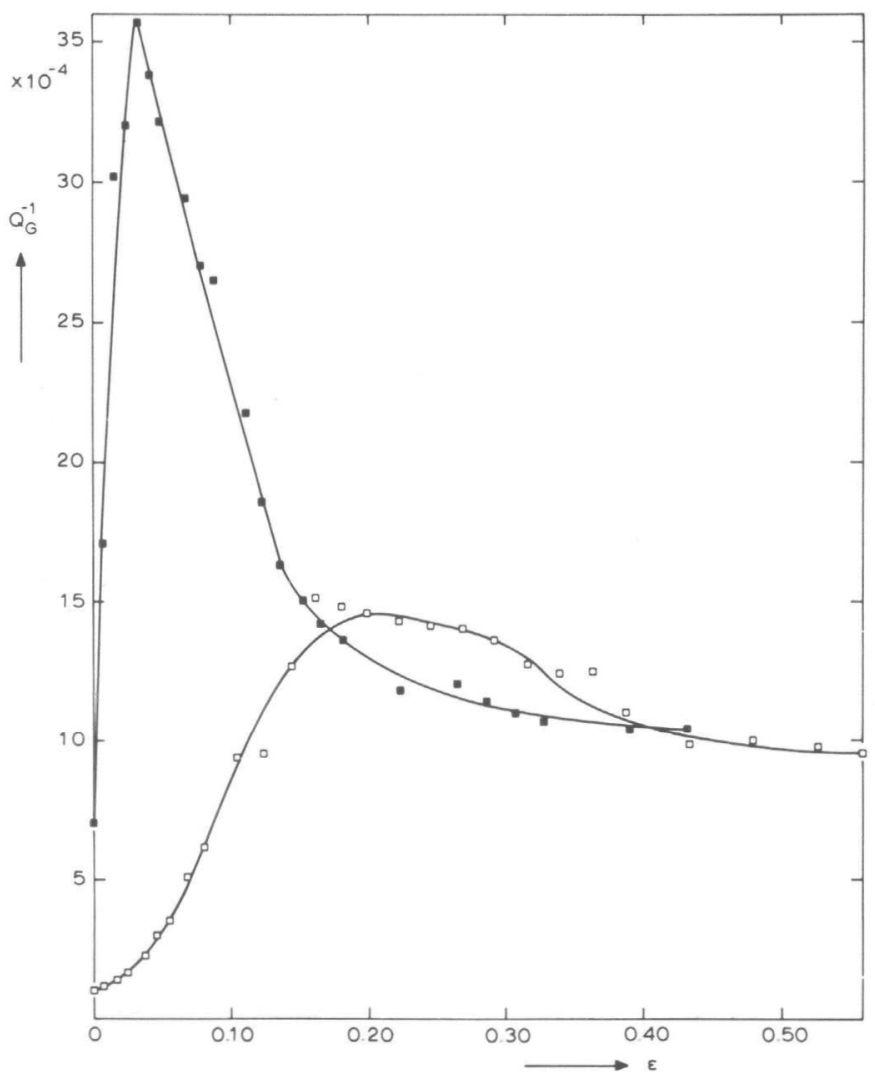

Fig. $84-$ In torsion. 


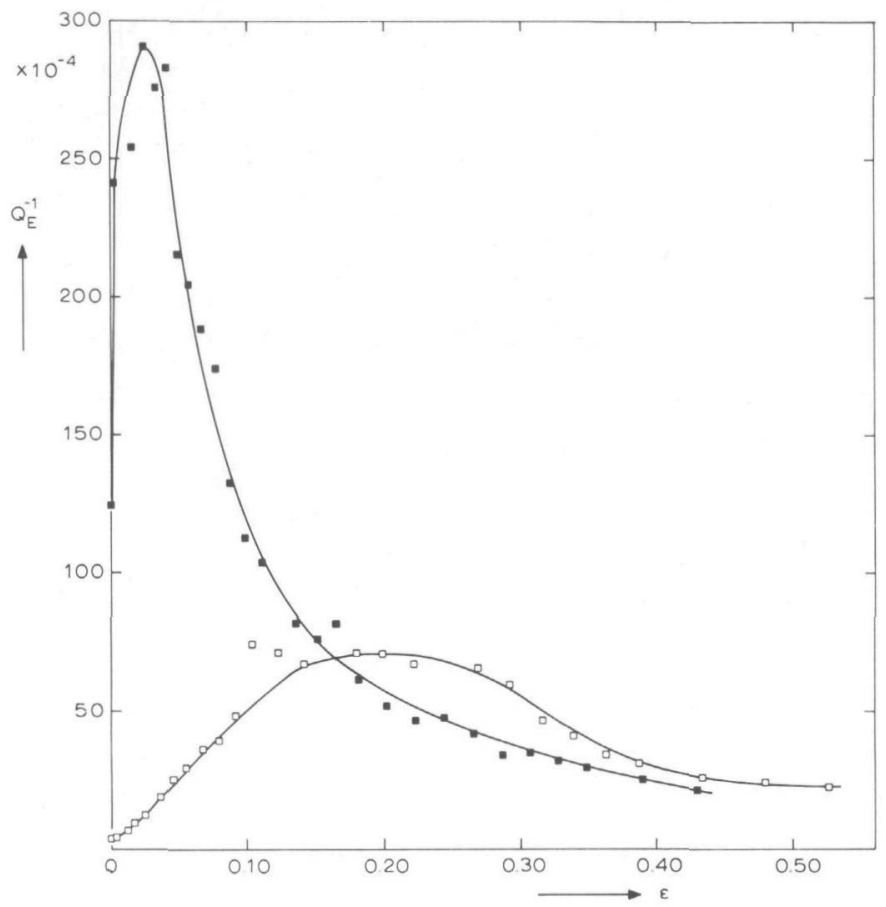

Fig. 85 -

In flexure.

\section{V.4.5 Change of internal friction by plastic extension}

The results on the change of the internal friction as a. function of strain are not sensitive to orientation but are different for specimens with different initial damping. There is also a difference in the value of the effects whether the internal friction is measured in torsional or flexural oscillations.

Fig. 84 and 85 show the change in internal friction as a function of plastic extension of two specimens of orientation No. 5, measured in torsional and in flexural oscillations respectively. The results for the two specimens with initial damping of $1 \cdot 10^{-4}$ and $7 \cdot 10^{-4}$ are, although qualitatively analogous (contrary to the $\Delta E$ and $\Delta G$ effects which are not), rather different in quantitative respect. The height of the maximum increases and shifts to lower values of the strain for increasing initial damping. For large strains $(\varepsilon>40 \%)$ the results of both specimens become about the same. The results of specimens in other orientations are similar. 


\section{VI \\ discussion}

VI. 1 INTRODUCTION

The primary purpose of the present work was to measure the change of the elastic modui $i$ and the internal friction of copper single crystals as a function of plastic strain, which might provide information on the dislocation structure. In order to isolate the effect of dislocations on the elastic moduli, it appeared necessary to investigate also the influence of the change of crystal orientation during plastic deformation as well as the effect of mechanical twinning on the elastic moduli (chapter $V .2$ and $V .3$ respectively). As dislocation structure and work hardening behaviour are closely related, the stress-strain curves of all specimens investigated were measured (chapter V.1).

From the conclusions of chapters V.1 to V.3 those which are important to the discussion of the results of modulus and damping experiments will be briefly summarized:

1) From the similarity of the influence of low initial dislocation density and low initial damping on the stress-strain curve it is concluded that the initial damping is, although indirectly, a measure of the initial dislocation density.

2) The initial damping influences the process of plastic extension of copper single crystals not only in the "easy glide" region but even during stage $\mid$ I.

3) The orientation of the specimen axis in the region where "single slip" is predicted, changes until the orientation reaches the [001]-[ī11] line.

4) When the axis orientation is on the [001]-[111] line, after deformation or from the beginning, this orientation does not change in the direction of [ $\overline{1} 12]$ as predicted. As a consequence the "crystallographic effect" (see section V.2) is small and can be 
neglected.

5) Single crystal specimens with an axis orientation in or near the $<111\rangle$ and in the <011> directions deform by mechanical twinning after a relatively small extension.

6) When copper single crystals are loaded in torsion they also deform partially by mechanical twinning.

It was shown in section V.4 that mechanical twinning has an appreciable effect on the moduli of elasticity and in this chapter a somewhat more quantitative discussion will be given.

The change of the moduli of elasticity and the internal friction as a result of slip i.e. the motion and multiplication of dislocations will be discussed in order to explain the differences in the size of the measured effects and to verify the applicability of the Köehler-Granato-Lücke theory.

\section{V.2 THE INFLUENCE OF MECHANICAL TWINNING ON THE ELASTIC MODULI}

From the law of twin transformation is it possible to calculate the new orientation indices $\vec{a}^{\prime}\left(A^{\prime} \vec{i} ; B^{\prime} \vec{j} ; C^{\prime} \vec{k}\right)$ of a part of a single crystal specimen $\vec{a}(A \vec{i} ; B \vec{j} ; C \vec{k})$ which has undergone a twinning transformation using the following equations (private communication of P. Penning):

$$
\begin{aligned}
& A^{\prime}=A-2 P \frac{\vec{a} \cdot \vec{m}}{|\vec{m}|^{2}} \\
& B^{\prime}=B-2 Q \frac{\vec{a} \cdot \vec{m}}{|\vec{m}|^{2}} \\
& C^{\prime}=C-2 R \frac{\vec{a} \cdot \vec{m}}{|\vec{m}|^{2}}
\end{aligned}
$$


in which $\vec{m}(P \vec{i} ; Q \vec{j} ; R \vec{k})$ is the normal to the twinning plane.

In fcc single crystals the twinning plane is a $\{111\}$ plane and the twinning direction is $<112>$. As there are four different $\{111\}$ planes there are also four possible twin orientations in a fcc crystal, but as the modulus of elasticity is only dependent on the axis orientation, in the following discussion a twin orientation will be considered different only if the indices are different. For the same indices all the permutations will be considered as the same orientation because they have the same $E$ and the same reflections in an $x$-ray photograph made with the rotating specimen method.

According to this rule the three symmetric orientations have only one twin orientation: the <001> with twin orientation <122>, the $<111>$ with twin orientation $<115>$ and $<011>$ with twin orientation $<114>$.

Using the compliance constants given in chapter 111 page 40 and formulae $(3-5)$ and $(3-5 A), E$ and $G$ of the matrix and twin orientation were calculated. The results are given in table VI.

Table VI.

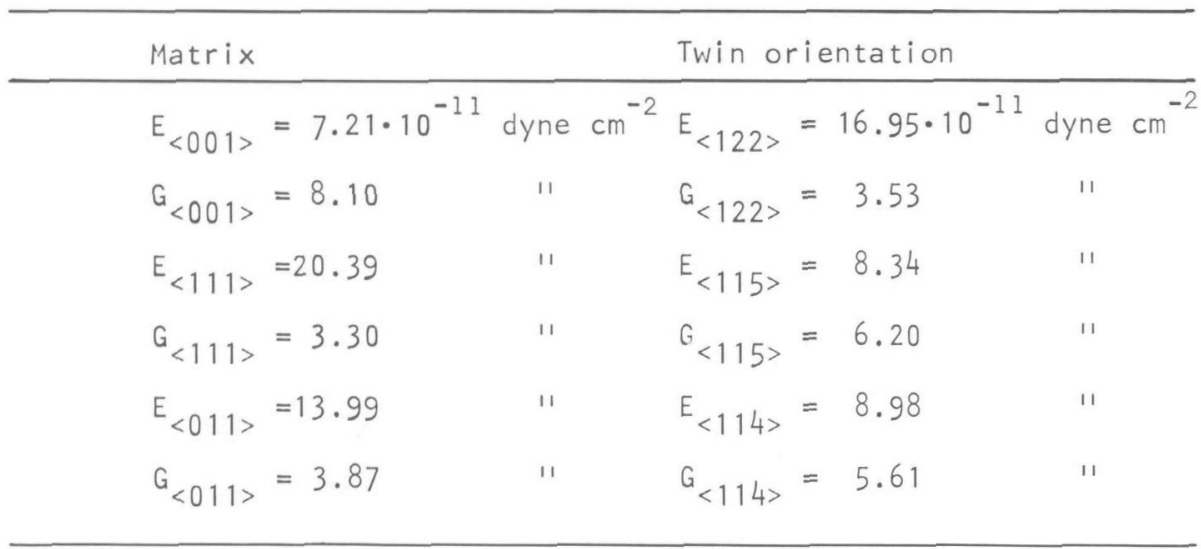

First the case of one twin transformation will be discussed using a simple coupling. If two specimens one of length $\ell_{1}$ with $E_{1}$ and the 
second with length $\ell_{2}$ and $E_{2}$ are joined together in series and the modulus of Young $E$ of this specimen is measured then the following relation between $E, E_{1}, E_{2}, \ell_{1}$ and $\ell_{2}$ (neglecting $\nu$ ) is found:

$$
\frac{1}{E}=\frac{l_{1}}{\ell} \frac{1}{E_{1}}+\frac{l_{2}}{\ell} \frac{1}{E_{2}} .
$$

$\left(l=l_{1}+l_{2}\right)$.

When, as a result of mechanical twinning, a single crystal of length $\&$ (with $E_{2}$ ) changes its orientation over a part $\ell_{1} / \ell$ (with $E_{1}$ ) and over a part $1-\ell_{1} / \ell$ has not changed, then the new $E$ of the specimen is given by $(6-4)$ and the change in $E$ is:

$$
\frac{\Delta E}{E}=\frac{E-E_{2}}{E_{2}}=\frac{1}{\left(1-\frac{l}{l}\right)+\frac{l_{1}}{l} \frac{E_{2}}{E_{1}}}-1
$$

from which the twinned part is found to be:

$$
\frac{\ell_{1}}{\ell}=\frac{\frac{\Delta E}{E}}{\left(1+\frac{\Delta E}{E}\right)\left(1-\frac{E_{2}}{E_{1}}\right)} .
$$

When two single crystals having cross-sections $A_{1}$ (with $E_{1}$ ) and $A_{2}$ (with $E_{2}$ ) are connected in parallel, then the relation between the measured $E$ of this specimen and $E_{1}, E_{2}, A_{1}$ and $A_{2}$ (neglecting $v$ ) is found to be:

$$
E=\frac{E_{1} A_{1}+E_{2} A_{2}}{A_{1}+A_{2}} .
$$

In a crystal were extensive mechanical twinning has taken place, there is a quasi-homogeneous distribution of twins in the specimen. We can consider the specimen as formed by a large number of bars joined in parallel and having a cross-section as small as the thinnest twin present. In every bar we then can calculate the resulting $E$ by use of formula $(6-4)$. As it was assumed that the distribution of twins in the specimen is quasi-homogeneous, then the effective $E$ of 
each bar will be the same and also equal for all the bars joined in parallel. As a consequence it is concluded that formula (6-6) alone enables us to calculate the part of a specimen that is filled with twins in all experiments were $\triangle E / E, E$, and $E_{2}$ are known. Mechanical twinning was observed in the following cases:

1) After extension, prior to necking, in $\langle 111\rangle,\langle 110\rangle$ and orientation No. 3. In the case of <111> and orientation No. 3 this model was not applied because as a result of experimental difficulties the elastic moduli cannot be measured after a larger period of twinning. After a short period of mechanical twinning in extension, the number of twins is small and inhomogeneously distributed so that the only conclusion we can draw in these cases is that qualitatively the change in $E$ and $G$ is as expected. Although it was proved beyond doubt that the <011> specimens deform by mechanical twinning even after a small extension and at the end of the experiment they are filled with twins, the change of $G$ is contrary to expectation because $G$ decreases instead of increasing and the results of the different $<011\rangle$ specimens do not reproduce as well as the ones of specimens of all other orientations. 2) After torsion in $\langle 100\rangle$, $\langle 110\rangle$ and $\langle 111\rangle$ specimens. In these specimens is it possible to compare the calculated values with the experimental results as the moduli can be measured during a large period of mechanical twinning.

The twins and matrix in a specimen deformed in torsion are in the form of long bars, having a cross-section of a circle segment, which are twisted around one another. Therefore, when a twisted specimen is polished and etched the twinned part (fig. 56b) which can be seen on this plane gives a correct impression of the distribution of twins in the whole volume of the specimen. In this way the part filled with twins in a deformed specimen was estimated and compared with the calculated value found by use of $(6-6)$ and was found to be in good agreement.

It must be pointed out that after a larger period of mechanical twinning the primary twins can twin again, forming secondary twins 
and their influence on the elastic moduli is then reversed to that of the primary twins. This effect can be seen in fig. 64-66 where after large strains, $E$ and $G$ are almost constant indicating that the influence of the primary twins is compensated by the secondary twins.

No change in internal friction as a result of mechanical twinning was found as expected.

\section{VI.3 THE INFLUENCE OF ORIENTATION ON THE MODULUS EFFECT}

The considerable influence of orientation on the modulus effect as given in fig. 69-77 is most surprising and contrary to the expectation. It was expected that the multiplication of dislocations will not depend much on orientation and only the effective dislocation line length could be larger if the possibility for single slip is larger. Therefore the difference in $\Delta E$ effect between specimens of orientation No. 2 and No. 4, which have approximately the same initial damping and expectation of single slip seems incomprehensible. As it was already pointed out $(V .4 .3)$ that the dependence of $-\triangle E / E$ (and $-\Delta G / G$ ) on orientation is the same as $E$ (and $G$ ), this difference is reduced almost to zero if $\Delta E / E$ is replaced by $\Delta(1 / E) \simeq-\Delta E / E^{2}$. According to Penning (1973) this manner of presenting the results is reasonable because the extra shear-strain due to the dislocations is

$$
\varepsilon_{d}=\left(\frac{1}{E}-\frac{1}{E_{0}}\right) \sigma=\Delta\left(\frac{1}{E}\right) \sigma .
$$

Therefore the quantity $\Delta(1 / E)$ represents the contribution of dislocations to the elastic strain per unit stress. In order to get a dimensionless quantity we multiply $\Delta(1 / E)$ by the constant $E_{<111>}$. When the results are presented in this manner it is found that with the exception of orientations No. 5, No. 6 and No. 3 all the other orientations have approximately the same effect if the difference in 


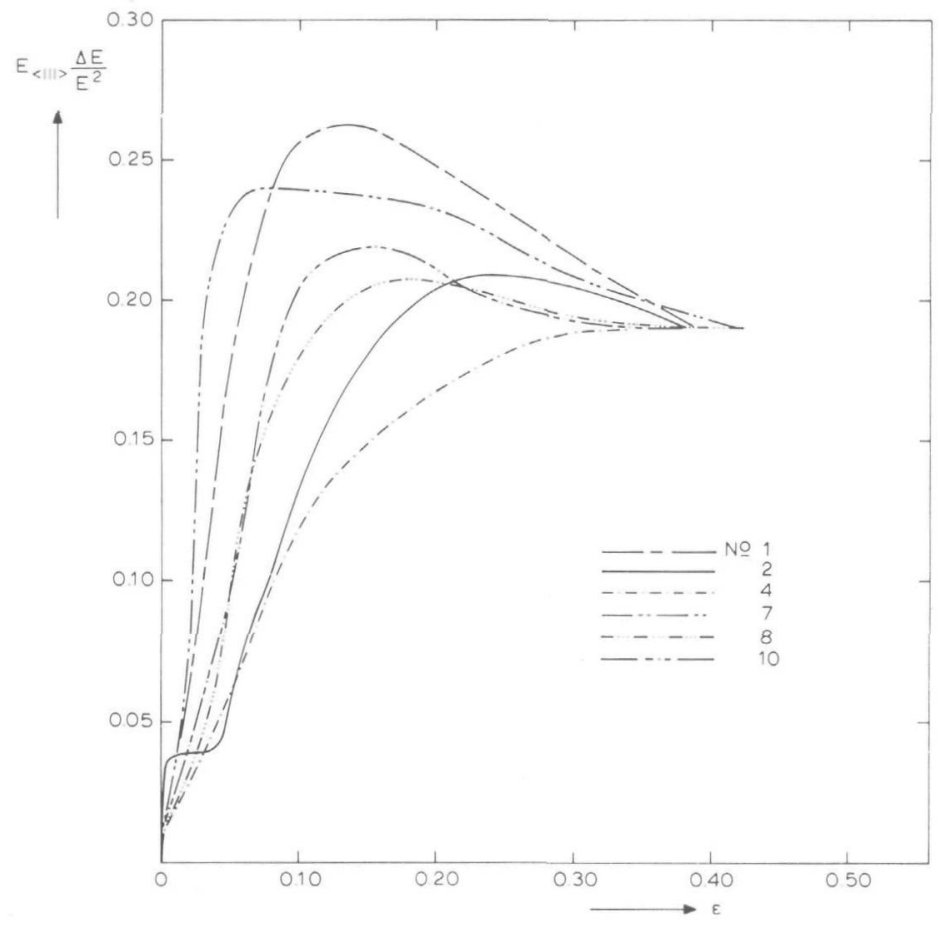

Fig. $86-E_{\langle 111\rangle} \cdot \Delta E / E^{2}$ of different orientations as a function of strain.

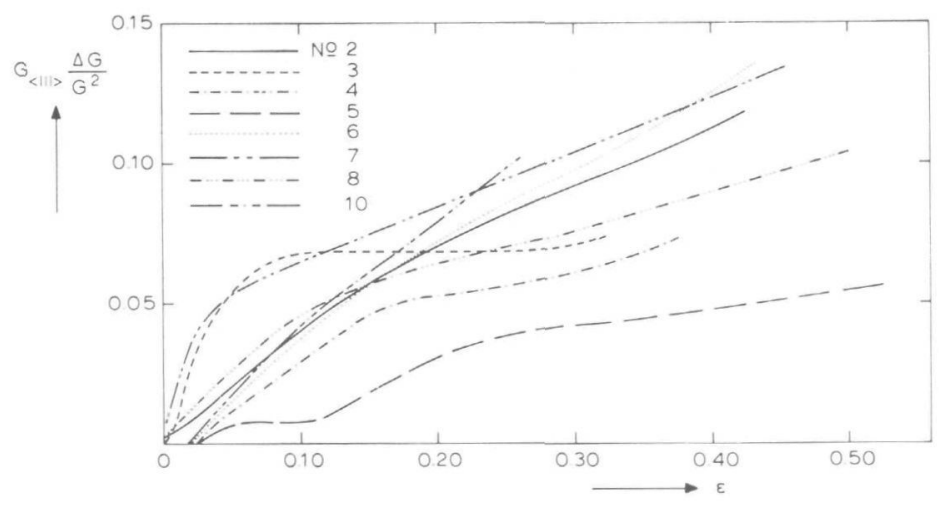

Fig. $87-G_{<111>} \cdot \Delta G / G^{2}$ of different orientations as a function of strain. 
initial damping is compensated as was done for the different specimens of orientation No. 5 (see fig. 78). These results are presented in fig. 86 but orientation No. 5 which is some $5 \%$ higher and No. 3 and No. 6 which are some 5\% lower are not in that figure. The reason for these differences is probably that specimens of orientation No. 5 have a higher expectation of single slip and therefore a higher $\Delta E$ effect. Specimens of orientation No. 3 which are near the symmetry line [111]-[011] and orientation No. 6 which is on the [001]-[111] line, have a high expectation for double slip and therefore a smaller effect.

When the $\Delta G$ effect is presented in the same way ( $\mathrm{fig} .87$ ) it can be seen that although the curves correspond less good than in fig. 86 the big differences have been considerably reduced. It is interesting to note that orientation No. 5 which has the largest $\Delta E$ effect shows the smallest $\Delta G$ effect.

VI.4 THE INFLUENCE OF DISLOCATION MULTIPLICATION ON THE ELASTIC MODULI E, G AND THE INTERNAL FRICTIION

The results presented in section $V .4$ will be analyzed by the theory of Köehler (1952) and Granato-Lücke (1956) based on the vibrating string model. This theory predicts both a modulus effect and internal friction as a result of dislocations vibrating, like strings, in a viscous medium. According to this theory a network with dislocation density $\Lambda$ and an effective dislocation line length $L$ gives rise to a decrease in Youngs modulus:

$$
-\frac{\Delta E}{E}=K \Lambda L^{2}
$$

and to an amplitude independent contribution to the internal friction

$$
Q^{-1}=f C \wedge L^{4} \text {. }
$$


$K$ and $C$ are constants and $f$ the frequency of the vibrating specimen.

This theory proved to be adequate for high frequencies but there are some discrepancies in the low frequency range. The constants calculated from high frequency experiments give wrong results when substituted in (6-7) and (6-8) for low measuring frequencies. Furthermore there are indications that in the low frequency range $Q^{-1}$ is independent of frequency (see e.g. Den Buurman and Weiner (1972)) contrary to (6-8). On the other hand there is evidence that equations (6-7) and (6-8) give the correct density and line length dependence also in the low frequency range.

As a result is it possible, from the change in $E, G$ and $Q^{-1}$ to calculate the relative change in $\Lambda$ and $L$. Before presenting the results of such a calculation, two factors which can influence these results will be mentioned:

1) Bordoni type effects could not be excluded from the experiments.

2) The initial modulus effect, resulting from the dislocations that are present in the undeformed specimen is unknown.

That Bordoni type effects are present in the results of the experiments can be deduced by the presence of a residual internal friction after high strains, when it can be expected that the dislocations are strongly pinned and therefore the internal friction should be minimal. A second indication to the presence of such effects is found in the experiments of Druyvesteyn and Blaisse (1962) who found a much smaller $\Delta \mathrm{E}$ effect at $4 \mathrm{~K}$ than at $78 \mathrm{~K}$. This problem has to be solved by performing a set of experiments at different temperatures between $4 \mathrm{~K}$ and $78 \mathrm{~K}$, in order to separate the temperature dependent part from the temperature independent one in the modulus effects and internal friction.

The second factor is not very serious as it was found that a variation of the initial modulus effect between reasonable limits does not change the result appreciably. The influence of the initial modulus effect on the calculated effective dislocation line length is important only at small plastic strains and vanishes after a few percent extension. 
By combining $(6-7)$ and $(6-8)$ we find:

$$
\begin{aligned}
& \Lambda=R \frac{\left(\frac{\Delta E}{E}\right)^{2}}{Q^{-1}} \\
& L=S \sqrt{\frac{Q^{-1}}{-\left(\frac{\Delta E}{E}\right)}},
\end{aligned}
$$

where $R$ and $S$ are constants and $\Delta E / E$ includes the initial modulus effect.

According to section $V I .3 \triangle E / E$ should be replaced by $-E_{<111>} \cdot \Delta(1 / E)$ and we get:

$$
\Lambda=r \frac{\left(E_{<111>} \cdot \Delta(1 / E)^{2}\right.}{Q^{-1}}
$$

and

$$
L=s \sqrt{\frac{Q^{-1}}{E_{<111>} \cdot \Delta(1 / E)}} .
$$

The change of $\Lambda / r$ as a function of strain calculated with (6-11) for four specimens (with low initial damping) of three different orientations (No. 2, 4 and 5) is presented in fig. 89. It can be seen that there is (for $\varepsilon>0.06$ ) a linear relation between the dislocation density and the strain and this relation is the same for all four specimens. The two specimens of orientation No. 6 (which have also a low initial damping) exhibit also a linear relation between the dislocation density and strain but the slope of the line is a little smaller than the slope of the line in fig. 88. It must be stressed here that at small strains, due to the inaccuracy of measuring the elongation, as was shown in chapter 111 , the deviation of the measured points from the line are largest. In these calculations, values of $10^{-4}$ have been assumed for $\Delta E / E(\varepsilon=0)$, and later on it will 
be shown how this estimation was done. If higher values, up to a few percent are assumed for $\triangle E / E(\varepsilon=0)$, this influences the curve only for strains smaller than 0.10 .

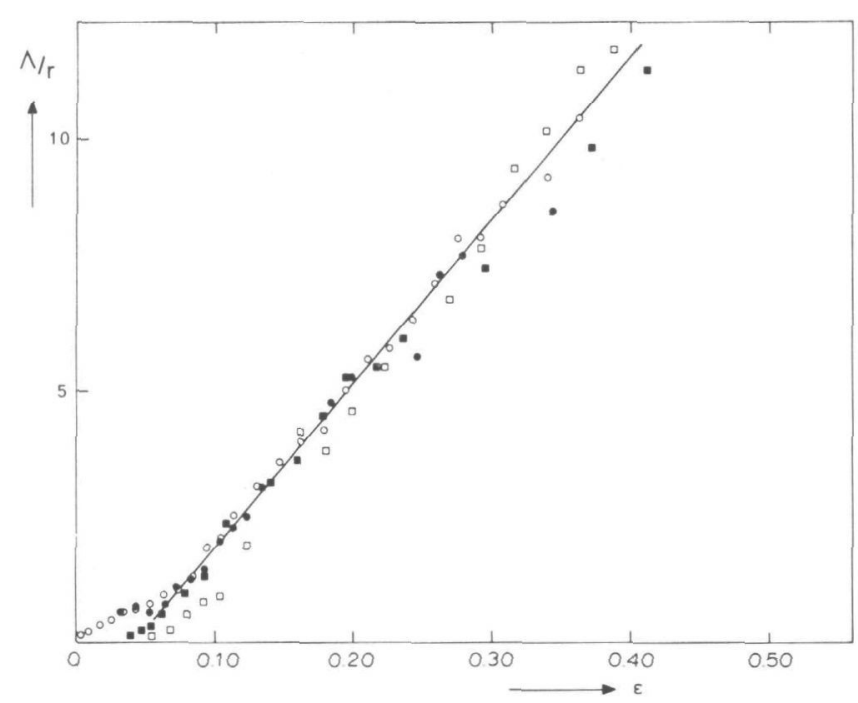

Fig. 88 - The chonge of dislocation density with strain of specimens with low initial damping of different omientations.

This result on the relation between the increase in dislocation density and strain is contrary to the current belief that the dislocation density is proportional to the square of the stress, because in the linear hardening region the dislocation density also increases linearly with strain. However, two papers published lately by H. Mughrabi (1971), U. Essman and M. Rapp (1973) also report a linear relation between the increase in dislocation density and strain, as measured directly from electron micrographs.

When the K.G.L. theory is applied to the change in $E$ and internal friction of specimens with higher initial damping (the initial modulus effect is estimated by equating the modulus effect of specimens, 
of the same orientation with low and higher initial damping after large strains) it is found that the calculated dislocation density is a linear function of strain, only up to an extension between $0.20-0.30$. For larger strains the calculated values deviate from this line and become constant or even show a decrease. In fig. 89 the results are presented for three specimens of orientation No. 5 , one (a) with an initial damping of $1 \cdot 10^{-4}$, one (b) with $Q^{-1}=8 \cdot 10^{-4}$ and the third (c) had a block structure (see fig. 2).

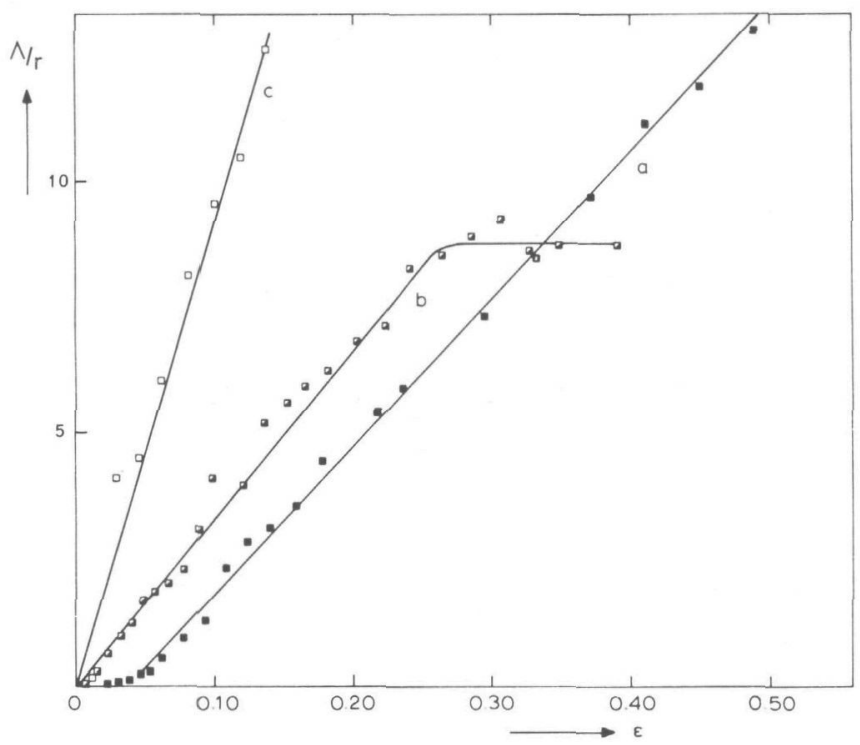

Fig. 89 - The change of dislocation density of three specimens of orientation No. 5 with different initial damping.

It can be seen that specimen a which had an extended easy glide region shows a very small increase of dislocation density for the first few percents of strain whereas the other two specimens exhibit the linear relation from the first measured point. A second difference is that for specimens with higher initial damping (higher 
initial dislocation density) the slope of the line is larger. As from direct observations of dislocations in strained crystals, a decrease of $\Lambda$ with strain is known to be contrary to reality, we assume that in the case of specimens with higher initial damping another effect influences the elastic moduli measurements or the initial damping or both.

By use of $(6-12)$ is it possible to calculate the change of the effective dislocation line length. The result for a specimen of orientation No. 5 is presented in fig. 90.

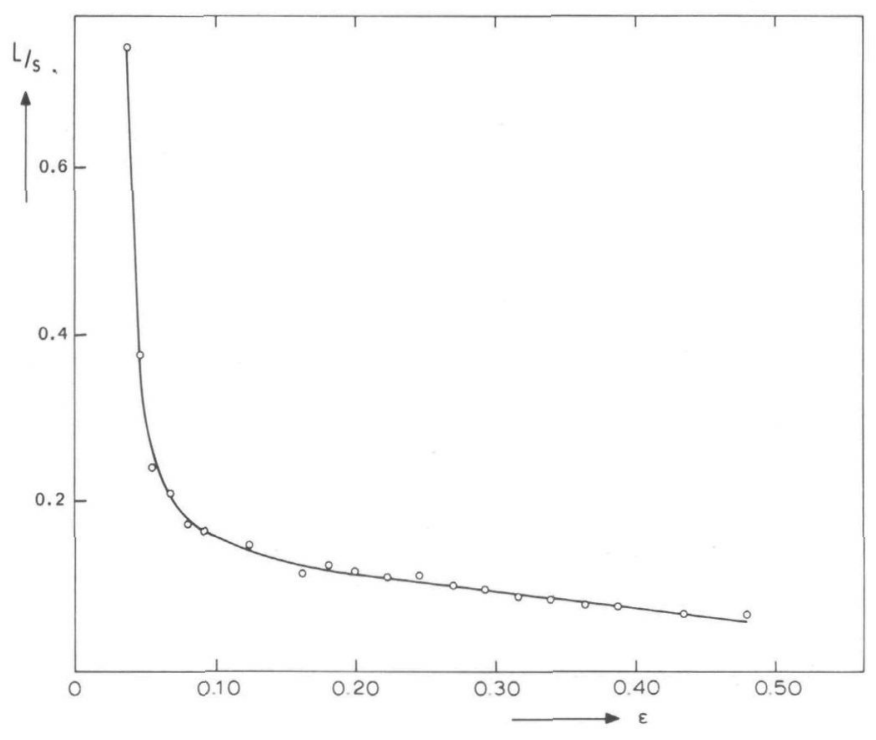

Fig. 90 - Change of the effective dislocation line length with strain of a specimen of orientation No. 5 with low initial damping.

The curve starts at a strain of 0.037 because at a lower strain the $\Delta E$ effect is practically zero in this specimen with low initial damping. Specimens with higher initial damping where a $\Delta E$ effect is found even at a very small strain give a similar result, the curve having the same character i.e. first a sharp decrease followed by a gentle decrease in line length. 
The form of the curve of the dislocation line length vs strain is similar to the one calculated by Van den Beukel and Brouwer (1968) from the results of measurements of the change in $G$ in polycrystalline specimens of copper and very dilute copper alloys, as a function of plastic torsion.

The influence of higher values for $\Delta E / E(\varepsilon=0)$ up to a few percent influence the change of the calculated line length only at small strains where the curve then shows first an increase in line length followed by a decrease. For strains higher than 0.10 all the curves, irrespective the $\Delta E / E(\varepsilon=0)$ assumed are practically parallel.

In their paper Essman and Rapp (1973) report that the reciprocal of the distance between successive layers of dislocations (cell wals) vs shear strain in stage 11 yields a straight line. When the reciprocal of $\mathrm{L} / \mathrm{s}$ is plotted vs strain (fig. 91) a linear relation is found.

For specimens with low initial damping a plot of the reciprocal of L/s vs strain in stage II and III always yields a straight line. However, for specimens with higher initial damping, deviations are observed at high strains which correspond to the deviations from a straight 1 ine found in the relation between $\Lambda / r$ vs strain. In fig. 91 we see that the line is straight only for $\varepsilon>0.08$ and in table III it can be seen that for a specimen of orientation No. 5 with low initial damping, stage 1 ends at $\varepsilon=0.082$ showing a correlation in this case between the indirect measurements and the stages of work hardening.

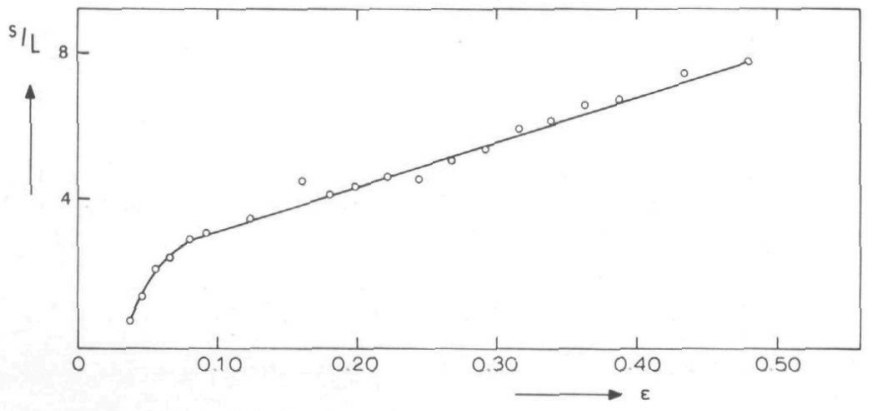

Fig. 91 - Change of the reciprocal of the effective line length of the same specimen as in fig. 90 . 
From this result we can conclude that there is probably a relation between the calculated effective dislocation line length and the size of the cells in copper, which are known to form only in stage II and $|1|$.

There is a difference in internal friction as measured in torsion and flexure as can be seen in fig. 84 and 85 . If the ratio between the internal friction as measured in flexure and torsion is plotted as a function of strain (fig. 92) it can be seen that for small strains this ratio is high but for larger strains it reaches a constant value (in all cases $2 \pm 0.7$ ). For higher initial damping the maximum of this ratio is also higher but the ultimate value is always approximately the same.

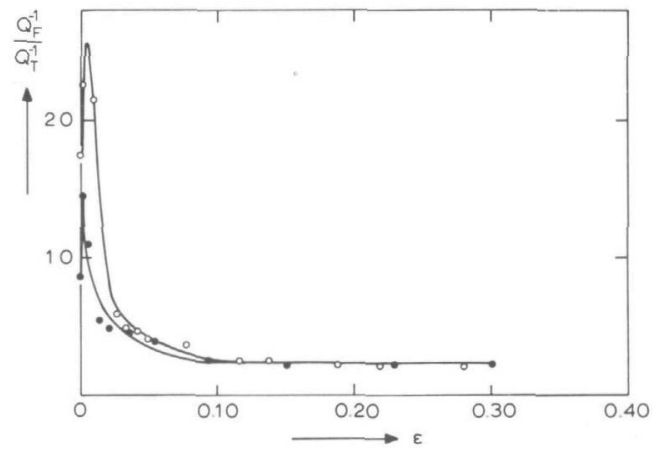

Fig. 92 - The ratio of intemal friction as measured in flexure $Q_{F}^{-1}$ and in torsion $Q_{T}^{-1}$ as a function of strain.

This effect can be explained qualitatively in the following manner: at small strains long dislocations are formed mainly in the primary slip system. When damping is measured in flexure the state of strain is the same as during deformation. If, following De Kock, Crans and Druyvesteyn (1965) we assume that the burgers vectors of the dislocations produced are preferably in the direction of maximum 
shear stress, the force on the dislocation is maximal when the applied stress in the damping experiment is in the same direction as during deformation. Therefore in specimens deformed by elongation dislocations will bow out more in flexural than in torsional damping. As a result the internal friction in flexure is larger than in torsion for a specimen deformed in extension, whereas for specimens deformed in torsion the reverse was observed. A similar effect was found also by Brouwer (1965) in measuring the change of $E$ and $G$ during the deformation of polycrystalline specimens of copper in torsion and extension. The size of the $\Delta E$ and $\Delta G$ effect was found to be related to the manner of deformation. For example, after deformation in torsion, where supposedly the burgers vectors of the formed dislocations make an angle of $90^{\circ}$ or $0^{\circ}$ with the axis, the $\Delta G$ effect which is measured by torsional oscillations is larger than the $\Delta E$ effect which is measured in flexure and vice versa. Also during the present investigation for low strains the same effect was observed. For this reason the K.G.L. analysis was applied to the change in $E$ and internal friction as measured in flexural oscillations on specimens deformed in extension. When the same aralysis is applied to the change in $G$ and internal friction as measured in torsional oscillations then the results are a little more complicated. For all specimens with low initial damping the calculated dislocation density shows also a linear or a bilinear relation with strain (i.e. first a linear relation with a low slope then one with a higher slope). However, for specimens of different orientations the slopes of the lines are different. For specimens with higher initial damping deviations occur analogous to those found in the case of the calculations from $\triangle E$.

$\Delta E / E(\varepsilon=0)$ was estimated in the following way. It was assumed that the undeformed specimen of orientation No. 4 had an initial dislocation density of $10^{4} \mathrm{~cm}^{-2}$ and after an extension of 0.01 $\Lambda=10^{7} \mathrm{~cm}^{-2}$. This assumption is reasonable as it was already reported in section 11.1 that the dislocation density, as found by counting etch pits, was even lower than $10^{4} \mathrm{~cm}^{-2}$. About the second 
assumption, it was found by several investigators (see for example Hordan (1962)) that after 0.01 extension the dislocation density is $\simeq 10^{7} \mathrm{~cm}^{-2}$. This latter fact is also demonstrated in fig. 93 where a specimen of the [011] orientation was bent in the [110] direction, then polished to reveal a $(1 \overline{1} 1)$ plane and etched in $\left(\mathrm{NH}_{4}\right)_{2} \mathrm{~S}_{2} \mathrm{O}_{8}$.

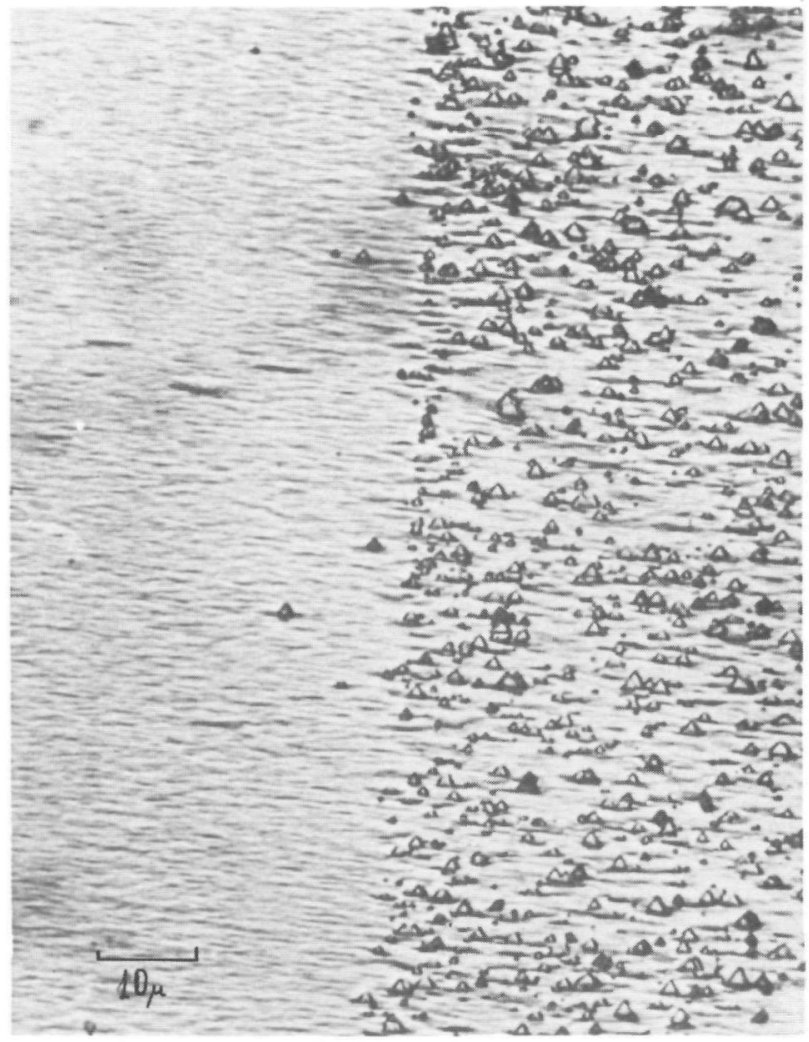

$$
\begin{aligned}
\text { Fig. } 93 \text { - } & \text { Etch pits in a lightly } \\
& \text { deformed copper single } \\
& \text { crystal. }
\end{aligned}
$$

It can be seen that in this case there is a sharp transition from deformed to undeformed material. Whereas in the deformed part there is a dislocation density of $\simeq 10^{7} \mathrm{~cm}^{-2}$ on the lefthand side the dislocation density is too small to be determined at this magnification $(1000 \mathrm{x})$. 
With this assumption we find:

$$
\frac{\Lambda(\varepsilon=0.01)}{\Lambda(\varepsilon=0)}=\frac{\left[\frac{\Delta E}{E}(\varepsilon=0.01)+\frac{\Delta E}{E}(\varepsilon=0)\right]^{2} Q_{(\varepsilon=0)}^{-1}}{\left[\frac{\Delta E}{E}(\varepsilon=0)\right]^{2} Q_{(\varepsilon=0.01)}^{-1}}=10^{3} .
$$

From this equation we calculate $\Delta E / E(\varepsilon=0)$ and the values found in this way are in the range of $10^{-4}$ for specimens with low initial damping. These values are reasonable as Naundorf (1973) reports that undeformed copper single crystals which were irradiated with electrons until all dislocations were pinned and $G$ did not increase any more, had an internal friction of $0.5 \cdot 10^{-4}$. The specimens which in the present investigation were labeled "low initial damping" had values of the internal friction between $0.8 \cdot 10^{-4}$ and $1.7 \cdot 10^{-4}$ which do not differ much from the values given by Naundorf of specimens where the modulus effect is practically zero.

As a result of this discussion it can be concluded that by measuring the change in E, G and internal friction as a function of strain in copper single crystal specimens of low initial damping qualitative insight in the increase in dislocation density, change in line length and cell size can be obtained by use of the KöehlerGranato-Lücke theory.

VI.5 A QUALITATIVE DISCUSSION OF SOME ASPECTS OF EASY GLIDE

There are a number of experimental results reported in literature and the present investigation on work hardening in "easy glide" for which a qualitative discussion will be given.

The experimental results are:

1) There is a minimum in the extent of "easy glide" as a function of dislocation density when $\rho_{0}<10^{6} \mathrm{~cm}^{-2}$ (see Hildebrand (1972)).

2) After a very small predeformation (in a different slip system) $\theta_{1}$ increases (Paxton and Cottrell (1954), Rebstock (1957)) which 
was verified by us.

3) Specimens of orientation No. 6 ([ $\overline{1} 14]$ ) have an "easy glide" stage

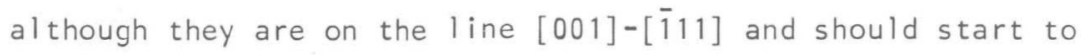
deform at least on two slip systems at the same time.

Stage I (easy glide) is often identified with single slip. However, for crystals of many orientations, especially those near the boundaries of the stereographic triangle, traces of slip on other systems have been detected during stage I. According to KuhlmannWilsdorf stage I persists as long as in certain areas within the crystal dislocations can move on different slip systems without mutually blocking their paths. The probability of encounter of dislocations on different slip systems and the consequent formation of barriers increases during stage I deformation, leaving less and less areas where dislocations can move over large distances wi thout being hindered by fixed barriers. If no more such areas are left, stage II begins.

In the light of this model the experimental results 1) to 3) can be discussed as follows. If the specimen is predeformed by a mode of deformation different from the subsequent deformation, many dislocations on other slip systems will be introduced. The areas where dislocations can move without hinder will be filled up quicker, requiring a faster increase of stress and therefore a larger $\theta_{1}$ results (result 2)). Result 3) directly fits in the model, because for low enough dislocation densities the activity of more than one slip system at the same time is not prohibitive for the occurrence of easy glide. Finally result 1) can be understood directly as far as the part at the lowest dislocation densities is concerned: with increasing initial density the probability of encounter will increase and therefore the extent of easy glide will decrease. The existence of a minimum is more difficult to explain. It has been found (see e.g. Garstone et.al. (1956) and Clarebrough and Hargreaves (1959)) that hardening of the crystal by increasing impurity concentration or by decreasing the temperature results in a larger extent of easy 
glide. Perhaps the same effect occurs beyond the minimum in the $\varepsilon_{1}$ vs $\rho_{0}$ curve, due to the hardening effect of the dislocations, which now act as forest dislocations. This effect has been explained (Clarebrough and Hargreaves (1959)) by assuming that due to the hardening the critical resolved shear stress for dislocation motion on large scale in the primary and secondary slip systems increase proportionally, which, for equal $\theta_{1}$ should lead to an increase of $\varepsilon_{1}$. 


\section{summary}

Plastic extension of single crystals will give rise to a change of the elastic moduli E (Young's modulus) and G (shear modulus) for the following reasons:

1) Due to the deformation the orientation of the crystal axis changes and this induces changes in $E$ and $G$ because they are dependent on orientation (the "crystallographic" modulus effect).

2) If deformation takes place partly by the process of mechanical twinning, part of the crystal changes its orientation and for the same reason as sub. 1) the moduli will change.

3) The dislocations produced by plastic deformation will bow out under a small applied stress causing an extra elastic strain and therefore a decrease of the elastic moduli. According to theory this modulus effect $\Delta(1 / E) \sim \Lambda L^{2}$ where $\Lambda$ and $L$ are dislocation density and line length respectively.

The internal friction of the deformed crystal only changes due to the dislocations produced and its magnitude is $Q^{-1} \sim \Lambda L^{4}$.

In the present investigation the change of the elastic moduli and internal friction of copper single crystals of various orientations during deformation at $78 \mathrm{~K}$ was measured. The crystals were grown from 99.999\% copper wire by a modified Bridgeman-Stockbarger method. The initial dislocation density was $10^{3}-10^{6} \mathrm{~cm} / \mathrm{cm}^{3}$ and the initial damping $0.6-20 \cdot 10^{-4}$. The elastic moduli and internal friction were measured by standard methods.

First the "crystallographic" modulus effect was investigated. During extension the orientation of the crystal first moves towards the $[001]-[\overline{1} 11]$ symmetry line. Contrary to the prediction, slip on more than one slip system occurs. The modulus changes on this path are small, in accordance with calculation. The major changes of the moduli should occur after reaching the symmetry line, where due to double slip the orientation should move towards [i112]. However, it 
was found that the change in orientation was only a fraction to the magnitude predicted on the basis of double slip and the corresponding "crystallographic" modulus effect is negligible.

In a number of orientations the start of mechanical twinning is observed both by audible clicks and by serrations on the stressstrain curve. The corresponding changes of $E$ and $G$ are qualitatively as expected. In a special case the fraction of the crystal volume filled with twins was estimated from the modulus change and found to be in fair agreement with the observation.

The remaining modulus effects, together with the internal friction, were attributed to dislocations and analyzed in terms of the formulae given. It was found that the dislocation density for $\varepsilon>0.10$ is linear with plastic strain. The reciprocal of dislocation line length in the same range also varies linearly with plastic strain. These results come from crystals with low initial damping. For specimens with high initial damping deviations are found which are not understood. The influence of crystal orientation on the computed dislocation density and line length is small.

A separate chapter (V.3) is dedicated to some aspects of mechanical twinning in plastic deformation. The main findings are:

1) Copper single crystals of $\langle 110\rangle$ orientation start to deform by mechanical twinning at a resolved shear stress smaller by an order of magnitude than for all other orientations investigated. In this case twinning is not accompanied by audible clicks or visible serrations on the stress-strain curve.

2) The mode of necking and fracture in copper single crystals depends on whether twinning occurs or not. In the former case fracture seems to take place by shearing over a single plane. In fact fracture occurs in a thin twinned layer.

3) In copper single crystals deformed in tension at 78K, twinning starts at about the same strain where fracture occurs when the deformation takes place at room temperature. In general in fcc crystals twinning makes possible higher strains to fracture.

4) After severe deformation in torsion helical grooves were observed 
on the surface of all copper crystals investigated. If the crystal axis has n-fold symmetry $n$ parallel spirals were found. The grooves correspond with twins.

Some of the results of this work have been published in:

D. Weiner, Mechanical twinning in Cu single crystals, Acta Met. 20 (1972) 1235.

D. Weiner, The relation between mechanical twinning and strain to fracture in fcc single crystals, Scripta Met. 6 (1972) 1149. 


\section{samenvatting}

Plastische verlenging van éénkristallen veroorzaakt een verandering van de elasticiteitsmodulus $E$ en de torsiemodulus $G$ om de volgende redenen:

1) Door de deformatie verandert de orientatie van de kristalas en daar de elastische moduli orientatie-afhankelijk zijn, zullen ze veranderen (het "kristallografisch" modulus effect).

2) Wanneer de vervorming gedeeltelijk plaats vindt door het proces van mechanische tweelingvorming verandert een gedeelte van het kristal van orientatie en daarom de moduli (zie 1)).

3) De dislokaties die tijdens de plastische deformatie worden gevormd, zullen uitbuigen wanneer een kleine uitwendige spanning wordt aangelegd. Daardoor treedt een extra elastische rek op en zullen de moduli afnemen. Volgens de theorie is dit modulus effect $\Delta(1 / E) \sim \Lambda L^{2}$ waarin $\Lambda$ en $L$ resp. de dichtheid en lijnlengte der dislokaties voorstellen.

De inwendige demping van een kristal zal tengevolge van plastische deformatie niet door kristallografische effecten worden beïnvloed, maar wel door de gevormde roosterfouten. De bijdrage tengevolge van dislokaties is de belangrijkste en volgens de theorie is de grootte van deze term $Q^{-1} \sim \Lambda L^{4}$.

In het beschreven onderzoek werden de verandering van de elastische moduli en de inwendige demping van koper éénkristallen van diverse orientaties gemeten tijdens plastische vervorming bij $78 \mathrm{~K}$. De kristallen werden vervaardigd van $99.999 \%$ zuiver koperdraad met een gewijzigde Bridgeman-Stockbarger methode. De dislokatiedichtheid in de uitgegloeide kristallen bedroeg $10^{3}-10^{6} \mathrm{~cm} / \mathrm{cm}^{3}$ en de begindemping was $0,6-20 \times 10^{-4}$. De elastische constanten en inwendige demping werden gemeten met standaard methoden.

Eerst werd het "kristallografisch" modulus effect onderzocht. Tijdens verlenging beweegt de orientatie van het kristal zich eerst 
in de richting van de [001]-[111] symmetrielijn. In tegenstelling tot de verwachting treedt daarbij glijding op over meer dan één glijsysteem. De veranderingen van de moduli die hierbijoptreden zijn klein, in overeenstemming met de berekeningen. De grootste veranderingen van de moduli werden verwacht na aankomst van de orientatie op de symmetrielijn waarna tengevolge van dubbele glijding de orientatie in de richting van [112] zou moeten bewegen. Gevonden werd echter dat de orientatieverandering slechts een fractie was van wat verwacht werd en dientengevolge is het "kristallografisch" modulus effect te verwarlozen.

In een aantal kristallen treedt vanaf een zekere rek mechanische tweelingvorming op. Het begin van dit proces is zichtbaar door hobbels op de trekkromme en hoorbaar door tikken. De overeenkomstige veranderingen van $E$ en G zijn kwalitatief zoals te voorspellen was. In een speciaal geval kon de volume fractie van het kristal die door tweelingen werd ingenomen worden geschat uit de veranderingen van de modulus. Het resultaat was in overeenstemming met de waarnemingen.

De overige modulus effecten werden, tezamen met de gemeten verandering van de inwendige demping, toegeschreven aan dislokaties en geanalyseerd met behulp van de gegeven formules. Voor $\varepsilon>0,10$ werd gevonden dat de dislokatiedichtheid lineair toeneemt met de plastische rek. In hetzelfde gebied verandert de reciproke van de dislokatielijnlengte eveneens lineair met de rek. Deze resultaten worden gevonden in kristallen met een lage begindemping. In kristallen met hogere begindemping treden onbegrepen afwijkingen op. De invloed van de kristalorientatie op de berekende dislokatiedichtheid en lijnlengte is klein.

Een apart hoofdstuk (V.3) is gewijd aan enige aspecten van mechanische tweelingvorming. De voornaamste resultaten zijn:

1) In koper éénkristallen met de <011> orientatie begint de tweelingvorming bij een schuifspanning die een orde van grootte kleiner is dan in de andere onderzochte orientaties. In dit geval gaat de tweelingvorming niet gepaard met hoorbaar tikken of zichtbare hobbels op de trekkromme. 
2) De wijze van insnoering en breuk in koper éénkristallen hangt samen met het al of niet optreden van tweelingvorming. In het eerste geval vindt de breuk schijnbaar plaats door afschuiving over één enkel vlak. In werkelijkheid vindt breuk plaats in een dunne vertweelingde laag.

3) In koperkristallen die bij $78 \mathrm{~K}$ plastisch gerekt worden begint de tweelingvorming ongeveer bij dezelfde rek als die warbij breuk optreedt als de vervorming bij kamertemperatuur plaats heeft. In het algemeen wordt in kubisch vlakken gecentreerde kristallen gevonden dat door tweelingvorming een grotere breukrek mogelijk wordt.

4) Na zware deformatie in torsie werden op het oppervlak van alle onderzochte koperkristallen spiraalvormige groeven waargenomen. Als de kristalas een n-tallige symmetrie-as is, worden $n$ evenwijdige spiralen gevonden. De groeven komen overeen met tweelingen. 


\section{references}

Ahlers, M. and P. Haasen, Acta Met. 10 (1962) 977.

Akita, H. and N.E. Fiore, J. Phys. Chem. Solids 31 (1970) 1941.

Argon, A.S. and W.T. Brydges, Phil. Mag. 18 (1968) 817.

Beukel, A. van den, "Vacancies and interstitials in metals", Con-

ference 23-28.9.1968 edited by Seeger, Schumacher Schilling and

Diehl North-Holland Pub. Co.

Beukel, A. van den and C. Brouwer, Phil. Mag. 17 (1968) 453. I

Blewitt, T.H., R.R. Coltman and J.K. Redman, Phys. Rev. 93 (1954)

891.

Blewitt, T.H., R.R. Coltman and J.K. Redman, "Defects in Crystalline

Solids", Phys. Soc. London 1955.

Bridgman, P.W., Proc. Am. Acad. Arts Sci. 60 (1925) 305.

Brown jr., W.F., Phys. Rev. 58 (1940) 998.

Brouwer, A.J., Physica 17 (1965) 5 Intern. Rep. T.H. 1964.

Brouwer, A.J. and C. Groenenboom-Eijgelaar, Acta Met. 15 (1967) 1597.

Bueren H.G., "Imperfections in Crystals", North-Holland Pub. Co.

Amsterdam Second ed. 1961.

Buurman, R. den and D. Weiner, Scripta Met. 5 (1971) 753.

Buurman, R. den and A.P. Snoep, Scripta Met. $\underline{6}$ (1972) 975.

Cahn, R.W., "Deformation Twinning", edited by Red-Hill, P. 117,

Gordon and Breach (1964).

Clarebrough, L.M. and M.E. Hargreaves, Progress in Metal Physics 8 (1959) 3 .

Cupp, C.R. and B. Chalmers, Acta Met. 2 (1954) 803.

Diehl, J., Z. Metallk. 47 (1956) 331.

Druyvesteyn, M.J., O.F.Z. Schannen and E.C.J. Swaving, Physica

25 (1959) 1271.

Druyvesteyn, W.F. and B.S. Blaisse, Physica $\underline{28}$ (1962) 695.

Essmann, U. and M. Rapp, Acta Met. 21 (1973) 1305.

Friede 1, J. Phi.1. Mag. 44 (1953) 444.

Friedel, J. Phil. Mag. 46 (1955) 1170. 
Garstone, J., R.W.K. Honeycombe and G. Greetham, Acta Met. 4 (1956) 485 .

Goens, E., Ann. der Physik 15 (1932) 455.

Granato, A. and K. Lücke, J. of App. Physics 27 (1956) 583.

Haasen, P., Phil. Mag. $\underline{3}$ (1958) 384.

Hearmon, R.F.S., Reviews of Modern Physics 18 (1946) 409.

Hildebrand, H., Phys. Stat. Solidi (a) 12 (1972) 239.

Hirsh, P.B. and T.E. Mitchell, Can. J. of Physics 45 (1967) 663. Honeycombe, R.W.K., 1968, "The Plastic deformation of Metals",

Edward Arnold Ltd., London.

Jackson, P.J. and Z.S. Bazinsky, Can. J. of Physics. 45 (1967) 707. Kock, A.J.R.W. de, W. Crans and M.J. Druyvesteyn, Physica $\underline{31}$ (1965) 866.

Köehler, J.S., "Imperfections in Nearly Perfect Crystals", John

Wi ley and Sons Inc., New York, 1952, P. 197.

Kohlrausch, F., "Praktische Physik", B.G. Teubner Verlag, Stuttgart,

21 auflage $(1960)$, p. 167.

Kuhlmann-Wilsdorf, D., Trans. AlME 224 (1962) 1047.

Landau, L.D. and E.M. Lifshitz, "Theory of Elasticity", Pergamon

Press London (1959) p. 72.

Lems, W., Physica 28 (1962) 445.

Livingston, J.D., Acta Met. 10 (1962) 229.

Mark, H., M. Polanyi and E. Schmid, Z. für Physik 12 (1922) 78.

Mitchell, T.E., Thesis Cambridge, 1962.

Mitcheli, T.E. and P.R. Thornton, Phil. Mag. 8 (1963) 1127.

Mitchell, T.E. and P.R. Thornton, Phil. Mag. 10 (1964) 315.

Mitchell, T.E., Progr. Appl. Mat. Res. 6 (1964) 117.

Mott, N.F., Phil. Mag. 43 (1952) 1151.

Mughrabi, H., Phil. Mag. 23 (1971) 931.

Nabarro, F.R.N., Z.S. Bazinski and D.B. Holt, "Advances in Physics"

$13(1964) 193$.

Naundorf, V., (1973), private communication.

Otte, H.M. and J.J. Hren, Experimental Mechanics (Soc. Exp. Stress Analysis) $\underline{6}$ (1966) 177. 
Overton jr., W.C. and J. Gaffney, Physical Review 98 (1955) 969. Paxton, H.W. and A.H. Cottrell, Acta Met. $\underline{2}$ (1954) 3.

Penning, P., (1971) private communication.

Penning, P., (1973) private communication.

Rebstock, H., Z. für Metallk. 48 (1957) 206.

Reid, C.iv., Phil. Mag. 27 (1973) 499.

Roberts, W. and Y. Bergstrom, Acta Met. 21 (1973) 457.

Rossi, F.D. and C.H. Mathewson, Trans. AlME 188 (1950) 1159.

Rossi, F.D., Trans. Amer. Inst. Min. Engrs 200 (1954) 1009.

Schmid, E. and W. Boas, "Plasticity of Crystals", reissued by Chapman \& Hall Ltd., (1968).

Sommerfeld, A., "Mechanics of Deformable Bodies" paper back Acad. Press N.Y. (1964) p. 296.

Stockbarger, D.C., Rev. Sci. Instr. 7 (1936) 133.

Suzuki, H., S. Ikeda and S. Takeuchi, J. Phys. Soc. Japan 11 (1956 854.

Suzuki, H. and C.S. Barret, Acta Met. 6 (1958) 156.

Taylor, G.I. and C.F. Elam, Proc. Roy, Soc. A102 (1923) 643.

Taylor, G.I. and C.F. Elam, Proc. Roy. Soc. A108 (1925) 28.

Thomson, D.0., D.K. Holmes and T.H. Blewitt, J. Appl. Phys. 26 (1955) 1188.

Thomson, D.0. and D.K. Holmes, J. Appl. Phys. 27 (1956) 713.

Thornton, P.R. and T.E. Mitchell, Phil. Mag. $\underline{7}$ (1962) 361.

Timoshenko, S.P. and J.N. Goodier, "Theory of Elasticity", 3rd ed. McGraw-Hill Book Co. 1970.

Voigt, W., "Lehrbuch der Krystallphysik", B.G. Teubner Leipzig 1910 , p. 673.

Von Mises, R., Z. Angew. Math. Mech. $\underline{8}$ (1928) 161.

Washburn, J. and G. Murty, Can. J. of Phys. 45 (1967) 523.

Weiner, D., Acta Met. 20 (1972) 1235.

Young jr., F.W. and J.R. Savage, J. Appl. Phys. 35 (1964) 1917. 
Mijn collega's op het Laboratorium voor Metaalkunde ben ik zeer erkentelijk voor hun medewerking en de vele nuttige en vruchtbare discussies.

Bij het tot stand komen van dit proefschrift hebben vele personeelsleden een helpende hand geboden, in het bijzonder de heren A.J. de Koster en H. Weerheym, warrvoor de schrijver hun zijn dank betuigt.

Voor de uitvoering van dit proefschrift is de schrijver dank verschuldigd aan de heer J.C.M. Jacobse voor fotografisch werk, mejuffrouw Constance E. Fenix voor het betoonde geduld bij het typen van het manuscript en de heer L. van den Eijkel voor het maken van de tekeningen en het ontwerpen van de omslag; het motief hiervoor is ontleend aan fig. 93 op pagina 118 . 


\section{stellingen}

1. Door een onjuiste beoordeling van experimentele resultaten zijn Seeger en medewerkers tot de onjuiste conclusie gekomen, dat een kleine torsie tijdens een rekproef de versteviging doet toenemen. A. Seeger, J. Diehl, S. Mader and H. Rebstock, Phil. Mag. 2 (1951) 323 .

2. Uit resultaten over orientatieveranderingen door een eenzijdige druk op een éénkristallijne kubus kunnen geen conclusies worden getrokken met betrekking tot het gedrag van de orientatie van gerekte lange éénkristallen.

L. Johnson, U.F. Kocks and B. Chalmers, Scripta Met. 2 (1968) 485.

C.N. Reid, Phil. Mag. 27 (1973) 499.

3. Ten onrechte wordt bij het interpreteren van walstexturen in koper en aluminium de mogelijke invloed van deformatietweelingen bij voorbaat uitgesloten.

P.H. Stüwe and E. Aernoudt, 'Textures in Research and Practice'i. Symp. 1968, ed. Grewen and Wassermann.

4. De stelling van R.W. Cahn dat tweelingvorming maar een zeer beperkte deformatie kan genereren is onjuist.

"Deformation Twinning", Conf. 1963, ed. Reed-Hill, Hirth and Rogers.

5. Het model dat door Tsivinsky en anderen wordt gebruikt voor de berekening van dislocatiedichtheden is fout.

S.V. Tsivinsky, L.A. Maslova and B.N. Alexandrof,

Fiz. Metal. Metalowd. 28 (1969) 487. 